\title{
THE EFFECTIVENESS OF PERIODICALLY-HARVESTED FISHERIES CLOSURES IN MEETING ECOLOGICAL AND SOCIOECONOMIC OBJECTIVES
}

\author{
A Thesis \\ presented to \\ the Faculty of California Polytechnic State University, \\ San Luis Obispo
}

In Partial Fulfillment of the Requirements for the Degree Master of Science in Biological Sciences

by

Paul George Carvalho August 2016 
(C) 2016

Paul George Carvalho

ALL RIGHTS RESERVED 


\section{COMMITTEE MEMBERSHIP}

TITLE: The Effectiveness of Periodically-Harvested Fisheries

Closures in Meeting Ecological and Socioeconomic

Objectives

AUTHOR: Paul George Carvalho

DATE SUBMITTED: August 2016

COMMITTEE CHAIR: Crow White, Ph.D.

Assistant Professor of Biological Sciences

COMMITTEE MEMBER: Benjamin Ruttenberg, Ph.D.

Assistant Professor of Biological Sciences

COMMITTEE MEMBER: Dean Wendt, Ph.D.

Dean of Research 


\begin{abstract}
The Effectiveness of Periodically-Harvested Fisheries Closures in Meeting Ecological and Socioeconomic Objectives

Paul George Carvalho
\end{abstract}

Periodically-harvested fisheries closures (PHCs) are a widespread form of community-based marine spatial management used throughout the Indo-Pacific that also is currently being intensively advocated by conservation organizations for supporting productive fisheries and healthy marine ecosystems. However, local implementation of PHCs has historically been designed to support occasional and efficient exploitation of fish stocks, and not necessarily sustainable fisheries yields and stock conservation. The efficacy of PHCs for achieving their historical cultural objectives of periodicity and efficiency of harvest, simultaneously with achieving contemporary fisheries objectives of fisheries productivity and conservation is undetermined. As a result, the utility of PHCs for supporting contemporary ecosystem-based fisheries management is uncertain given environmental, social and climate change. We developed a biological-economic fisheries model of PHCs to test the value of this form of marine resource management for achieving cultural, fisheries and conservation objectives under sustainable and overfishing scenarios. Our results reveal PHCs to be more effective at achieving the multiple objectives than either non-spatial or fully-protected area management when fisher impact on fish behavior is considered. These results describe the performance of PHCs in general when fish behavior is considered, but does not provide detailed guidance for a particular PHC. Thus, we modified and calibrated our biological-economic fisheries model with empirical data from Nakodu Village on Koro Island in Fiji. The calibrated 
model allowed us to estimate the effectiveness of Nakodu Village's current PHC management and predict consequences of future management actions. Results suggest that 5-year PHC closures are optimal for simultaneously achieving fisheries productivity and conservation goals in Nakodu Village. These findings challenge the dogma that PHCs are simply a cultural legacy and warrant further investigation of the utility of PHCs for supporting ecosystem-based management beyond the Indo-Pacific. 


\section{ACKNOWLEDGMENTS}

I would like to thank Crow White for mentoring me through the process of writing my thesis and presenting me with endless opportunities to advance my career in the sciences and develop professional skills. I am thankful for the quality input from my committee members Benjamin Ruttenberg and Dean Wendt, and former committee member Jennifer O'Leary. This research was very much a collaborative effort and I would like to especially thank Stacy Jupiter from the Wildlife Conservation Society for including my project in her funding proposals to the David and Lucile Packard Foundation. Jordan Goetze, Fraser Januchowski-Hartley, Rebecca Weeks, and Joachim Claudet deserve thanks for contributing data and input on model analyses. I must also thank Grant Waltz, Joel Stevens, and Madelyn Roycroft for their valuable input during discussions regarding my thesis. Ellen Calcagno, Melanie Gutierrez, and the rest of the faculty at Cal Poly San Luis Obispo and fellow graduate students gave so much administrative and moral support, and for this I sincerely thank all of them. This research was funded by the Tenera Environmental Scholarship (Paul Carvalho), the David and Lucile Packard Foundation (Grant No. 2014-39332; Stacy Jupiter, Crow White), National Science Foundation Graduate Research Fellowship Program (Grant No. 51445; Paul Carvalho), and Cal Poly Graduate Student Funds. 


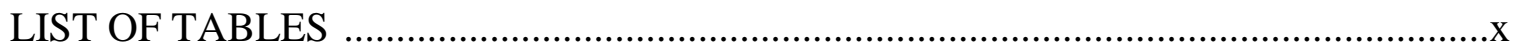

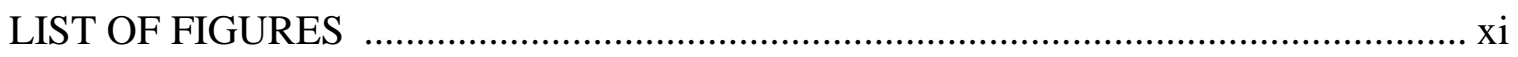

CHAPTER ONE

PERIODICALLY-HARVESTED CLOSURES EMERGE AS OPTIMAL MANAGEMENT WHEN FISH BEHAVIOR IS CONSIDERED ..................................1

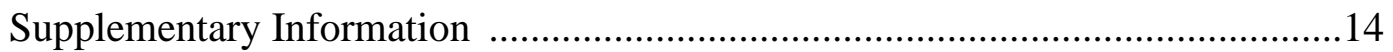

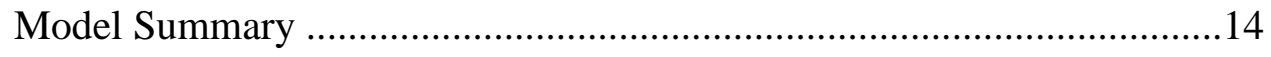

Model Details ........................................................................................

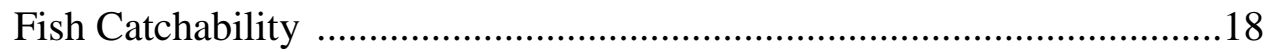

\section{CHAPTER TWO}

ASSESSMENT OF THE NAKODU VILLAGE (KORO ISLAND, FIJI)

PERIODICALLY-HARVESTED CLOSURE USING AN EMPIRICALLY

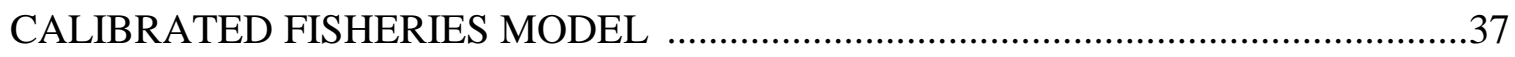

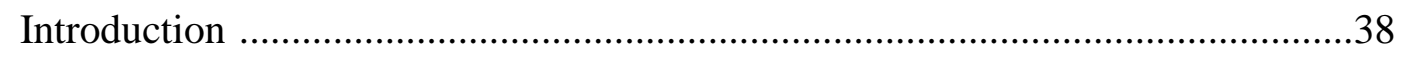

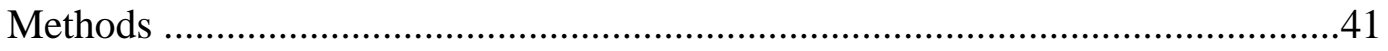

Study Site ..........................................................................................

Diver Operated Stereo-Video (DOV) ....................................................42

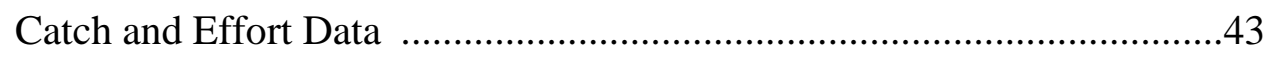

Fishery Model Summary ………………………………......................4

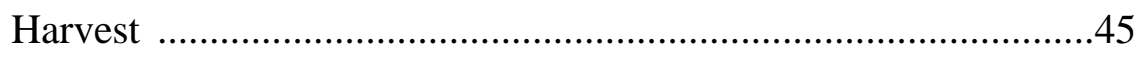

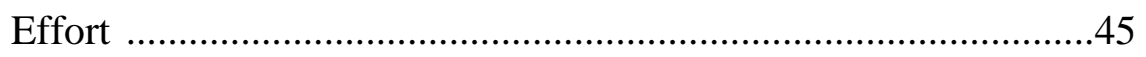

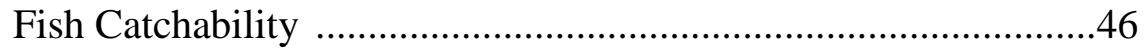

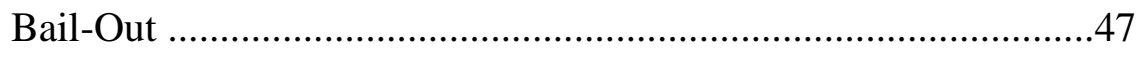

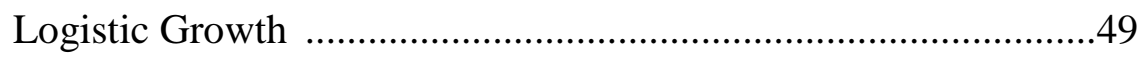

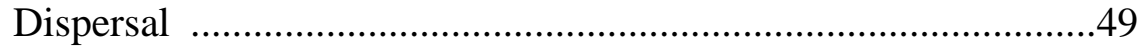

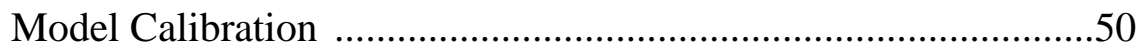

Predicted Future Scenarios .....................................................52

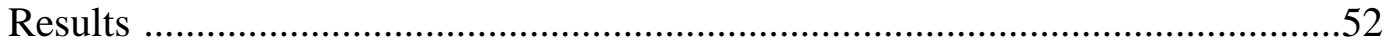

Acanthuridae - Model Calibration ........................................................52 
Acanthuridae - Predicted Future Scenarios

Scenario 1: One-Year Closure Between PHC

Harvests at Present Average Annual Yield

Scenario 2: Five-Year Closure Between PHC

Harvests at Present Average Annual Yield .54

Scenario 3: Maximum Sustainable Average Annual

Yield for One-Year Closures .54

Scenario 4: Maximum Sustainable Average Annual

Yield for Five-Year Closures .55

Scarinae (Labridae Subfamily) - Model Calibration .55

Scarinae (Labridae Subfamily) - Predicted Future Scenarios .56

Scenario 1: One-Year Closure Between PHC

Harvests at Present Average Annual Yield .56

Scenario 2: Five-Year Closure Between PHC

Harvests at Present Average Annual Yield .57

Scenario 3: Maximum Sustainable Average Annual

Yield for One-Year Closures .57

Scenario 4: Maximum Sustainable Average Annual

Yield for Five-Year Closures ………………………….............58

Labridae - Model Calibration ............................................................58

Labridae - Predicted Future Scenarios ………………………………....59

Scenario 1: One-Year Closure Between PHC

Harvests at Present Average Annual Yield

Scenario 2: Five-Year Closure Between PHC

Harvests at Present Average Annual Yield

Scenario 3: Maximum Sustainable Average Annual

Yield for One-Year Closures

Scenario 4: Maximum Sustainable Average Annual

Yield for Five-Year Closures

Lethrinidae - Model Calibration ...............................................................61

Lethrinidae - Predicted Future Scenarios 
Scenario 1: One-Year Closure Between PHC

Harvests at Present Average Annual Yield

Scenario 2: Five-Year Closure Between PHC

Harvests at Present Average Annual Yield .62

Scenario 3: Maximum Sustainable Average Annual

Yield for One-Year Closures

Scenario 4: Maximum Sustainable Average Annual

Yield for Five-Year Closures

Lutjanidae - Model Calibration

Lutjanidae - Predicted Future Scenarios

Scenario 1: One-Year Closure Between PHC

Harvests at Present Average Annual Yield .64

Scenario 2: Five-Year Closure Between PHC

Harvests at Present Average Annual Yield .65

Scenario 3: Maximum Sustainable Average Annual

Yield for One-Year Closures

Scenario 4: Maximum Sustainable Average Annual

Yield for Five-Year Closures .66

Discussion .66

REFERENCES 104 


\section{LIST OF TABLES}

Table

Page

S1.1 Empirical data on fish flight initiation distance (FID) for families Acanthuridae and Labridae (subfamily Scarinae) under periodicallyharvested closure, fully-protected area, and non-spatial management regimes in Papua New Guinea, Vanuatu, Philippines, and Chagos .36

2.1 Biomass density $(\mathrm{kg} / \mathrm{ha})$ data by family from diver-operated-video surveys

2.2 Diver operated stereo-video (DOV) survey and harvest (yield and effort) data collection timeline for Nakodu Village, Koro Island, Fiji

2.3 Nakodu species list from diver operated stereo-video surveys and catch data with estimated intrinsic population growth rates

$2.4 \quad$ Yield density ( $\mathrm{kg} / \mathrm{ha}$ ) and effort (\# fisher hours/ha) density in the periodically-harvested closure (PHC) and open-to-fishing area (fished) area by family

2.5 Parameter values after model calibration and quality of model fit to empirical data 


\section{LIST OF FIGURES}

Figure

Page

1.1 Map of countries/regions that practice traditional periodically-harvested closures for marine resources highlighted by EEZ (dark-gray shading)

1.2 Fishery (yield, catch per unit effort [CPUE]) and fish conservation (stock) outcomes for non-spatial, (permanent) fully-protected area (FPA), and periodically-harvested closure (PHC) management for target species with moderate site-fidelity $(S=0.2)$

1.3 Average annual harvest efficiency (i.e., catch per unit effort [CPUE]) in relation to fishery yield (A) and fish stock conservation (B) values for a range of closed-open harvest cycles (all combinations of 1, 2, 3 ...10 years each)

1.4 Size of periodically-harvested closures (PHCs) in practice and their estimated fisheries value (catch per unit effort [CPUE])

S1.1 An example cumulative probability distribution of fish initiating flight response less than a given distance $(\mathrm{cm})$ from a simulated spearfisher for Acanthuridae at a site in Papua New Guinea that was protected 4 years prior to empirical measurements of flight initiation distance $($ mean $=270.12 \mathrm{~cm}$, variance $=5193.96 \mathrm{~cm})$

S1.2 Normal cumulative probability values in relation to years protected from fishing pressure for families Acanthuridae and Scarinae (Labridae subfamily)

S1.3 Rate of change for fish catchability in relation to a scalar parameter $(\alpha)$ and years protected for the periodically-harvested closures (PHC).

S1.4 Fishery (yield, catch per unit effort [CPUE]) and fish conservation (stock) outcomes for non-spatial, permanent fully-protected area (FPA), and periodically-harvested closure (PHC) management for target species with a low intrinsic rate of population growth $(r=0.1)$, and moderate site-fidelity $(S=0.2)$

S1.5 Fishery (yield, catch per unit effort [CPUE]) and fish conservation (stock) outcomes for non-spatial, permanent fully-protected area (FPA), and periodically-harvested closure (PHC) management for target species with a high intrinsic rate of population growth $(r=0.5)$, and moderate site-fidelity $(S=0.2)$ 
S1.6 Fishery (yield, CPUE) and fish conservation (stock) outcomes under non-spatial, permanent fully-protected area (FPA), and periodicallyharvested closure (PHC) management scenarios, given constant catchability $(q=1 ; \alpha=0)$, moderate site-fidelity $(S=0.2)$, and, in the case of FPA and PHC management, $30 \%$ of the domain protected from fishing $(c=0.3)$

S1.7 Harvest efficiency (i.e., catch per unit area [CPUE]) in relation to rate and magnitude of change in fish catchability $(0 \leq \alpha \leq 1.5)$ for periodically-harvested closure (PHC), fully-protected area (FPA) and non-spatial management

S1.8 Average annual yield in relation to the size of the protected area $(0 \% \leq c \leq 50 \%)$ and fish site-fidelity $(0 \leq S \leq 1$, shading) in wellmanaged (A) and an overfished (B) systems

S1.9 Average annual stock in relation to the size of the protected area $(0 \% \leq c \leq 50 \%)$ and fish site-fidelity $(0 \leq S \leq 1$, shading) in wellmanaged (A) and an overfished (B) systems

S1.10 Average annual harvest efficiency (i.e., catch per unit effort, CPUE) in relation to size of the protected area $(0 \% \leq c \leq 50 \%)$ and fish sitefidelity ( $0 \leq S \leq 1$, shading) for species with a low ( $r=0.1)$ intrinsic rate of population growth

S1.11 Average annual yield in relation to size of the protected area $(0 \% \leq c \leq 50 \%)$ and fish site-fidelity $(0 \leq S \leq 1$, shading) for species with a low $(r=0.1)$ intrinsic rate of population growth

S1.12 Average annual stock abundance in relation to the size of the protected area $(0 \% \leq c \leq 50 \%)$ and fish site-fidelity $(0 \leq S \leq 1$, shading) for species with a low $(r=0.1)$ intrinsic rate of population growth

S1.13 Average annual harvest efficiency (i.e., catch per unit effort, CPUE) in relation to size of the protected area $(0 \% \leq c \leq 50 \%)$ and fish sitefidelity ( $0 \leq S \leq 1$, shading) for species with a high ( $r=0.5$ ) intrinsic rate of population growth

S1.14 Average annual yield in relation to periodically-harvested closure (PHC) and fully-protected area (FPA) size $(0 \% \leq c \leq 50 \%)$ and fish site-fidelity ( $0 \leq S \leq 1$, shading) for species with a high $(r=0.5)$ intrinsic rate of population growth 
S1.15 Average annual stock abundance in relation to periodically-harvested closure (PHC) and fully-protected area size $(0 \% \leq c \leq 50 \%)$ and fish site-fidelity $(0 \leq S \leq 1$; shading $)$ for species with a high $(r=0.5)$ intrinsic rate of population growth

2.1 Map of Nakodu customary marine tenure area. Red shading indicates open-to-fishing area (115 ha), green indicates the periodicallyharvested closure (68 ha), and yellow indicates the fore reef area (27 ha)

2.2 Realized effort in relation to number of fishers per hour per hectare (potential effort)

2.3 Model calibration results for Acanthuridae. The model is simultaneously calibrated to biomass (A) and yield (B) density empirical data

2.4 Time series data for Acanthuridae (A) biomass, (B) yield, and (C) catch per unit effort at present average annual yield in Nakodu when the PHC is harvested once a year

2.5 Time series data for Acanthuridae (A) biomass, (B) yield, and (C) catch per unit effort at present average annual yield in Nakodu with 5-year closures between PHC harvests

2.6 Time series data for Acanthuridae (A) biomass, (B) yield, and (C) catch per unit effort at maximum sustainable average annual yield (optimal harvest for each patch and year) in Nakodu when the PHC is harvested once a year .76

2.7 Time series data for Acanthuridae (A) biomass, (B) yield, and (C) catch per unit effort at maximum sustainable average annual yield (optimal harvest for each patch and year) in Nakodu with 5-year closures between PHC harvests

2.8 Model calibration results for Scarinae (Labridae subfamily). The model is simultaneously calibrated to biomass (A) and yield (B) density empirical data

2.9 Time series data for Scarinae (A) biomass, (B) yield, and (C) catch per unit effort at present average annual yield in Nakodu when the PHC is harvested once a year

2.10 Time series data for Scarinae (A) biomass, (B) yield, and (C) catch per unit effort at present average annual yield in Nakodu with 5-year closures between PHC harvests 
2.11 Time series data for Scarinae (A) biomass, (B) yield, and (C) catch per unit effort at maximum sustainable average annual yield (optimal harvest for each patch and year) in Nakodu when the PHC is harvested once a year

2.12 Time series data for Scarinae (A) biomass, (B) yield, and (C) catch per unit effort at maximum sustainable average annual yield (optimal harvest for each patch and year) in Nakodu with 5-year closures between PHC harvests

2.13 Model calibration results for Labridae. The model is simultaneously calibrated to biomass (A) and yield (B) density empirical data

2.14 Time series data for Labridae (A) biomass, (B) yield, and (C) catch per unit effort at present average annual yield in Nakodu when the PHC is harvested once a year

2.15 Time series data for Labridae (A) biomass, (B) yield, and (C) catch per unit effort at present average annual yield in Nakodu with 5-year closures between PHC harvests

2.16 Time series data for Labridae (A) biomass, (B) yield, and (C) catch per unit effort at maximum sustainable average annual yield (optimal harvest for each patch and year) in Nakodu when the PHC is harvested once a year

2.17 Time series data for Labridae (A) biomass, (B) yield, and (C) catch per unit effort at maximum sustainable average annual yield (optimal harvest for each patch and year) in Nakodu with 5-year closures between PHC harvests

2.18 Model calibration results for Lethrinidae. The model is simultaneously calibrated to biomass (A) and yield (B) density empirical data

2.19 Time series data for Lethrinidae (A) biomass, (B) yield, and (C) catch per unit effort at present average annual yield in Nakodu when the PHC is harvested once a year

2.20 Time series data for Lethrinidae (A) biomass, (B) yield, and (C) catch per unit effort at present average annual yield in Nakodu with 5-year closures between PHC harvests

2.21 Time series data for Lethrinidae (A) biomass, (B) yield, and (C) catch per unit effort at maximum sustainable average annual yield (optimal harvest in each patch and year) in Nakodu when the PHC is harvested once a year 
2.22 Time series data for Lethrinidae (A) biomass, (B) yield, and (C) catch per unit effort at maximum sustainable average annual yield (optimal harvest in each patch and year) in Nakodu with 5-year closures between PHC harvests

2.23 Model calibration results for Lutjanidae. The model is simultaneously calibrated to biomass (A) and yield (B) density empirical data

2.24 Time series data for Lutjanidae (A) biomass, (B) yield, and (C) catch per unit effort at present average annual yield in Nakodu when the PHC is harvested once a year

2.25 Time series data for Lutjanidae (A) biomass, (B) yield, and (C) catch per unit effort at present average annual yield in Nakodu with 5-year closures between PHC harvests

2.26 Time series data for Lutjanidae (A) biomass, (B) yield, and (C) catch per unit effort at maximum sustainable average annual yield (optimal harvest in each patch and year) in Nakodu when the PHC is harvested once a year

2.27 Time series data for Lutjanidae (A) biomass, (B) yield, and (C) catch per unit effort at maximum sustainable average annual yield (optimal harvest in each patch and year) in Nakodu with 5-year closures between PHC harvests 
CHAPTER ONE

PERIODICALLY-HARVESTED CLOSURES EMERGE AS OPTIMAL

MANAGEMENT WHEN FISH BEHAVIOR IS CONSIDERED 
Marine protected areas (MPAs) are widely used as an effective spatial management tool for mediating overfishing and promoting stock recovery (Gerber et al. 2003), but they are generally considered less appropriate for enhancing the value of fisheries that are already well managed (Hilborn et al. 2004, Parrish 1999). This perception of the mixed utility of MPAs is driven by scientific inquiry focused on the evaluation of fully protected areas (FPAs), a type of MPA that restricts all fish harvest permanently. In these scenarios, fishing effort displaced by the FPA undergoes at least one of two fates, each with negative consequences for fisheries value: (i) displaced effort is concentrated into the remaining fishing ground, potentially generating equivalence in yield compared with that achievable without the FPA (Hastings and Botsford 1999), but at the price of reduced harvest efficiency and thus excess fishing cost (White et al. 2008); or (ii) displaced effort could be removed from the system (i.e., fishermen leave the fishery), resulting in a level of harvest efficiency equivalent to a system without FPAs and no excess cost in the remaining fishing ground, but at the price of reduced yield compared with that achievable without FPAs (Hilborn et al. 2004). Thus, displaced fishing effort by FPAs can compromise either the economic or food-provisioning value of fisheries, or both. However, literature suggests that with overfishing, when yield and harvest efficiency are already reduced and cost of fishing is inflated, the above fates of displaced fishing effort by FPAs increases fisheries value compared with an overfished system without FPAs (Gerber et al. 2003, Lester and Halpern 2008; for exceptions in relation to source-sink dynamics see Costello et al. 2010, Rassweiler et al. 2012). Consequently, FPA management involves tradeoffs, and is not always able to 
simultaneously enhance yield, harvest efficiency, and stock abundance to maximize fisheries value (Gerber et al. 2003, Hart 2006).

Fully protected areas (FPAs) are often not socially acceptable or feasible in developed and developing countries (Smith et al. 2010). Alternatively, small-scale fishing communities around the world often use a type of MPA that receives far less attention than conventional management strategies: periodically-harvested closures (PHCs; Govan et al. 2009, Cohen and Foale 2013). Instead of permanently restricting access to fish stocks, PHCs provide temporary protection between fishing bouts. In the Indo-Pacific in particular, PHCs have been used in varying forms for centuries for occasional and efficient exploitation of fish stocks (Fig. 1.1; Cohen and Foale 2013, Govan et al. 2009, Williams et al. 2006, Bess 2001, Ayres 1979, Luna 2003). As with FPAs, PHCs displace fishing effort. However, this impact is not permanent and, importantly, the closed period can reduce fish wariness to fishing gear (i.e., fish are tamed; Cinner et al. 2006), potentially leading to increased harvest efficiency upon the PHC's re-opening (Januchowski-Hartley et al. 2014). Increased harvest efficiency is one of the main reasons communities practice PHC management throughout the Indo-Pacific because fishers observe that after a period of closure, they can more easily approach fish within effective speargun range before the target fish flees (Cinner et al. 2006). Consequently, PHCs may work as an active management tool for simultaneously maximizing yield, stock abundance, and harvest efficiency above that attainable without FPAs. Support for this hypothesis could recast the perception of MPAs beyond that as a tool limited to mitigating overfishing and promoting conservation (in the form of FPAs), to one that, in the form of PHCs, generates optimal fisheries management. 
We constructed a coupled biological-economic fisheries model and simulated change in fish behavior in relation to closure period to quantify the value of PHCs and assess their ability to simultaneously maximize fisheries yield, stock abundance, and harvest efficiency (i.e., catch per unit effort) beyond that attainable by non-spatial management or management with (permanent) FPAs. Fish behavior was integrated into the model because an important goal for PHC implementation across the Indo-Pacific is to increase harvest efficiency by exploiting reduction in fish wariness to fishing gear. We modeled scenarios that represent a broad range of management conditions and targeted fish stocks found in the world's PHCs (Cohen and Foale 2013). A PHC is represented by the percentage of the total management area that it covers $(c)$ and its prescribed closedopen harvest cycle (here on the scale of years). The fish stock is characterized by its intrinsic rate of population growth $(r)$ and level of movement (spillover) between the PHC and the rest of the management area in relation to their dimensions and the species' site-fidelity $(S)$. Taming of fish to fishing gear is represented by their increase in catchability with increase in PHC closure period (Fig. S1.1-S1.3, Table S1.1), following a saturating function derived from empirical studies on fish behavior conducted in PHCs, FPAs, and non-spatial management areas (Feary et al. 2011, Januchowski-Hartley et al. 2015). Consistent with PHCs in practice, the modeled PHCs were assumed to be small ( 1 km²; Govan et al. 2009), and harvest effort in the PHC upon its opening was assumed to take place over a short period of time immediately after the opening and before fish 
become wary of fishing gear (<1 week; Januchowski-Hartley et al. 2014). Models were run to equilibrium thus implicitly achieving sustainability.

We tested the value of PHCs first with an example case study (Fig. 1.2). Suppose the PHC constitutes $30 \%$ of the management area $(c=0.3)$, and the target fish stock has a relatively high population growth rate $(r=0.3)$ and moderate site-fidelity $(S=0.2$; which in relation to $c$ equates to $44 \%$ stock self-recruitment to the $\mathrm{PHC}$, and $76 \%$ to the fished area annually). These values represent a stock with moderate resilience (Froese and Pauly 2012) and moderate annual movement between protected and open-to-fishing areas, such as parrotfishes and surgeonfishes (families Labridae [subfamily Scarinae] and Acanthuridae, respectively; Chateau and Wantiez 2009, Meyer et al. 2010), which are often key target fishes in PHCs throughout the Indo-Pacific (Jupiter et al. 2012, Williams et al. 2006). We found that keeping the PHC closed for 1-2 years between single short fishing bouts enables the fishery to generate average annual levels of fishery yield and stock abundance equivalent to the highest levels attainable under either optimal sustainable non-spatial fisheries management or management with (permanent) FPAs (Fig. 1.2A). Additionally, the PHC achieves an average annual harvest efficiency $3 \%$ greater than by non-spatial management and 9\% greater than by (permanent) FPA management (Fig. 1.2A). These results hold across a range of fish stock population growth rates (Fig. S1.4 and S1.5) and emerge because PHC management induces a reduction in fish wariness to fishing gear during its closure that is then exploited to increase fish catchability upon the PHC's re-opening (for comparison when fish catchability is held constant, and various rates and magnitudes of change in fish catchability, see Fig. S1.6 and S1.7). 
We also examined the ability of PHCs to mitigate adverse effects of overfishing. The example case study ( $c=0.3, S=0.2, r=0.3)$ with excessive harvest $(25 \%$ increased fishing effort) reveals a tradeoff between PHCs and (permanent) FPAs in their improvement over non-spatial management: the PHC maximizes harvest efficiency (if closed for 1 year between short fishing bouts), but a FPA maximizes stock conservation and yield (Fig. 1.2B). The tradeoff, however, is unbalanced in favor of PHCs: harvest efficiency under PHC management is $6 \%$ greater than that in FPA management, but yield and stock abundance are $<2 \%$ less than those under FPA management (Fig. 1.2B). These results hold across longer PHC closed periods as well. Extending the PHC's closed period makes it more similar to a FPA (i.e., harvest efficiency declines and stock abundance and yield increase), but even when the PHC is closed for 10 years harvest efficiency is proportionally greater (3\%) than the loss in yield and stock abundance $(<1 \%)$ compared with values generated with a FPA (Fig. 1.3).

To expand the scope of our analysis and maximize its applicability, we examined the sensitivity of our results to the size of the PHC ( $c=0-50 \%$ of the total management area, representing that found in practice; Mills et al. 2011) and the level of site-fidelity of the target fish ( $S=0-1$, representing the full range of movement patterns, from "common pool" dispersal to sedentary; Fig. 1.4 and S1.7). For each combination of $c$ and $S$ we identified the PHC closed-open harvest cycle that maximized yield. When multiple closed-open harvest cycles maximized yield, we selected the cycle among the subset that generated the greatest harvest efficiency. For well-managed (no overfishing) scenarios, we found all closed-open harvest cycles selected to have short open periods (1-year with single short pulse harvest), and closed periods ranging from 1-4 years. Only very-small 
PHCs $(c \leq 5 \%)$ targeting sedentary species $(S=1)$ indicate a 4-year closed period to be optimal; with increased PHC size and/or target fish movement the closed period decreases. For well-managed scenarios, average annual yield and stock abundance for PHC management are insensitive to $c$ and $S$, consistently generating outcomes equivalent to the highest levels achievable by non-spatial management (Fig. S1.8 and S1.9). Average annual harvest efficiency under PHC management, however, exceeds that by non-spatial management and a (permanent) FPA, regardless of PHC size or fish stock movement rate (Fig. 1.4).

Application of the above sensitivity analysis to overfishing scenarios also found average annual harvest efficiency under PHC management to consistently be greater than that under non-spatial management or with a (permanent) FPA (Fig. 1.4). Further, the unbalanced tradeoff in harvest efficiency versus yield between PHCs and FPA revealed by the case study either persists or dissolves in favor of the PHC. For target fish with moderate to low site-fidelity $(S \leq 0.4)$, FPAs generate higher average annual yield compared with that under PHCs, but the percentage difference in yield between the PHC and FPA always is less than the difference in harvest efficiency (Fig. 1.4 and S1.8). For target fish with high site-fidelity ( $S \geq 0.6$ ), spillover is limited, and a FPA generates less yield than that possible under PHC and non-spatial management (Fig. S1.8). In regard to stock conservation, its tradeoff with harvest efficiency is balanced between PHC and FPA management for target species with low to moderate site-fidelity $(S \leq 0.2)$; however, for high site-fidelity species the tradeoff becomes unbalanced in favor of FPAs because of their high stock conservation value (Fig. S1.9). Results for the sensitivity analysis on 
well-managed and overfished systems are robust to intrinsic rates of population growth (Fig. S1.10 - S1.15).

This study quantifies the potential value of PHCs for achieving and maintaining cultural, fisheries, and conservation objectives. We directly compare PHCs with nonspatial and (permanent) FPA management approaches, and reveal PHC management to be superior at simultaneously maximizing fisheries yield, stock abundance, and harvest efficiency in a well-managed fishery. Even with overfishing PHCs emerge as an optimal or near-optimal management strategy. Also, our estimate for change in fish catchability is based on empirical data on simulated spearfishing, but change in fish catchability in response to release from fishing pressure is also documented for hook-and-line fisheries, possibly extending the applicability of our model to various gear types (Young and Hayes 2004, Askey et al. 2006, Alós et al. 2014). Empirical studies have also documented spillover of fish behavior between FPAs and adjacent open area (Januchowski-Hartley et al. 2013), suggesting a gradient of fish behavioral change from the center of a FPA or PHC to a given distance outside of the protected area. This gradient could influence harvest efficiency (i.e., catch per unit effort) outcomes based on where fishing pressure is concentrated during PHC closure and open periods. We expect catch per unit effort to be greatest at the center of the FPA or PHC and decrease away from the center of the protected area. Further inspection of the performance of PHCs in relation to more complex closed-open harvest cycles, use of multiple fishing gear types, and social, cultural and political objectives found outside of the Indo-Pacific would contribute substantially to our understanding of the utility of this form of management for enhancing fisheries value and supporting local ecosystem-based management. Periodically- 
harvested closures now are widespread throughout the Indo-Pacific, and these findings

challenge the dogma that PHCs are simply a cultural legacy, and suggests that PHCs may be an innovative optimal fisheries management strategy well beyond the Indo-Pacific. 


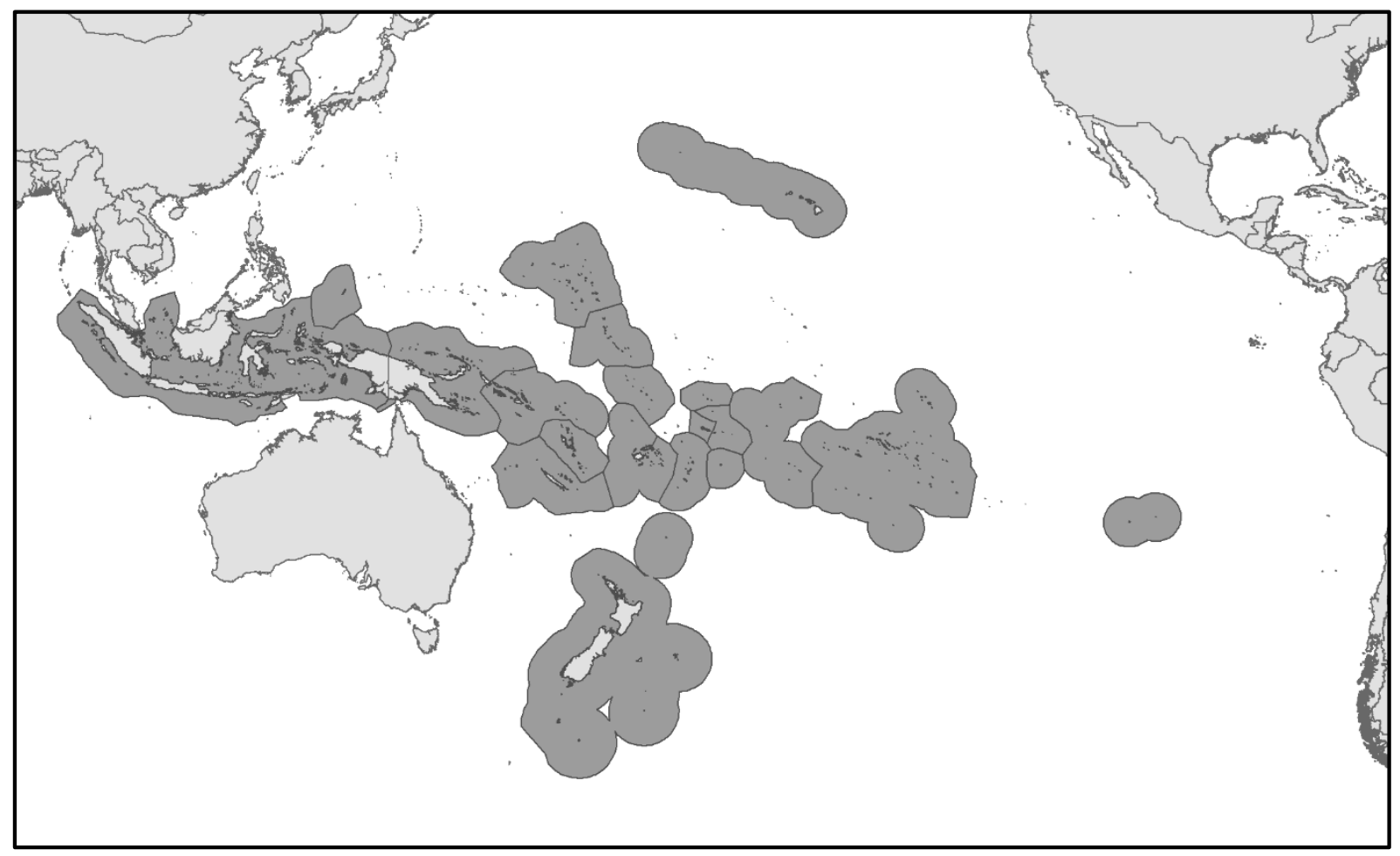

Figure 1.1. Map of countries/regions that practice traditional periodically-harvested closures for marine resources highlighted by EEZ (dark-gray shading). 
A

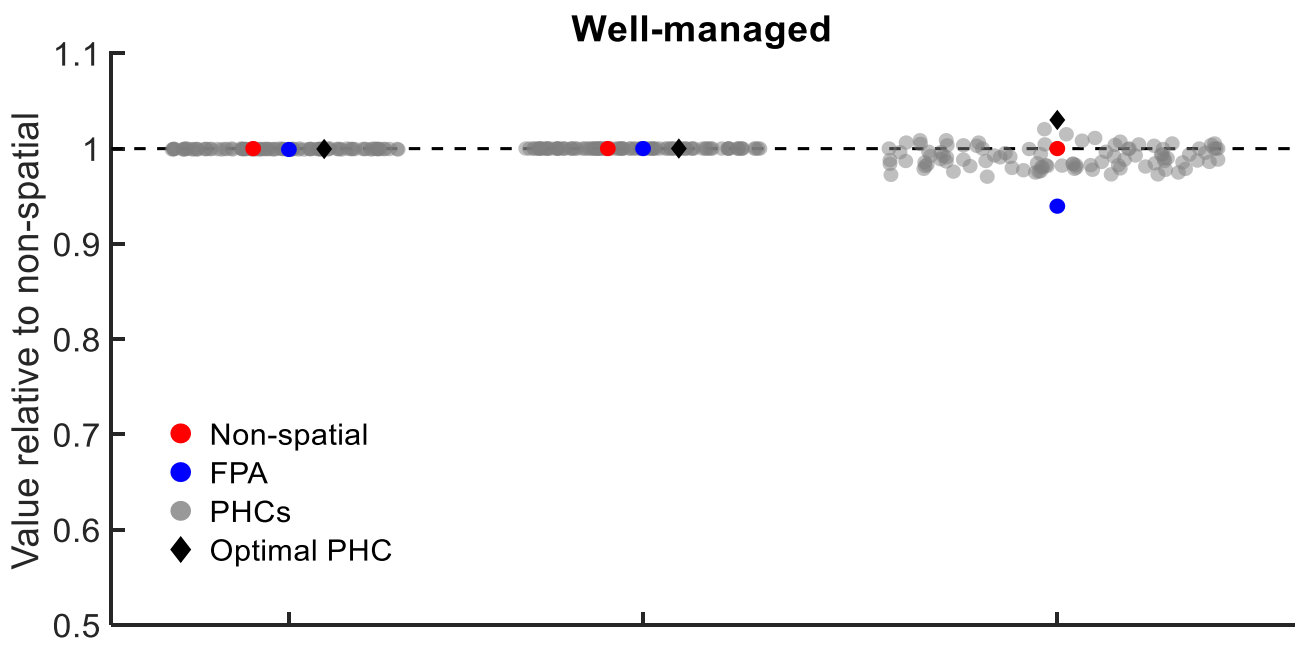

B

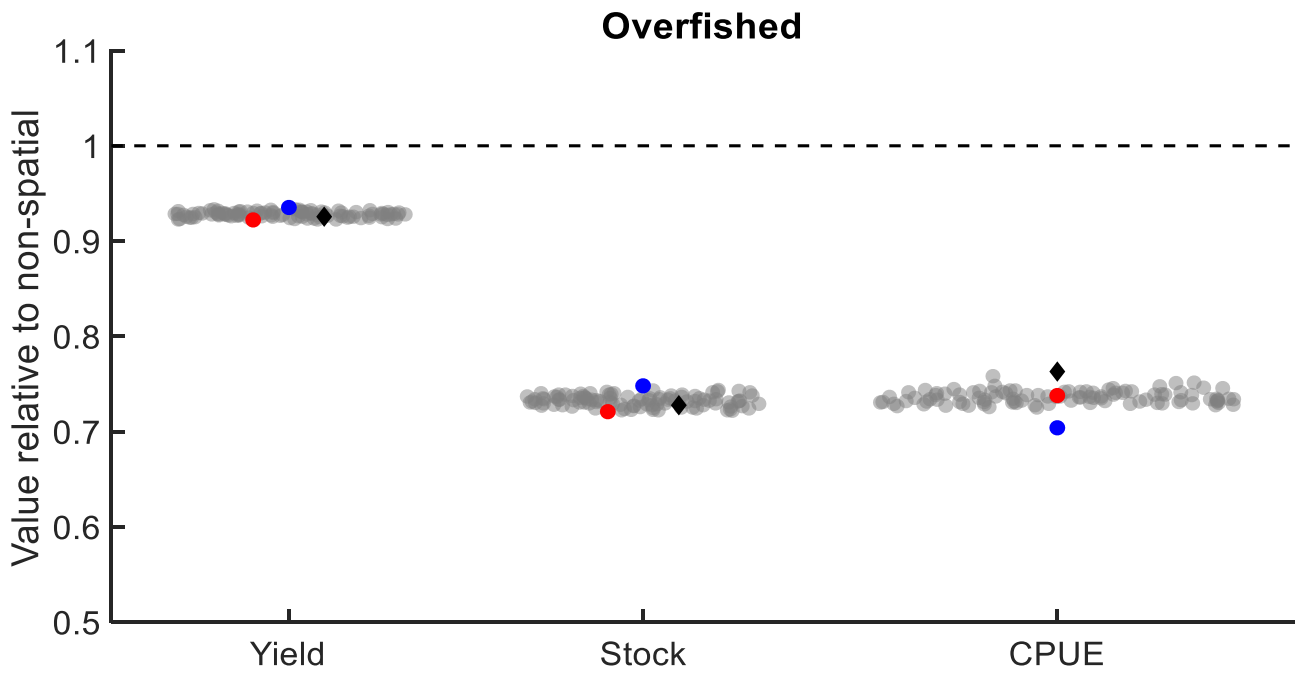

Figure 1.2. Fishery (yield, catch per unit effort [CPUE]) and fish conservation (stock) outcomes for non-spatial, (permanent) fully-protected area (FPA), and periodically-harvested closure (PHC) management for target species with moderate site-fidelity $(\boldsymbol{S}=\mathbf{0 . 2})$. FPA and PHC closures represent $30 \%(c=0.3)$ of the management area and, for the PHC, the closure is fished briefly every other year. (A) Outcomes of a well-managed fishery (i.e., optimal harvest effort levels for maximizing sustainable average annual yield). (B) Outcomes of an overfished fishery (25\% increase over optimal harvest rates). All outcomes are relative to non-spatial management values in a well-managed fishery (i.e., outcome $=1$ for optimal non-spatial management). All diamonds indicate a 1-year closed and 1-year open harvest cycle (optimal for a wellmanaged fishery). Gray points indicate outcomes for the full range of closed-open harvest cycles (all combinations of 1, 2, $3 \ldots 10$ years each). 

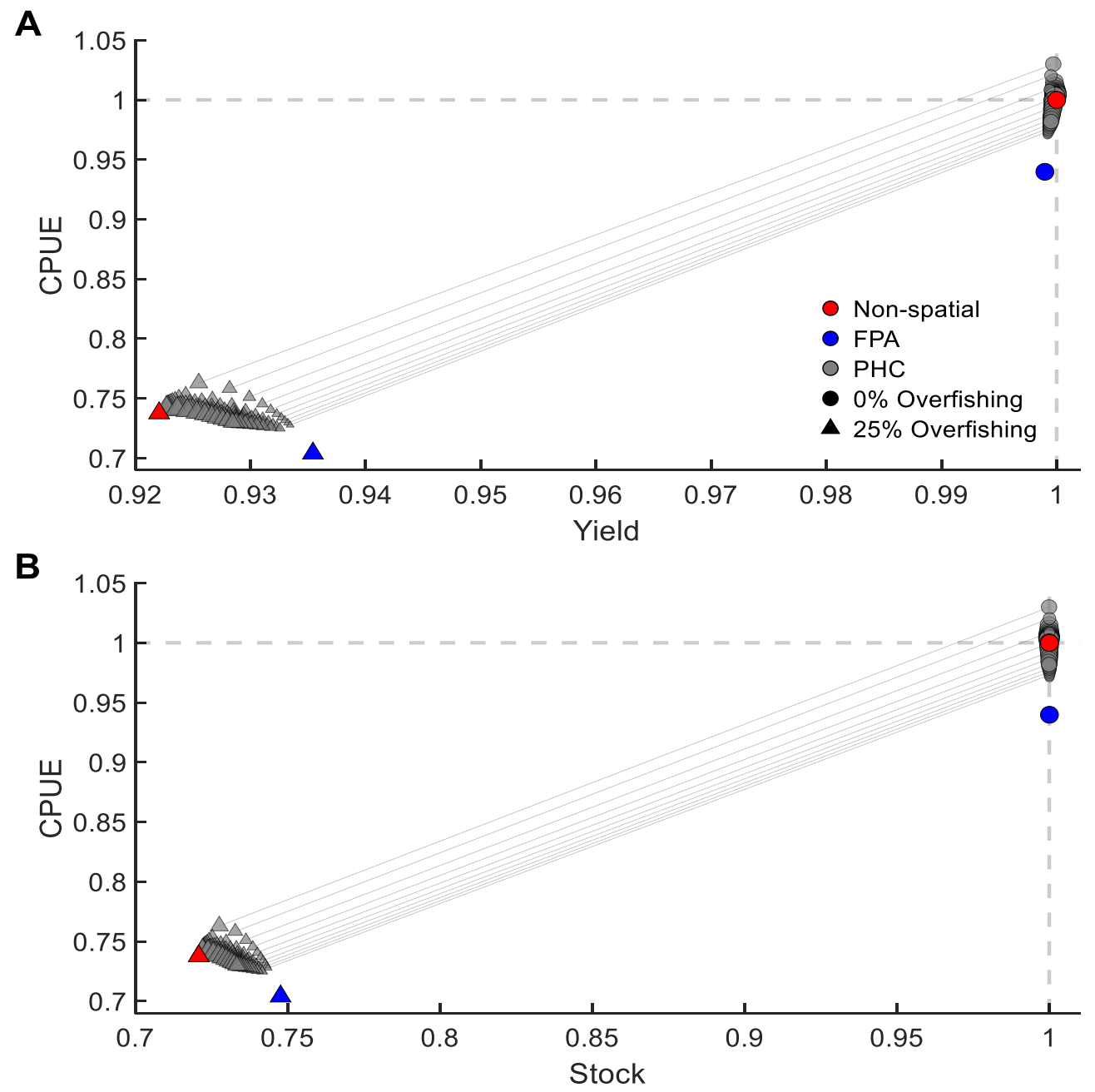

Figure 1.3. Average annual harvest efficiency (i.e., catch per unit effort [CPUE]) in relation to fishery yield (A) and fish stock conservation (B) values for a range of closed-open harvest cycles (all combinations of 1, 2, 3 ...10 years each). The target species has a moderate site-fidelity $(S=0.2)$, and the (permanent) fully-protected area (FPA) and periodically-harvested closure (PHC) comprise $30 \%(c=0.3)$ of the management area. The size of the marker correlates with the proportion of time the PHC is open. Circles indicate well-managed and triangles indicate overfished scenarios; gray solid lines connect scenarios with the same closed-open harvest cycle that lie on the efficiency frontier for an overfished system. Symbol color indicates management type: non-spatial in red; MR in blue; and PHC management in gray. Horizontal and vertical gray dashed lines are for reference, indicating outcome under optimal non-spatial management. 

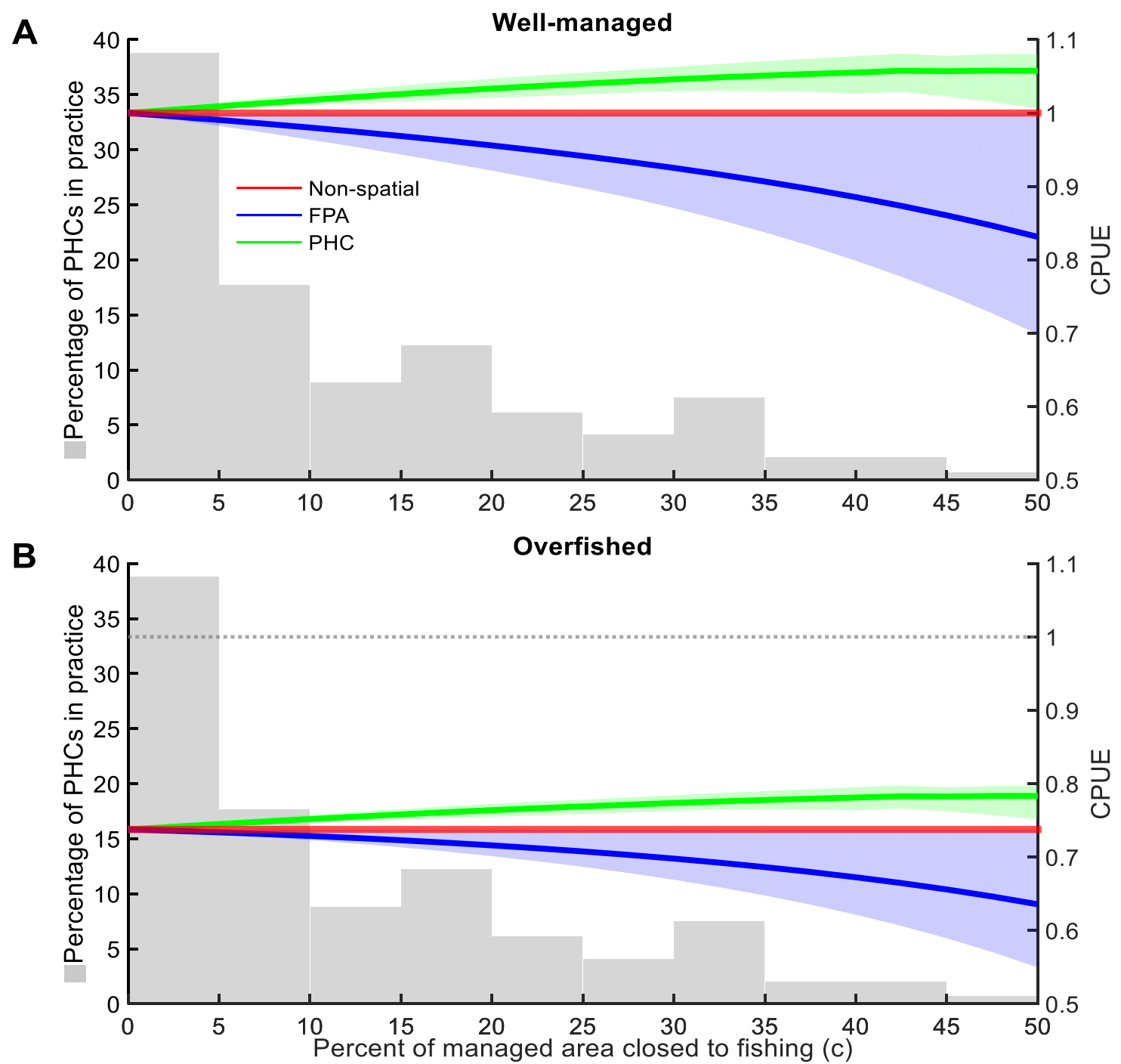

Figure 1.4. Size of periodically-harvested closures (PHCs) in practice and their estimated fisheries value (catch per unit effort [CPUE]). Frequency distribution of PHC sizes relative to total management areas, as found in practice in the Indo-Pacific (left axis, bars). Average annual harvest efficiency (CPUE; right axis, lines and shading) in relation to PHC size $(0 \% \leq c \leq 50 \%)$ and fish site-fidelity $(0 \leq S \leq 1$; shading) in wellmanaged (A) and overfished (B) systems. Values for CPUE are relative to non-spatial management in a well-managed system, and is highest when $S=1.0$ and decreases as site-fidelity decreases. 


\section{Supplementary Information}

\section{Model Summary}

We simulated non-spatial and marine protected area (MPA) fisheries management strategies using a spatially explicit fish population model coupled with an economic fisheries harvest model. Two forms of MPAs were included in our analysis: permanent fully-protected areas (FPA) and periodically-harvested closures (PHC). Fully-protected areas are permanently closed areas that restrict all fishing activities, and PHCs are temporary closures that protect fish stocks between short pulse harvest events. The model contained two patches, one of which could be closed permanently (FPA) or temporarily (PHC). The fish stock in each patch exhibits logistic population growth. Following growth, the fish stock is harvested (always harvested from the open patch, and only harvested in the PHC patch during open periods), and then the remaining stock that escaped harvest disperses between patches. Yield is a function of fishing effort, stock density, and fish catchability. Change in fish catchability in relation to the length of the PHC closed period followed an asymptotic catchability curve derived from empirical measurements on fish flight initiation distance - the distance at which prey flees when it senses a predator (i.e., spearfisher; Table S1.1; Feary et al. 2011, Januchowski-Hartley et al. 2015). Dispersal of stock between patches was calculated proportional to patch size ("common pool" dispersal), and then modified to reduce dispersal with an enhanced sitefidelity parameter ( $S$; White and Costello 2014). We tested the value of PHC management with an example case study: the PHC constitutes $30 \%$ of the total management area $(c=0.3)$; the target species has a relatively high population growth rate $(r=0.3)$ and moderate site-fidelity $(S=0.2)$. For the sensitivity analysis, we 
evaluated the model in relation to a full factorial combination of values for the proportion of area protected $(c=0-0.5)$ and enhanced site-fidelity $(S=0-1)$. Proportion of area protected did not exceed 50\% $(c=0.5)$ in our model to remain consistent with PHCs used throughout the Indo-Pacific. Also, we examined outcomes for a range of intrinsic rates of population growth $(r=0.1-0.5)$ and under various rates and magnitudes of change in fish catchability, the latter was done by modulating the original catchability curve with a adjustment variable ( $\alpha$; Fig. 1.7).

Fishing effort in a patch was optimized across fishable patches and for each annual time step in the model to achieve maximum sustainable yield (MSY). That is, under nonspatial management effort was optimized in both patches to achieve MSY, under permanent FPA management effort was optimized in the fishable patch to achieve MSY, and under PHC management effort was optimized for each year and patch to achieve MSY, with one patch always open to fishing and the other open periodically in accordance with a prescribed closed-open harvest cycle (here on a yearly time scale). In all cases, MSY was measured across the study system (i.e., both patches) and over the complete management cycle (i.e., one year for non-spatial and FPA scenarios, and the closed plus open periods for the PHC). For the PHC, we considered a range of harvest cycles, ranging from 1-10 years open in combination with 1-10 years closed. Overfishing also was considered; in this case harvest effort in each patch and year was increased by a constant proportion $(25 \%)$ of the effort levels that generated MSY. 


\section{$\underline{\text { Model Details }}$}

There are two-patches in the domain, one of which could be protected from fishing. The proportional area of the domain represented by the patch that could be protected from fishing is $c$, with the remaining area $(1-c)$ always open to fishing. The equation of spatial population dynamics in patch $i$ is:

$$
x_{i, t+1}=\frac{\sum_{j=1}^{N} D_{j i} A_{j} e_{j, t}}{A_{i}} .
$$

The timing is thus: the present stock density in each patch $\left(x_{j, t}\right)$ grows $\left(g\left(x_{j, t}\right)\right)$, and then is harvested $\left(h_{j, t}\right)$, giving residual (i.e., escaped) stock density $\left(e_{j, t}\right)$. Following conversion to stock abundance (via multiplication by patch area, $A_{j}$ ), the escaped stock disperses between patches $\left(D_{j i}\right)$. The resulting stock abundance is divided by patch area $\left(A_{i}\right)$ to indicate stock density at the beginning of the subsequent time $\operatorname{step}\left(x_{i, t+1}\right)$.

We simulated population growth using the discrete-time logistic population growth function (Schaefer 1957):

$$
g\left(x_{i}\right)=x_{i}+r_{d} x_{i}\left(1-x_{i} / K\right)
$$

where $K$ is the carrying capacity and $r_{d}$ is the discrete population growth rate. We assumed a carrying capacity of $K=1$ unit biomass density without losing generality. Discrete population growth rate is derived from the intrinsic rate of population growth $(r$; Gotelli 1995):

$$
r_{d}=e^{r}-1
$$


We assumed as a baseline intrinsic rate of population growth $r=0.3$, which represents fish with moderate resilience, such as those in families Acanthuridae and Labridae (subfamily Scarinae) that often are primary target fishes in PHCs in the Indo-Pacific (Feary et al. 2011, Januchowski-Hartley et al. 2015, Froese and Pauly 2012). Also, we examined outcomes for species with low and high intrinsic population growth rates, $r=0.1$ and 0.5 , respectively (Fig. S1.4, S1.5, and S1.10 - S1.15; Januchowski-Hartley et al. 2015). Harvest (i.e., yield abundance) is a function of stock density after growth, fishing effort in each patch $\left(E_{i}\right)$, and patch area:

$$
h_{i}=g\left(x_{i}\right) f\left(E_{i}\right) A_{i},
$$

where $f\left(E_{i}\right)$ is the fraction of stock harvested and calculated using an exponential survival function:

$$
f\left(E_{i}\right)=1-e^{-E_{i} q_{i}}
$$

The catchability coefficient $\left(q_{i}\right)$ is a function of how long the patch had been previously closed to fishing (i.e., never for permanently open patches under all three management scenarios, and 1-10 years for the PHC patch, depending on its closed period; Fig. 1.7). The escaped stock density after harvest is thus:

$$
e_{i}=g\left(x_{i}\right)\left(1-f\left(E_{i}\right)\right) \text {. }
$$

Dispersal is based on a common pool model modified to consider enhanced sitefidelity (White and Costello 2014). In the common pool model, dispersal between patches is proportional to the size of each patch:

$$
\mathbf{D}=\left[\begin{array}{ll}
Q_{1,1} & Q_{1,2} \\
Q_{2,1} & Q_{2,2}
\end{array}\right],
$$


where rows indicate source patches and columns indicate destination patches $\left(Q_{\text {source,destination }}\right)$. Each row-column cell signifies the fraction of the population that disperses from row patch to column patch. The model system is closed; thus rows sum to 1. For our example case study, where $30 \%$ of total management area is protected $(c=0.3)$, common pool dispersal is thus:

$$
\mathbf{D}=\left[\begin{array}{ll}
0.7 & 0.3 \\
0.7 & 0.3
\end{array}\right]
$$

Introduction of site-fidelity parameter, $S$, increases the fraction of the population that remains in a given patch (e.g., via self-recruitment and/or territoriality), with a commensurate decrease in cross-patch movement. The dispersal matrix is thus:

$$
\mathbf{D}=\left[\begin{array}{cc}
Q_{1,1}+\left(1-Q_{1,1}\right) S & Q_{1,2}-Q_{1,2} S \\
Q_{2,1}-Q_{2,1} S & Q_{2,2}+\left(1-Q_{2,2}\right) S
\end{array}\right],
$$

where $0 \leq S \leq 1$. If $S=0$, enhanced site fidelity is removed and dispersal is represented by the common pool model (i.e., equation 1.7). If $S=1$, site-fidelity is $100 \%$ and no dispersal occurs out of either patch (i.e., in equation 1.9, diagonal values equal 1 and offdiagonal values equal 0). For our example case study where $30 \%$ of total management area is protected $(c=0.3)$ and the target species has moderate site-fidelity $(S=0.2)$, the dispersal matrix is thus:

$$
\mathbf{D}=\left[\begin{array}{ll}
0.76 & 0.24 \\
0.56 & 0.44
\end{array}\right]
$$

\section{$\underline{\text { Fish Catchability }}$}

We generated a catchability curve using empirical data on the distance reef fish initiated flight from simulated spearfishers (flight initiation distance). Empirical data are 
from two studies that measured flight initiation distance for families Acanthuridae and Labridae (subfamily Scarinae) in four Indo-Pacific countries: Papua New Guinea, Vanuatu, Philippines, and Chagos (Table S1.1; Feary et al. 2011, Januchowski-Hartley et al. 2015). Flight initiation distance was quantified in non-spatial, FPA, and PHC management areas ( $\mathrm{n}=24$ total) and in relation to the length of time the area had been protected from fishing prior to the empirical study ( 0 - 39 years; Feary et al. 2011, Januchowski-Hartley et al. 2015). Using flight initiation distance mean and variance for each family at each site (Table S1.1), we calculated the normal cumulative probability distribution to obtain probability of observing fish initiate flight at a distance less than the mean effective speargun range required to successfully spear a fish $(323.75 \mathrm{~cm}$, given a rifle style speargun similar to that used in Vanuatu and Papua New Guinea; for example, see Fig. S1.6; Table S1.1). A logarithmic curve best fit normal cumulative probability values in relation to years closed $\left(R^{2}=0.58\right.$; Fig. S1.6):

$$
F_{t}=0.1724 \log \left(C_{t}+1\right)+0.4314,
$$

where $F_{t}$ is the probability of fish initiating flight at a distance less than the mean effective speargun range $(323.75 \mathrm{~cm})$ and $C_{t}$ is years protected from fishing. Given that a fish needs to be within speargun range to be harvested, we assumed the catchability of fish in an area and during a particular year $\left(q_{t, i}\right)$ to be a function of $F_{t}$. Catchability was set to $F_{t}$; then, to maintain generality, we scaled catchability relative to the level calculated when an area is always open to fishing and thus fish catchability is not enhanced (i.e., $q_{t, i}=1$ when $C_{t, i}=0$; Fig. 1.7):

$$
q_{t, i}=\frac{0.1724 \log \left(C_{t, i}+1\right)+0.4314}{0.4314}
$$


To examine the sensitivity of our results to a range of catchability curves we used a adjustment variable $(\alpha)$ to modulate the rate and magnitude of change in fish catchability in relation to years closed (Fig. 1.7):

$$
q_{t, i}=\frac{\alpha(0.1724) \log \left(C_{t, i}+1\right)+0.4314}{0.4314},
$$

where $0 \leq \alpha \leq 1.5$. If $\alpha=0$, fish catchability is held constant through time $(q=1)$. If $\alpha=1$, then fish catchability changes in accordance with empirical data on fish flight initiation distance and the cumulative probability of fish initiating flight response to a spearfisher at a distance less than the mean effective speargun range (i.e., equation 1.12). 


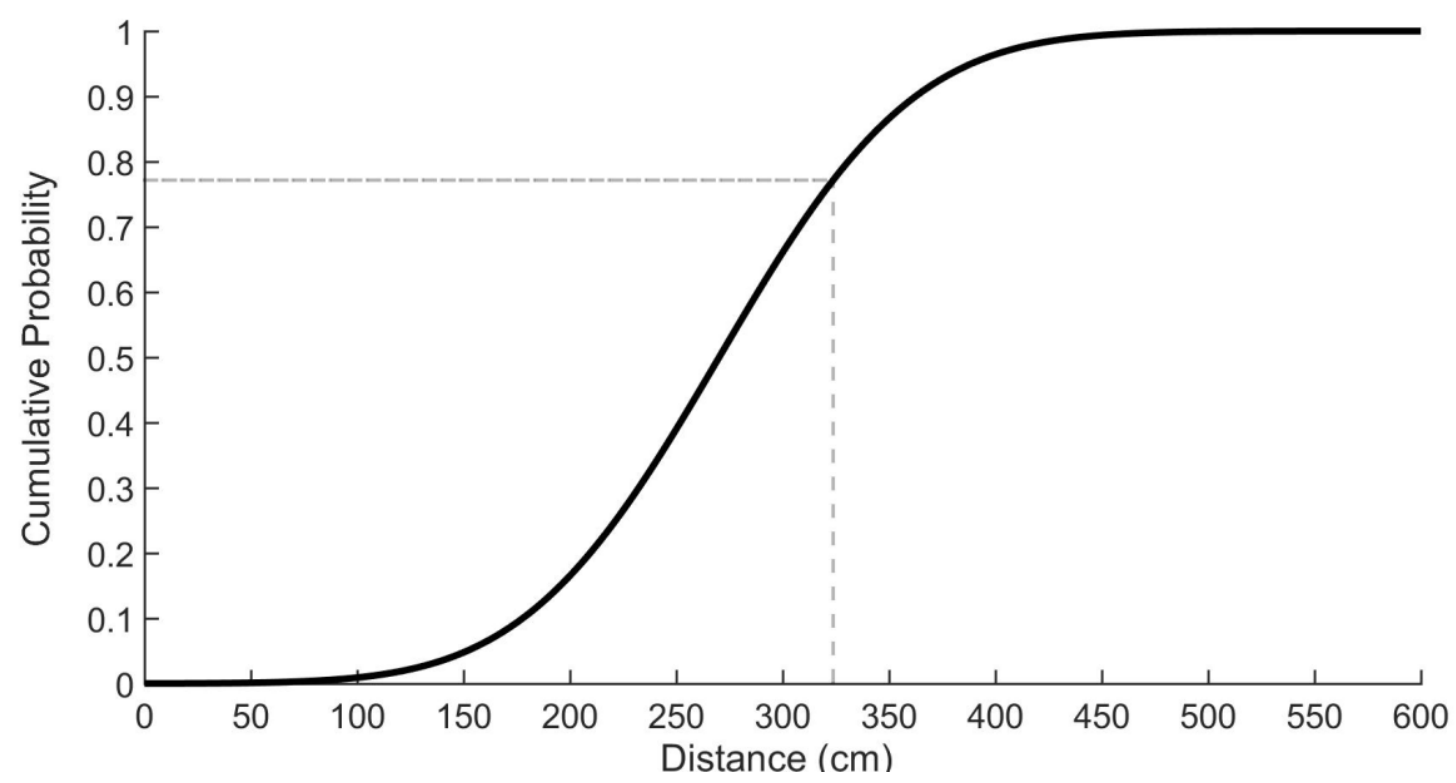

Figure S1.1. An example cumulative probability distribution of fish initiating flight response less than a given distance $(\mathrm{cm})$ from a simulated spearfisher for Acanthuridae at a site in Papua New Guinea that was protected 4 years prior to empirical measurements of flight initiation distance $($ mean $=270.12 \mathrm{~cm}$, variance $=$ $5193.96 \mathrm{~cm}$ ). The normal cumulative probability of fish initiating flight less than the mean effective range (vertical dashed line, $323.75 \mathrm{~cm}$ ) for rifle style spearguns used in Vanuatu and Papua New Guinea is 0.77 (horizontal dashed line). 


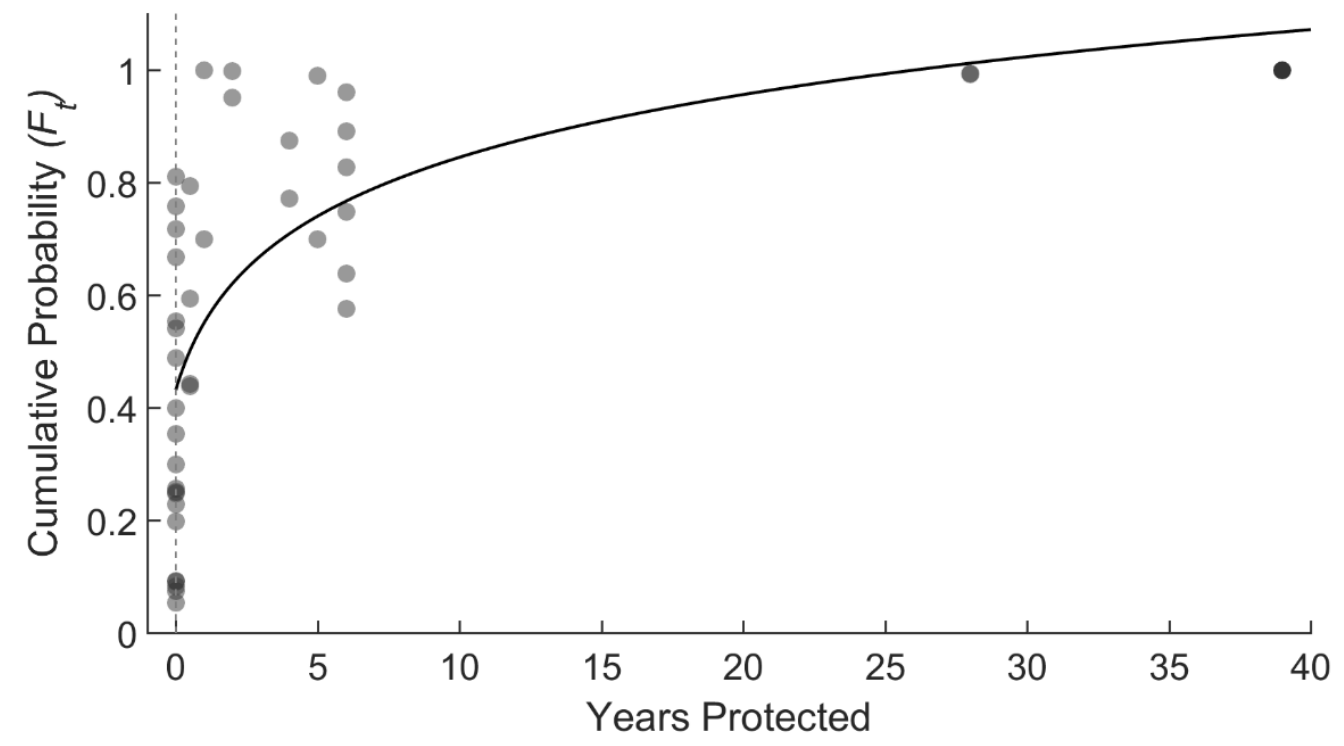

Figure S1.2. Normal cumulative probability values in relation to years protected from fishing pressure for families Acanthuridae and Scarinae (Labridae subfamily).

Cumulative probability values indicate the probability of observing flight initiation distance lower than the mean effective lethal range for rifle style spearguns used in Vanuatu and Papua New Guinea $(323.75 \mathrm{~cm})$. A logarithmic curve best fit the data $\left(R^{2}=0.5763\right)$. Points are transparent to reveal overlapping data points. Note, there are eight data points overlapped at the 39-year closure in Chagos and two data points overlapped at 28-year closure in the Philippines. 


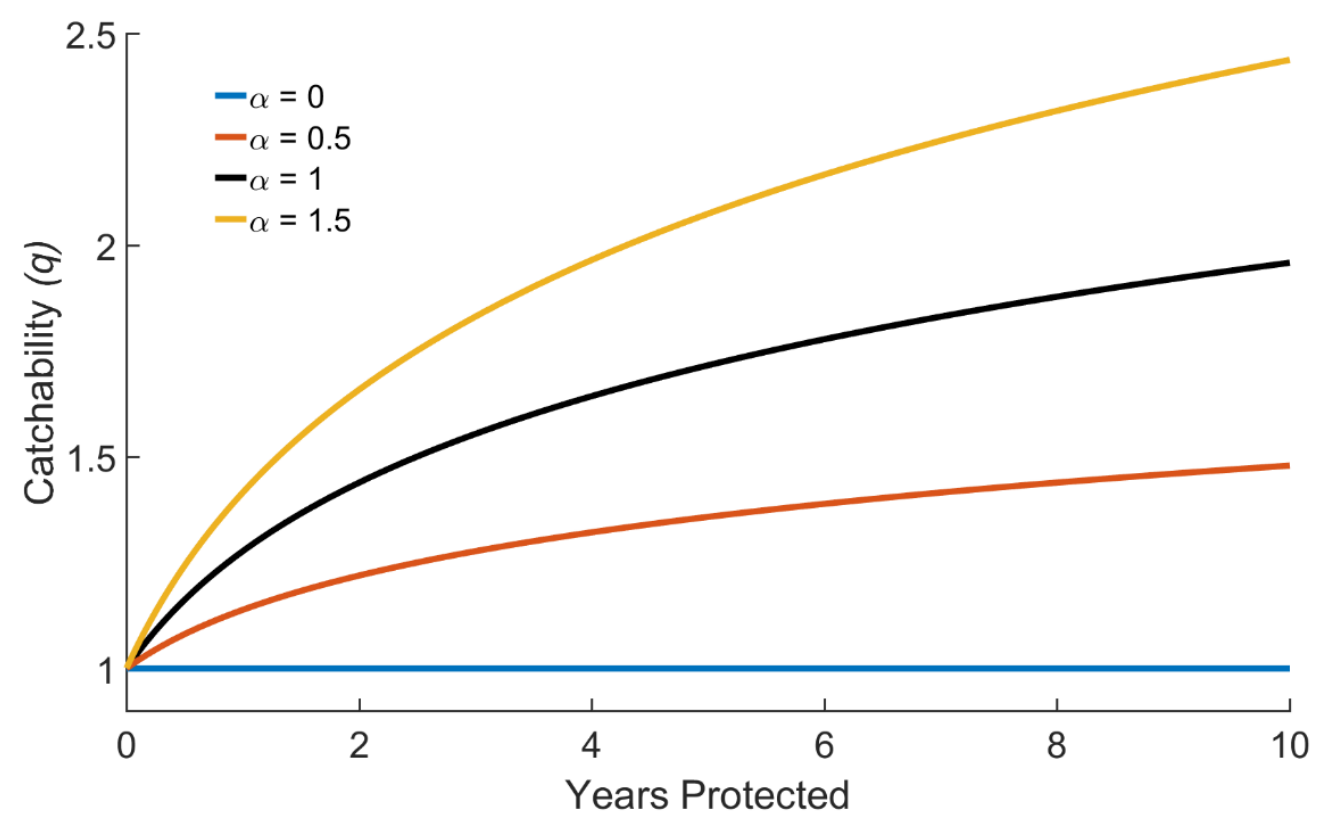

Figure S1.3. Rate of change for fish catchability in relation to a scalar parameter $(\alpha)$ and years protected for the periodically-harvested closures (PHC). Enhanced catchability (i.e., $q>1$ ) is generated by protection from fishing and assumed to return to the baseline level observed in fished areas (i.e., $q=1$ ) shortly after the fish stock in the PHC is exposed to fishing pressure. The catchability curve is modulated with an adjustment variable $(\alpha) ; \alpha=1$ indicates the catchability curve derived from normal cumulative probabilities of observing fish flight initiation distance less than the mean effective speargun range for rifle style spearguns used in Vanuatu and Papua New Guinea $(323.75 \mathrm{~cm})$. Fish catchability is held constant $(q=1)$ when $\alpha=0$. 


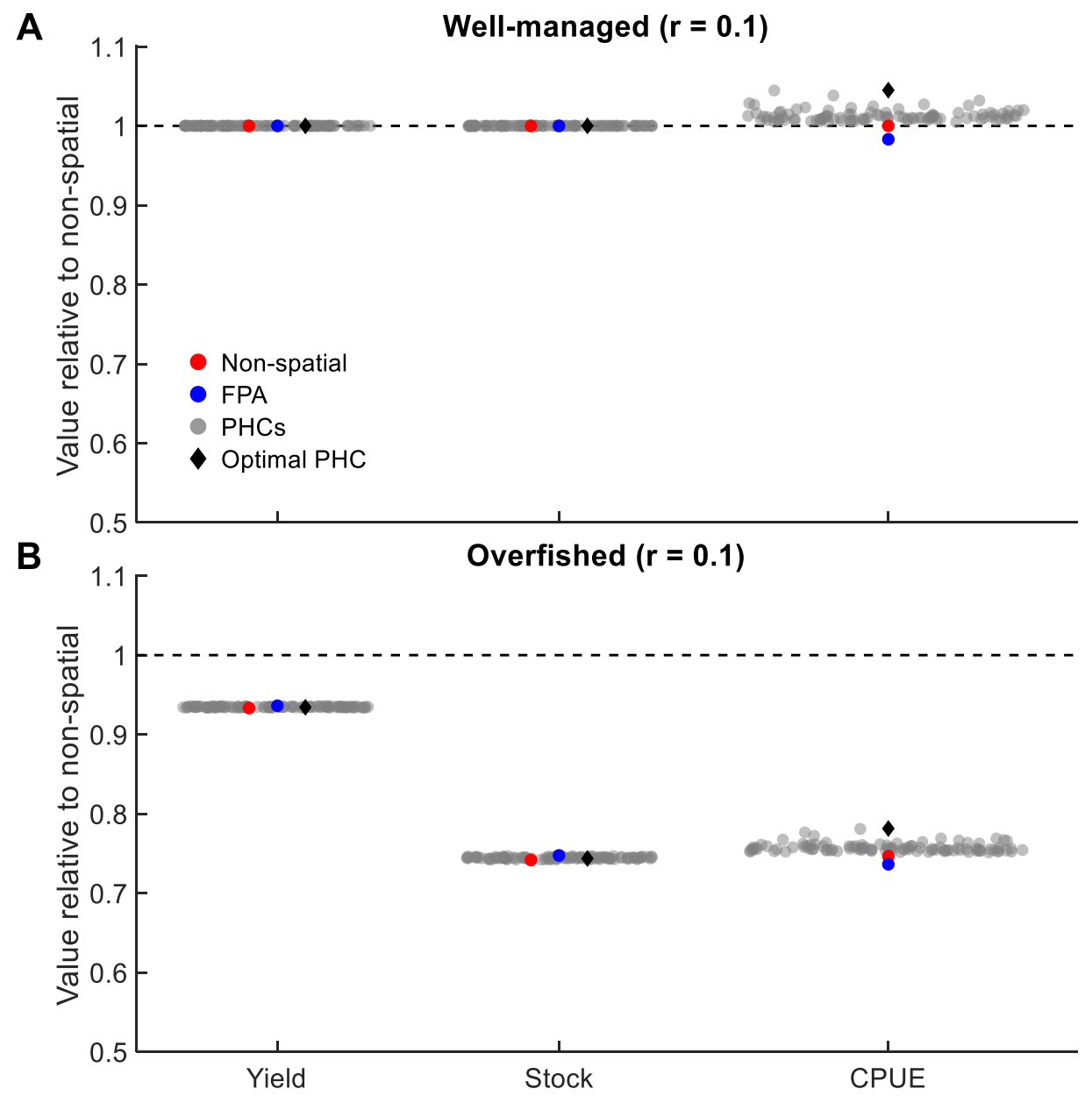

Figure S1.4. Fishery (yield, catch per unit effort [CPUE]) and fish conservation (stock) outcomes for non-spatial, permanent fully-protected area (FPA), and periodically-harvested closure (PHC) management for target species with a low intrinsic rate of population growth $(r=0.1)$, and moderate site-fidelity $(S=0.2)$. Fully-protected area and PHC closures represent $c=30 \%$ of the management area and, for the PHC, the closure is fished briefly every other year. (A) Outcomes of a wellmanaged fishery and (B) and an overfished fishery (25\% increase over optimal harvest rates). All outcomes are relative to non-spatial management values in a well-managed fishery (i.e., outcome $=1$ for optimal non-spatial management). Diamonds for PHC management indicate optimal 1-year closed and 1-year open harvest cycle in a wellmanaged fishery (i.e., $0 \%$ overfishing). Gray points indicate the full range of closed-open harvest cycles (all combinations of 1, 2, $3 \ldots 10$ years each). 


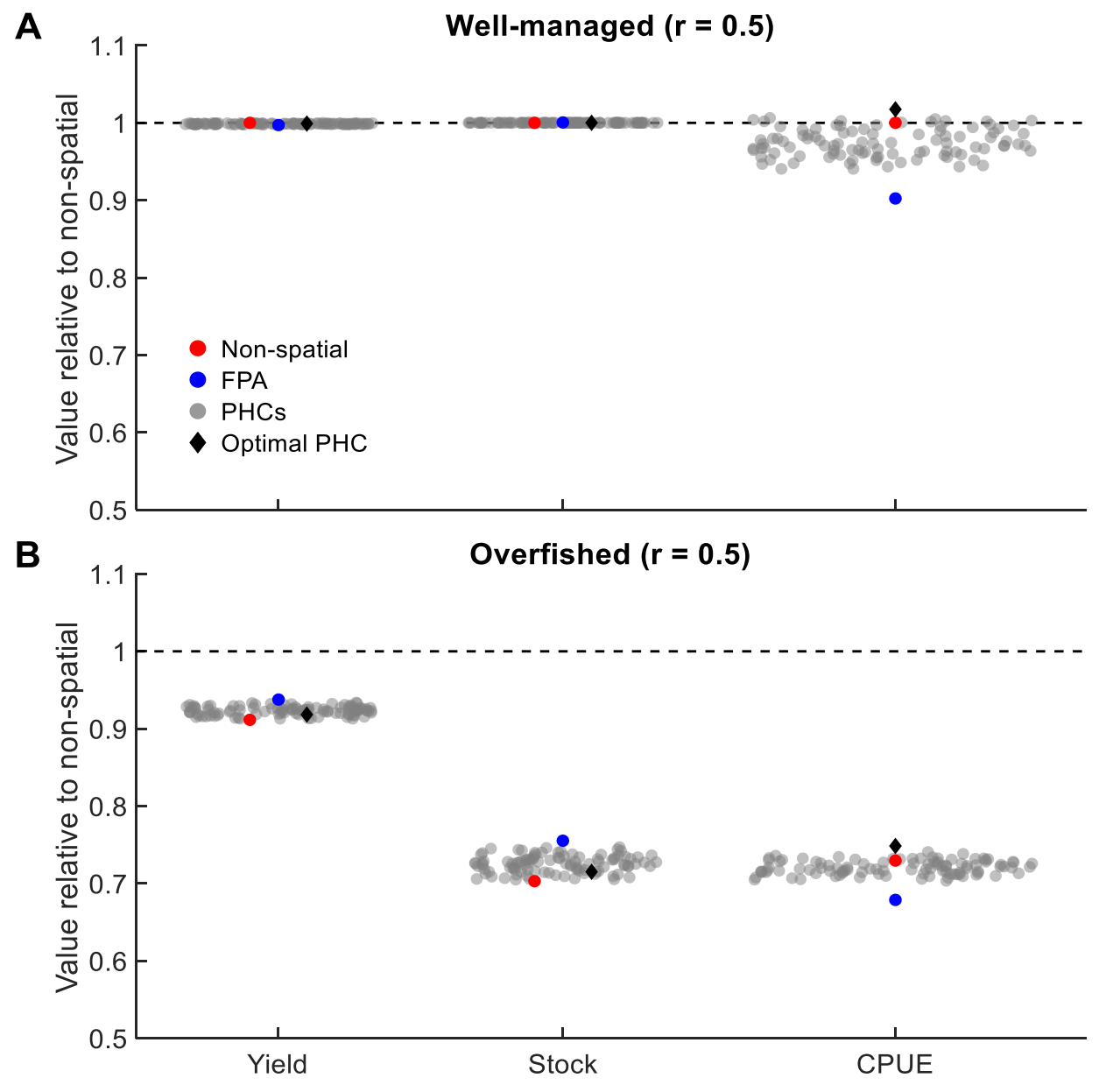

Figure S1.5. Fishery (yield, catch per unit effort [CPUE]) and fish conservation (stock) outcomes for non-spatial, permanent fully-protected area (FPA), and periodically-harvested closure (PHC) management for target species with a high intrinsic rate of population growth $(r=0.5)$, and moderate site-fidelity $(S=0.2)$. Fully-protected area and PHC closures represent $c=30 \%$ of the management area and, for the PHC, the closure is fished briefly every other year. (A) Outcomes of a wellmanaged fishery and (B) and an overfished fishery (25\% increase over optimal harvest rates). All outcomes are relative to non-spatial management values in a well-managed fishery (i.e., outcome $=1$ for optimal non-spatial management). Diamonds for PHC management indicate optimal 1-year closed and 1-year open harvest cycle in a wellmanaged fishery (i.e., $0 \%$ overfishing). Gray points indicate the full range of closed-open harvest cycles (all combinations of 1, 2, $3 \ldots 10$ years each). 


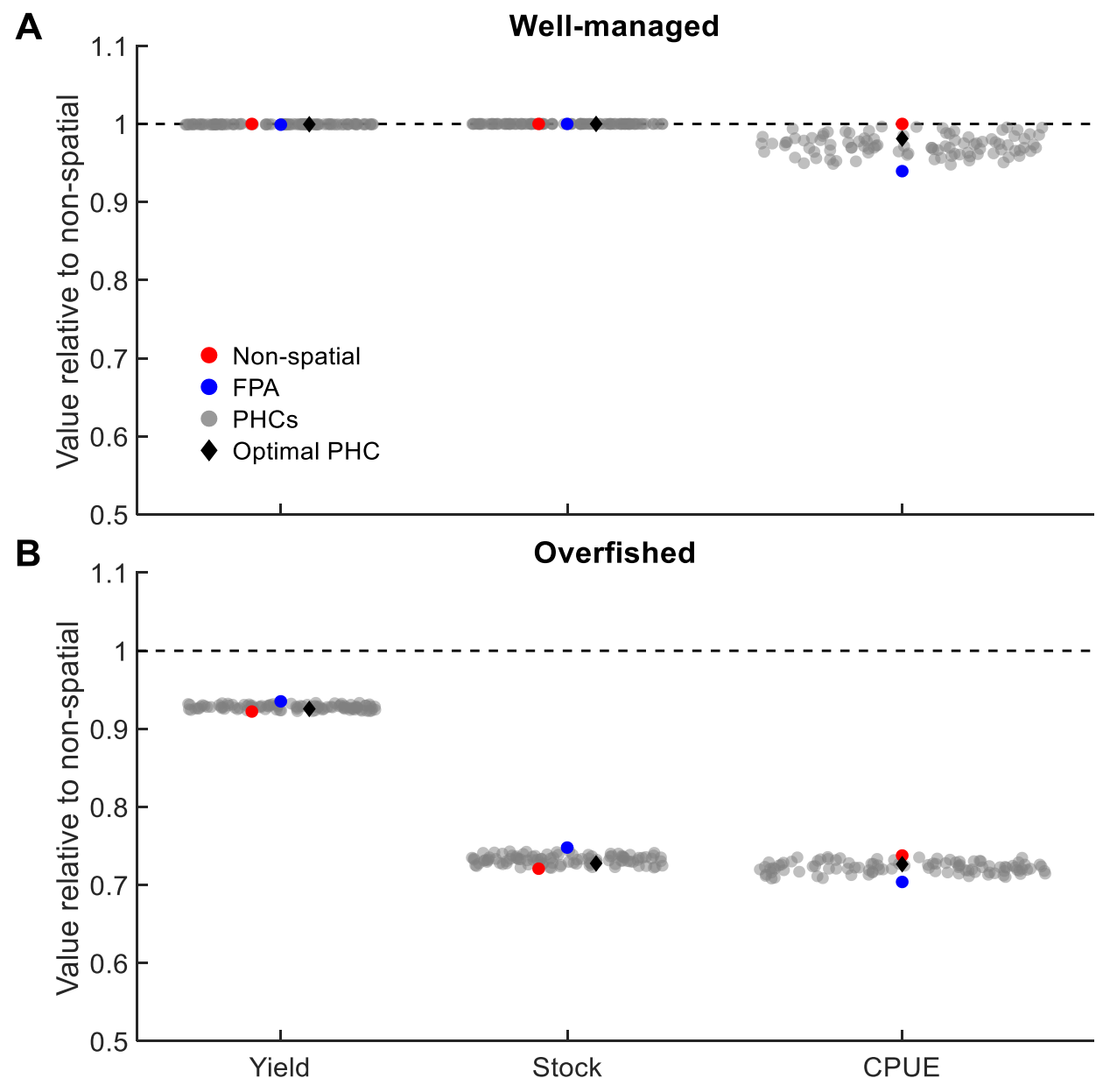

Figure S1.6. Fishery (yield, CPUE) and fish conservation (stock) outcomes under non-spatial, permanent fully-protected area (FPA), and periodically-harvested closure (PHC) management scenarios, given constant catchability $(q=1 ; \alpha=0)$, moderate site-fidelity $(S=0.2)$, and, in the case of FPA and PHC management, 30\% of the domain protected from fishing $(\boldsymbol{c}=\mathbf{0 . 3})$. For PHC management, the closure is fished briefly every other year. (A) Outcome of a well-managed fishery (i.e., optimal harvest effort levels for maximizing sustainable average yield). (B) Outcome of an overfished fishery ( $25 \%$ increase over optimal harvest rates). Outcomes are relative to non-spatial management values in a well-managed fishery (i.e., outcome $=1$ for optimal non-spatial management). Diamonds for PHC management indicate optimal 1-year closed and 1-year open harvest cycle when change in fish catchability is considered for a well-managed fishery (i.e., $0 \%$ overfishing). Gray points indicate the full range of closedopen harvest cycles (all combinations of 1,2, $3 \ldots 10$ years each). 


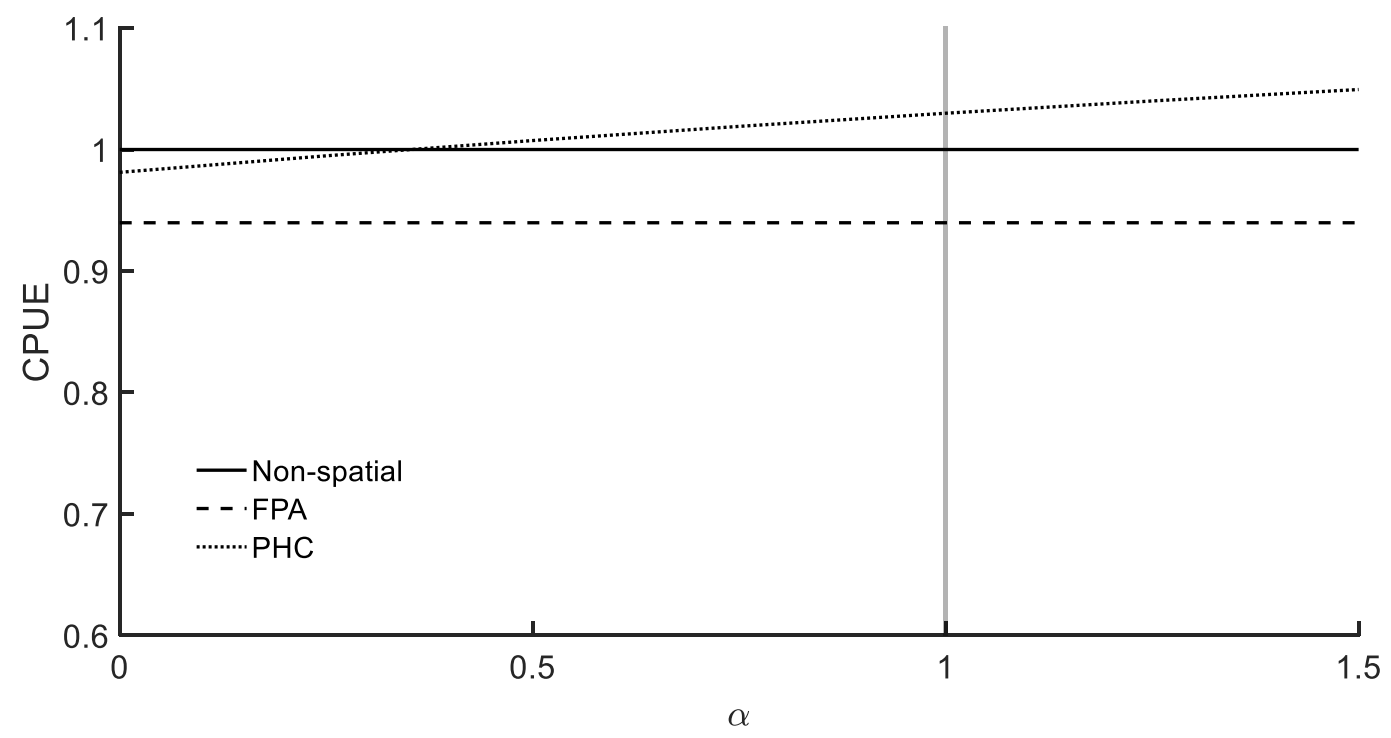

Figure S1.7. Harvest efficiency (i.e., catch per unit area [CPUE]) in relation to rate and magnitude of change in fish catchability $(0 \leq \alpha \leq 1.5)$ for periodically-harvested closure (PHC), fully-protected area (FPA) and non-spatial management. CPUE values are relative to that under non-spatial management in a well-managed fishery. The vertical grey line $(\alpha=1)$ indicates CPUE for estimated change in catchability from empirical data on fish flight initiation distance and normal cumulative probability distributions. 

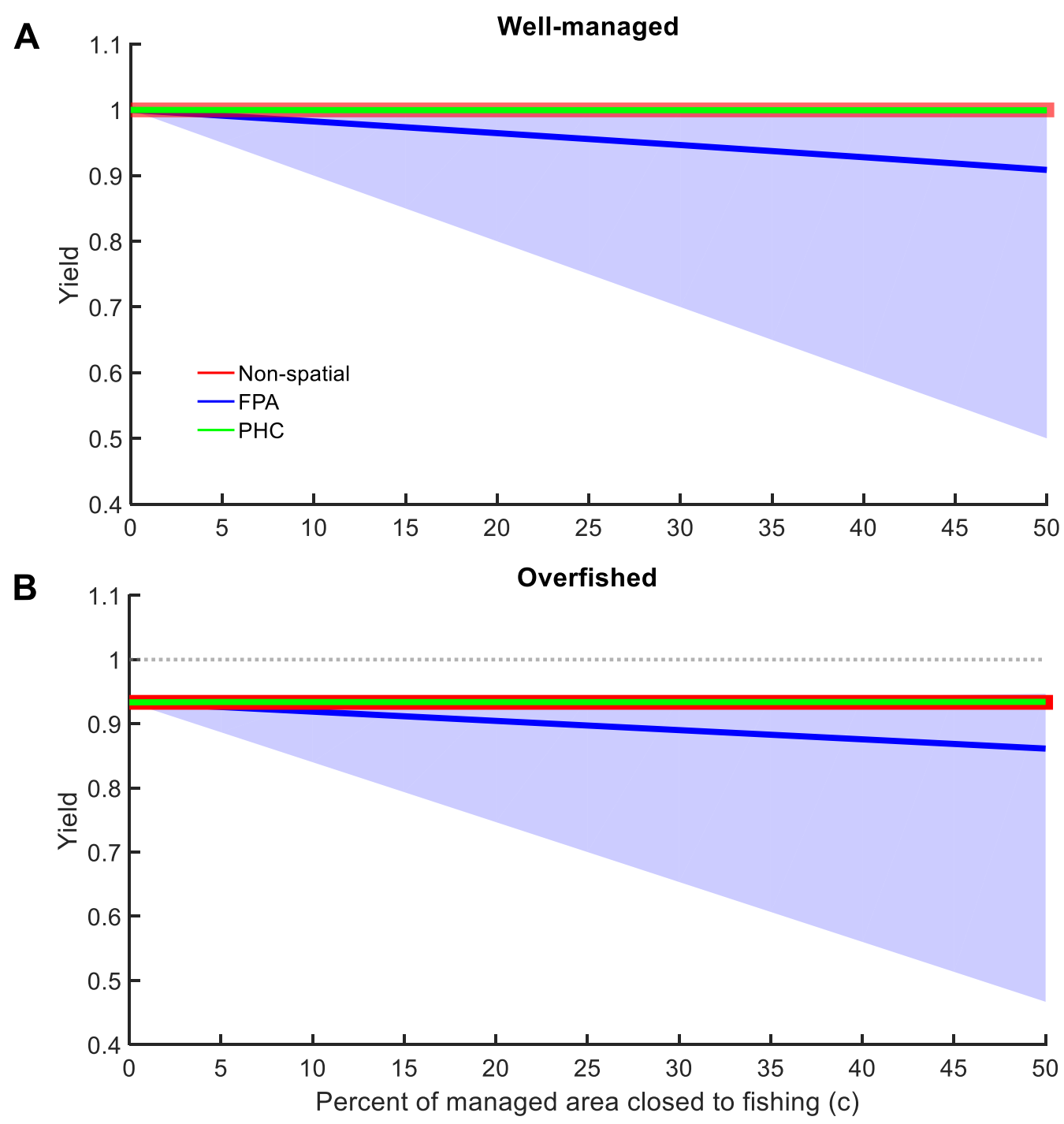

Figure S1.8. Average annual yield in relation to the size of the protected area $(0 \% \leq c \leq 50 \%)$ and fish site-fidelity $(0 \leq S \leq 1$, shading) in well-managed (A) and an overfished (B) systems. The protected area is either a periodically-harvested closure (PHC) or fully-protected area (FPA). Values are plotted relative to non-spatial management in a well-managed fishery (i.e., outcome $=1$ for optimal non-spatial management). Outcomes under PHC and non-spatial management are insensitive to $S$, thus shading is absent. 


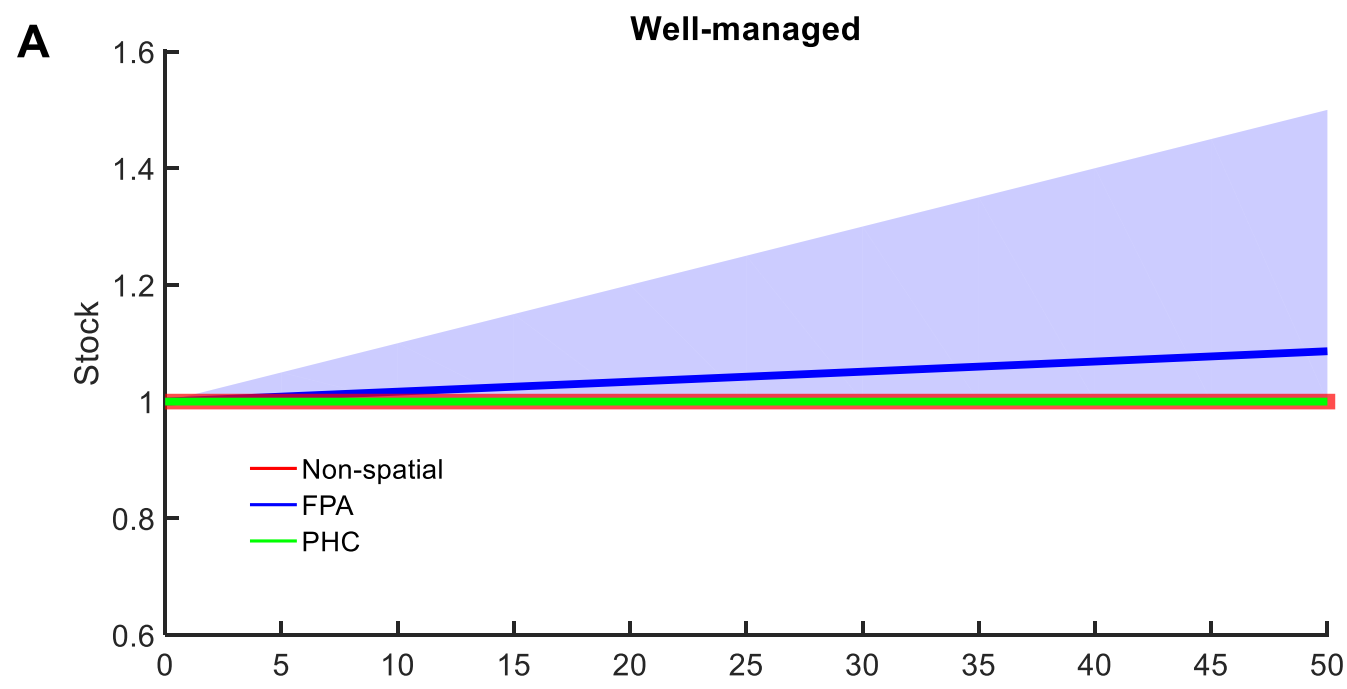

B

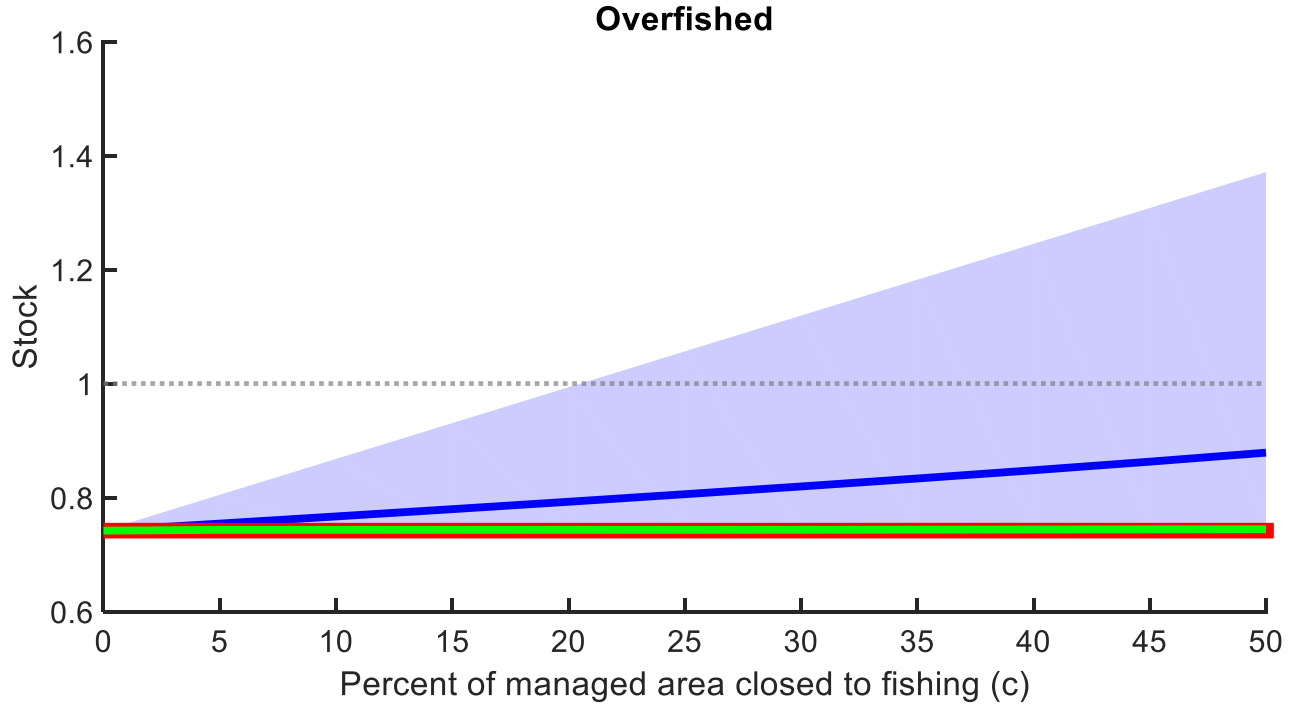

Figure S1.9. Average annual stock in relation to the size of the protected area $(0 \% \leq c \leq 50 \%)$ and fish site-fidelity $(0 \leq S \leq 1$, shading) in well-managed (A) and an overfished (B) systems. The protected area is either a periodically-harvested closure (PHC) or fully-protected area (FPA). Values are plotted relative to non-spatial management in a well-managed fishery (i.e., outcome $=1$ for optimal non-spatial management). Outcomes under PHC and non-spatial management are insensitive to $S$, thus shading is absent. 

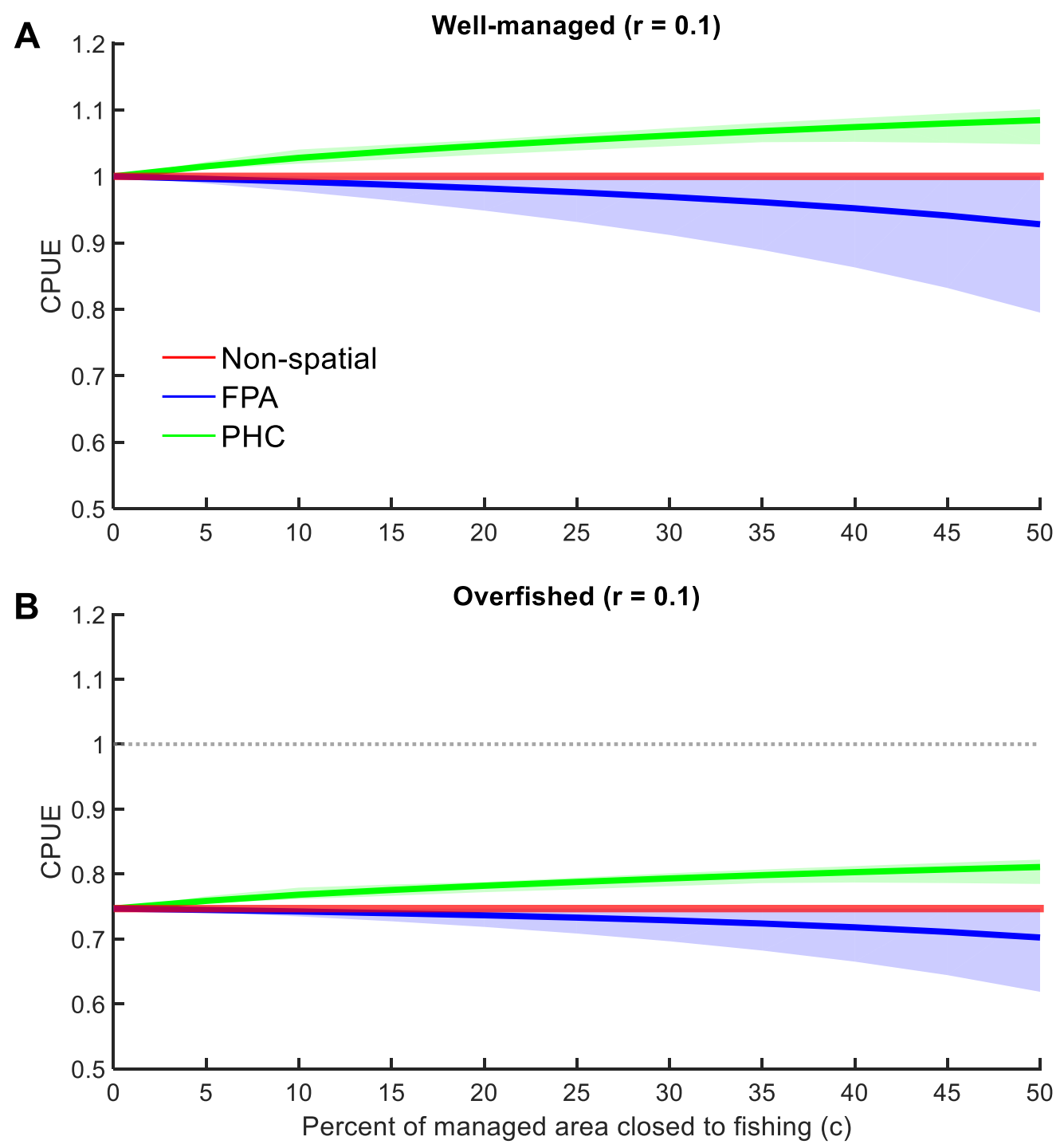

Figure S1.10. Average annual harvest efficiency (i.e., catch per unit effort, CPUE) in relation to size of the protected area $(0 \% \leq c \leq 50 \%)$ and fish site-fidelity $(0 \leq S \leq 1$, shading) for species with a low $(r=0.1)$ intrinsic rate of population growth. The protected area is either a periodically-harvested closure (PHC) or a fully-protected area (FPA). The gray dashed line in (B) indicates the CPUE for a well-managed fishery. 

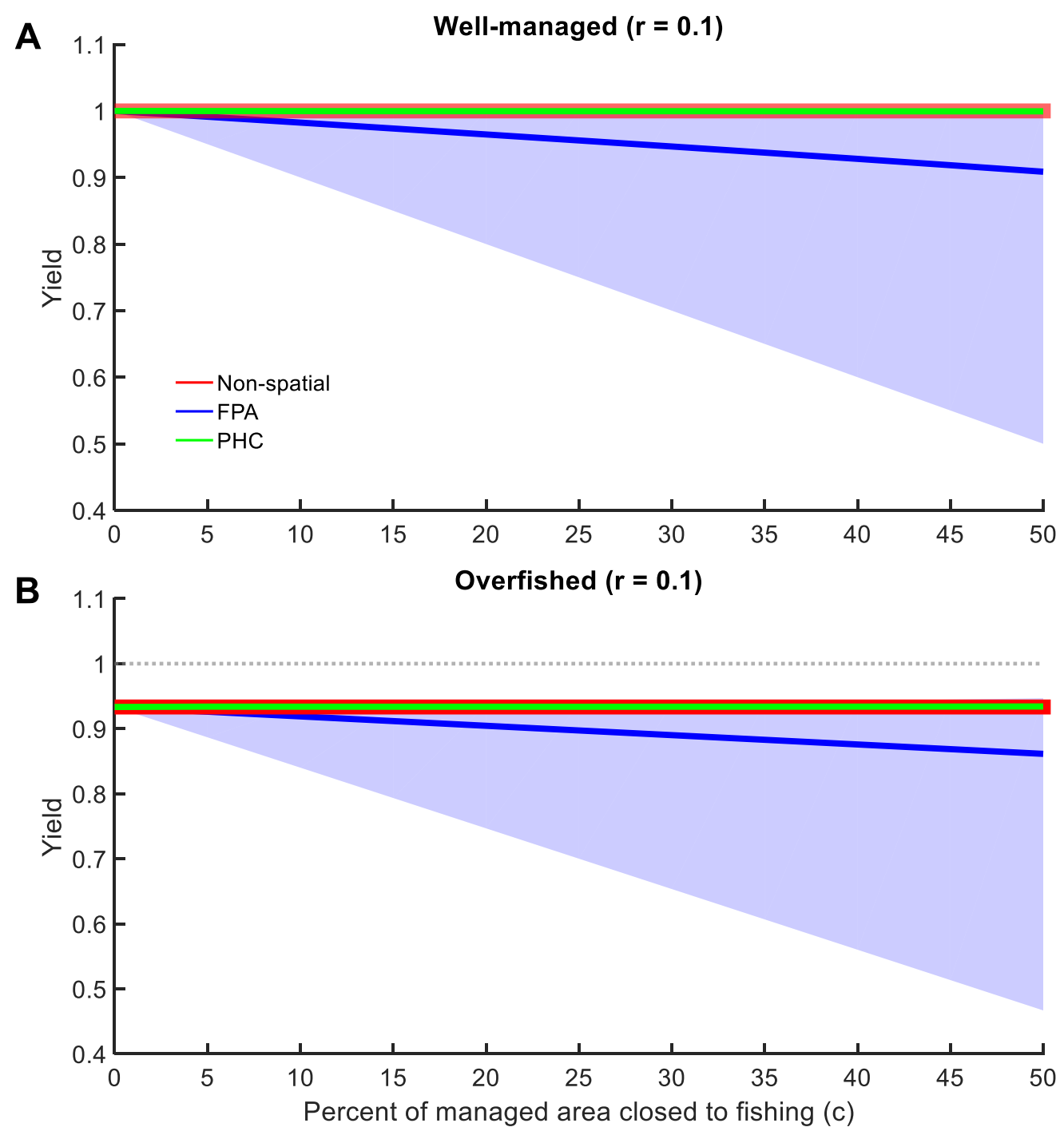

Figure S1.11. Average annual yield in relation to size of the protected area $(0 \% \leq c \leq 50 \%)$ and fish site-fidelity $(0 \leq S \leq 1$, shading) for species with a low $(r=0.1)$ intrinsic rate of population growth. The protected area is either a periodically-harvested closure (PHC) or fully-protected area (FPA). Yield under PHC and non-spatial management are insensitive to $S$, thus shading is absent. The gray dashed line in (B) indicates the yield for a well-managed fishery. 

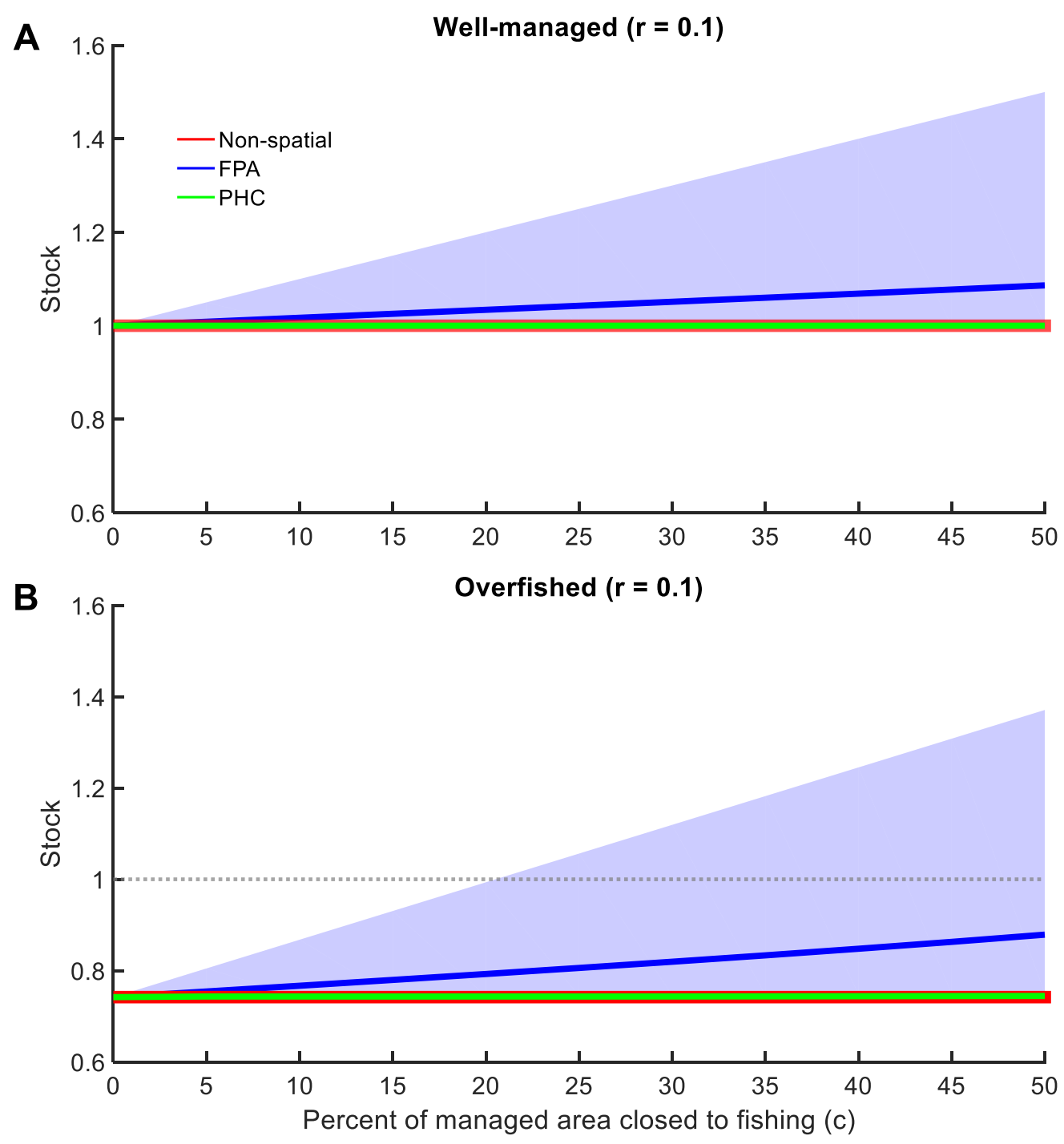

Figure S1.12. Average annual stock abundance in relation to the size of the protected area $(0 \% \leq c \leq 50 \%)$ and fish site-fidelity $(0 \leq S \leq 1$, shading) for species with a low $(r=0.1)$ intrinsic rate of population growth. The protected area is either a periodically-harvested closure (PHC) or fully-protected area (FPA). Stock abundance under PHC and non-spatial management are insensitive to $S$, thus shading is absent. The gray dashed line in (B) indicates the stock for a well-managed fishery. 

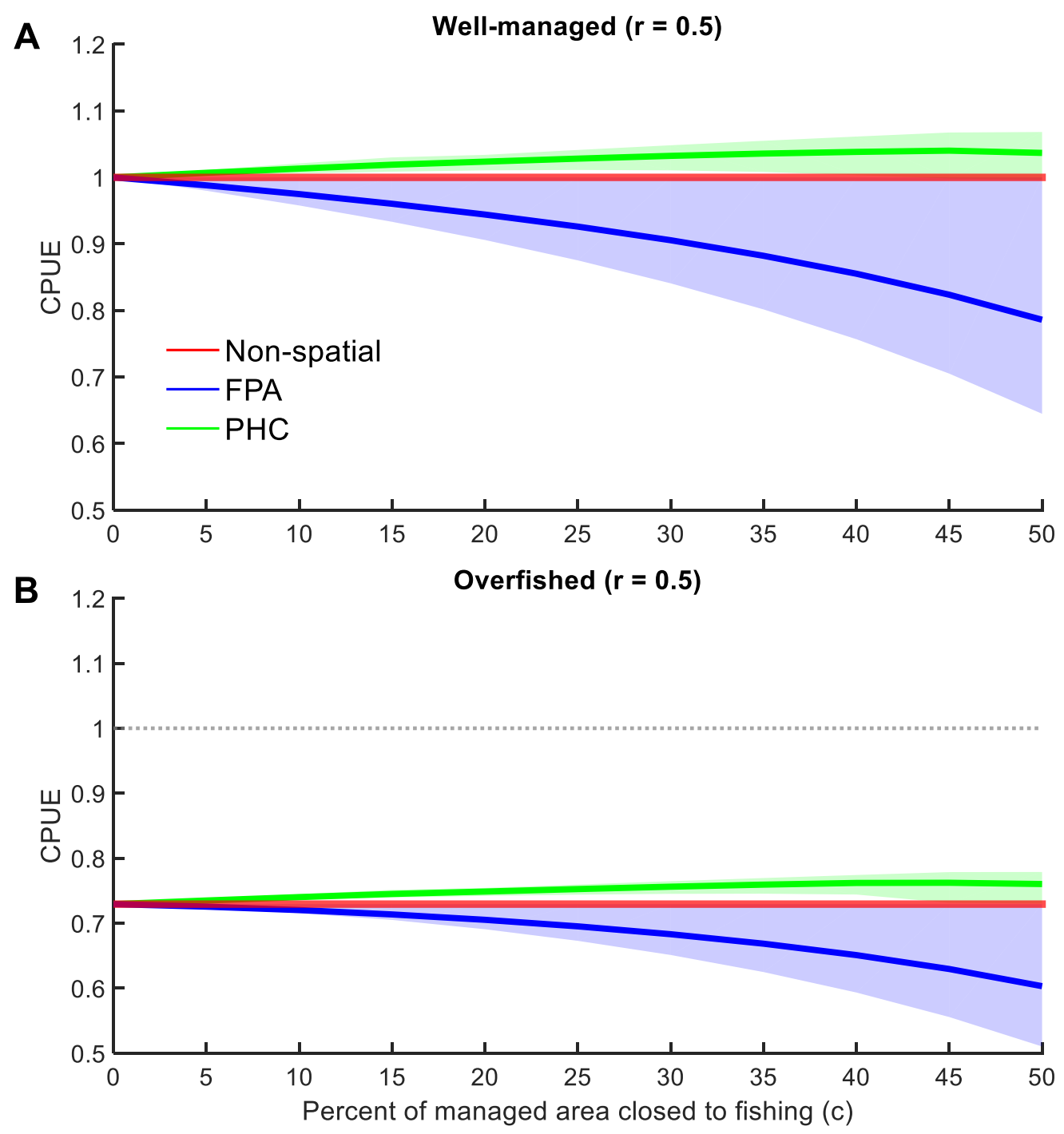

Figure S1.13. Average annual harvest efficiency (i.e., catch per unit effort, CPUE) in relation to size of the protected area $(0 \% \leq c \leq 50 \%)$ and fish site-fidelity $(0 \leq S \leq 1$, shading) for species with a high $(r=0.5)$ intrinsic rate of population growth. The protected area is either a periodically-harvested closure (PHC) or fully-protected area (FPA). The gray dashed line in (B) indicates the CPUE for a well-managed fishery. 


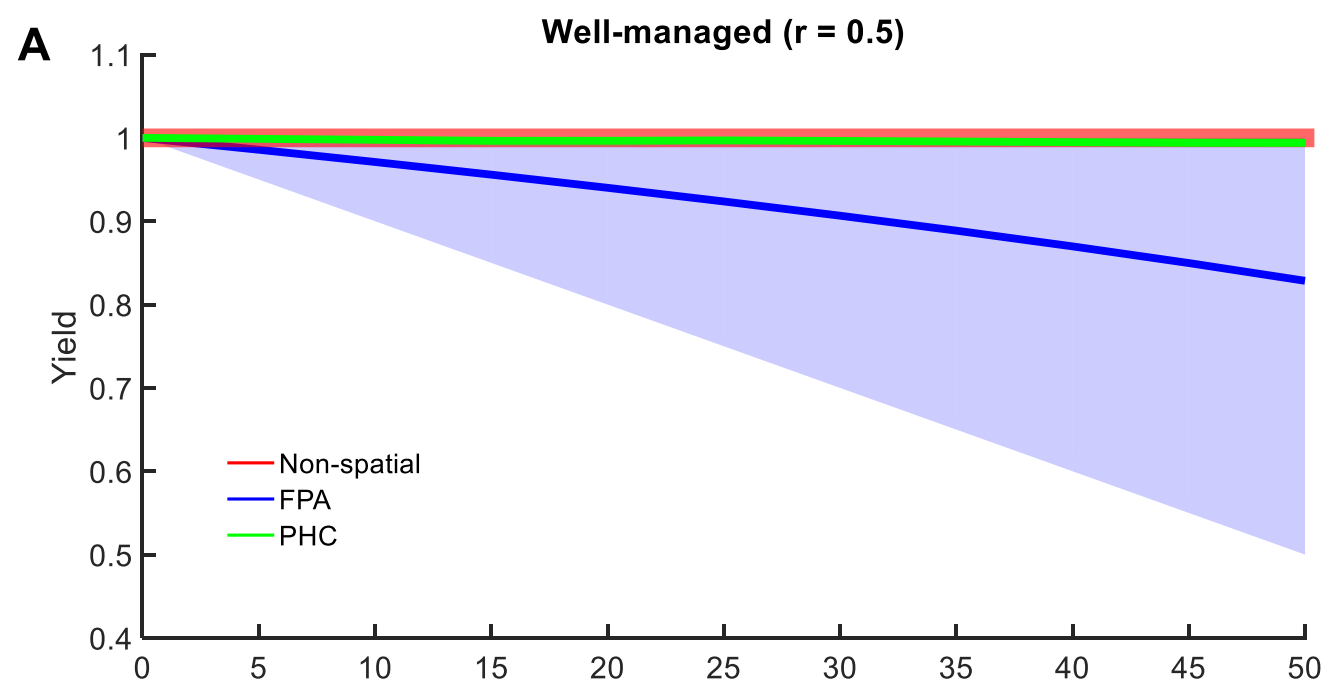

B

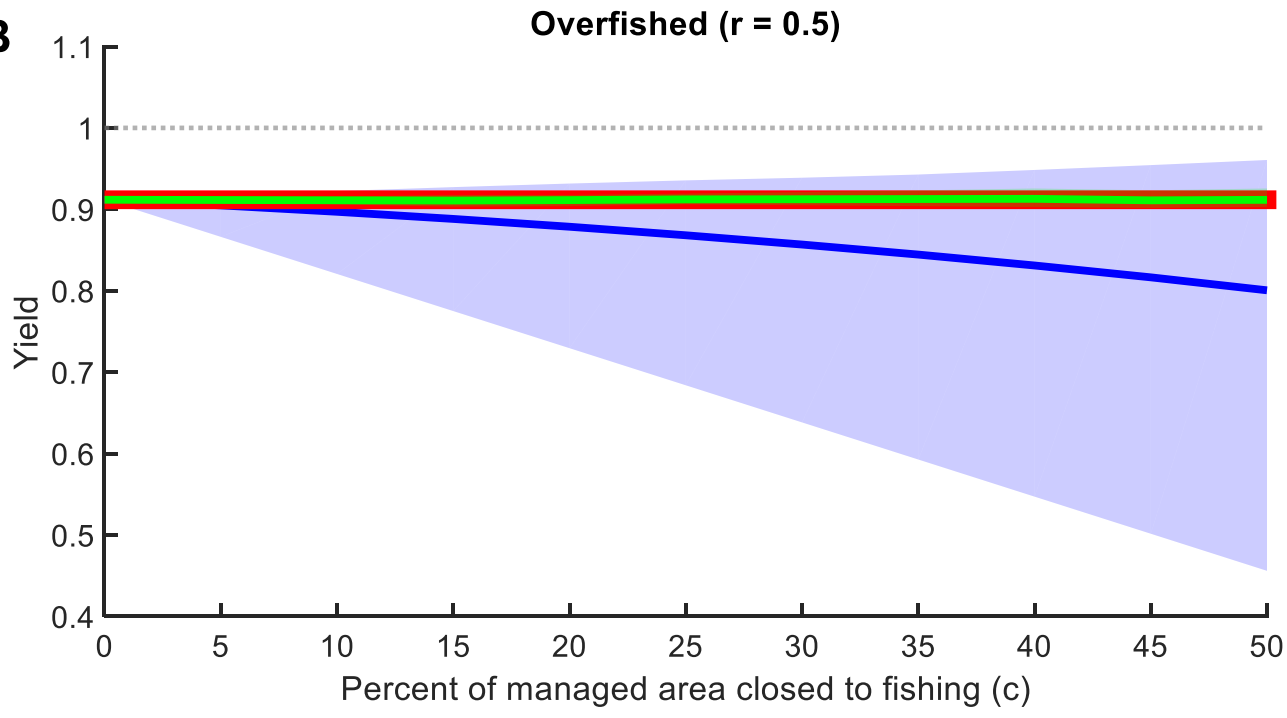

Figure S1.14. Average annual yield in relation to periodically-harvested closure (PHC) and fully-protected area (FPA) size $(0 \% \leq c \leq 50 \%)$ and fish site-fidelity $(0 \leq S \leq 1$, shading) for species with a high $(r=0.5)$ intrinsic rate of population growth. Yield under PHC and non-spatial management are insensitive to $S$, thus shading is absent. The gray dashed line in (B) indicates the yield for a well-managed fishery. 

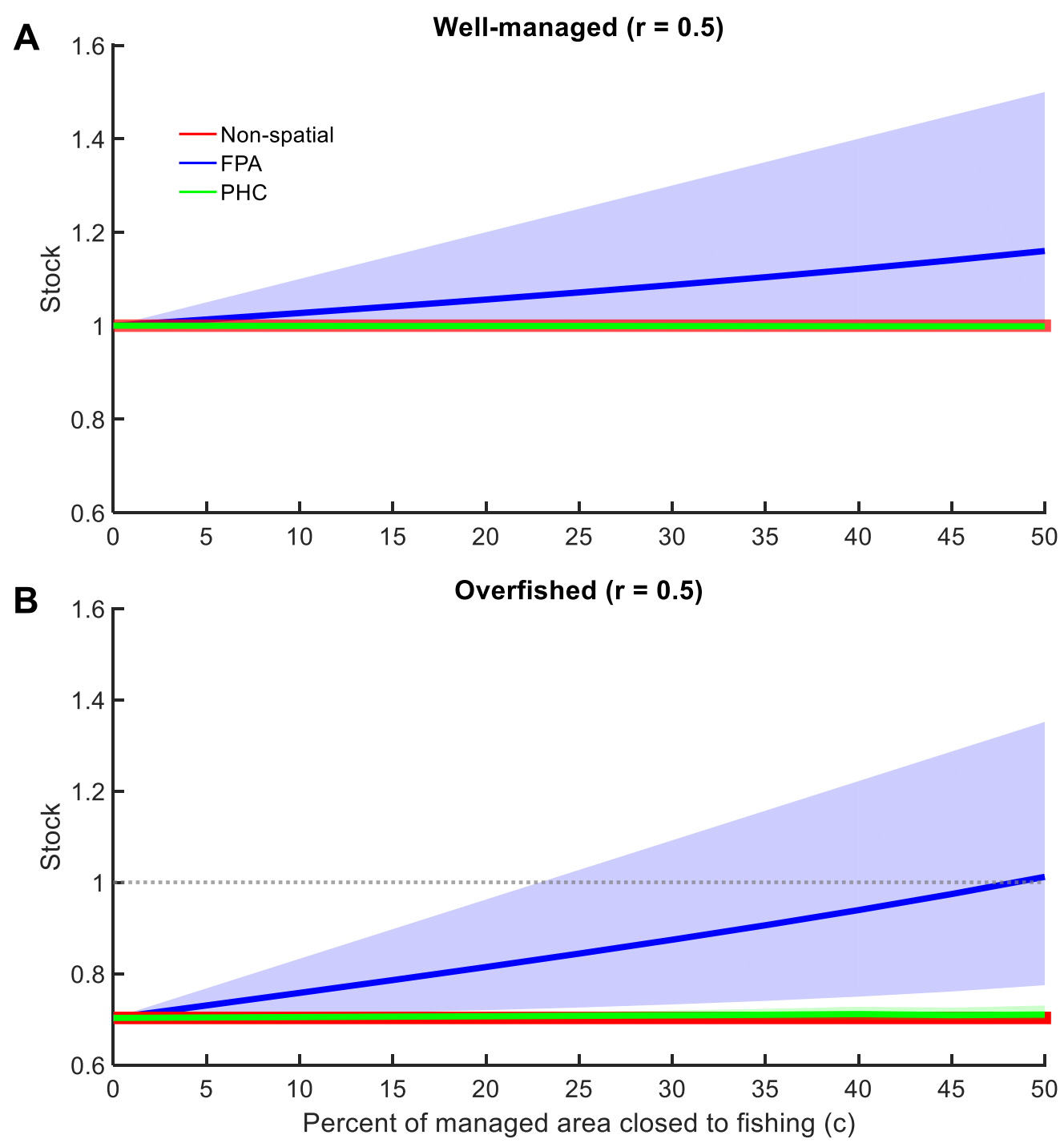

Figure S1.15. Average annual stock abundance in relation to periodically-harvested closure (PHC) and fully-protected area size $(0 \% \leq c \leq 50 \%)$ and fish site-fidelity $(0 \leq S \leq 1$; shading $)$ for species with a high $(r=0.5)$ intrinsic rate of population growth. Stock abundance under PHC and non-spatial management are insensitive to $S$, thus shading is absent. The gray dashed line in (B) indicates the stock for a well-managed fishery. 
Table S1.1. Empirical data on fish flight initiation distance (FID) for families Acanthuridae and Labridae (subfamily Scarinae) under periodically-harvested closure, fully-protected area, and non-spatial management regimes in Papua New Guinea, Vanuatu, Philippines, and Chagos. Normal cumulative probability distributions were generated using FID mean and variance to determine the cumulative probability (CDF) of fish initiating flight response to simulated spearfisher at a distance less than average effective speargun range (for rifle style spearguns used in Vanuatu and Papua New Guinea, $323.75 \mathrm{~cm}$ ).

\begin{tabular}{|c|c|c|c|c|c|c|c|}
\hline \multirow{2}{*}{ Country } & \multirow{2}{*}{$\begin{array}{c}\text { Duration of } \\
\text { protection } \\
\text { (years) }\end{array}$} & \multicolumn{3}{|c|}{ Acanthuridae } & \multicolumn{3}{|c|}{ Scarinae } \\
\hline & & $\begin{array}{l}\text { FID Mean } \\
\text { (cm) }\end{array}$ & $\begin{array}{c}\text { FID } \\
\text { Variance }\end{array}$ & CDF & $\begin{array}{l}\text { FID Mean } \\
\text { (cm) }\end{array}$ & $\begin{array}{c}\text { FID } \\
\text { Variance }\end{array}$ & CDF \\
\hline Papua New Guinea & 0.00 & 250.07 & 11118.95 & 0.76 & 278.60 & 10809.71 & 0.67 \\
\hline Papua New Guinea & 0.00 & 257.50 & 13264.52 & 0.72 & 467.14 & 10733.83 & 0.08 \\
\hline Papua New Guinea & 0.00 & 259.78 & 5269.27 & 0.81 & 326.95 & 11525.01 & 0.49 \\
\hline Vanuatu & 0.00 & 418.63 & 5091.20 & 0.09 & 495.83 & 14143.88 & 0.07 \\
\hline Vanuatu & 0.00 & 343.79 & 6108.95 & 0.40 & 416.25 & 4786.72 & 0.09 \\
\hline Philippines & 0.00 & 310.37 & 10046.59 & 0.55 & 367.80 & 4547.70 & 0.26 \\
\hline Philippines & 0.00 & 315.76 & 6113.02 & 0.54 & 365.94 & 3203.29 & 0.23 \\
\hline Philippines & 0.00 & 350.78 & 5213.98 & 0.35 & 444.44 & 5605.93 & 0.05 \\
\hline Papua New Guinea & 2.00 & 169.78 & 2877.43 & 1.00 & 204.40 & 5198.15 & 0.95 \\
\hline Philippines & 5.00 & 207.18 & 2547.03 & 0.99 & 283.06 & 6087.00 & 0.70 \\
\hline Philippines & 6.00 & 230.50 & 2828.97 & 0.96 & 282.61 & 3802.60 & 0.75 \\
\hline Vanuatu & 6.00 & 297.58 & 5454.51 & 0.64 & 302.50 & 12282.61 & 0.58 \\
\hline Vanuatu & 6.00 & 232.48 & 5484.57 & 0.89 & 251.22 & 5938.10 & 0.83 \\
\hline Philippines & 28.00 & 204.63 & 2233.13 & 0.99 & 218.72 & 1898.79 & 0.99 \\
\hline Papua New Guinea & 1.00 & 170.42 & 1360.69 & 1.00 & 281.38 & 6600.40 & 0.70 \\
\hline Papua New Guinea & 4.00 & 270.12 & 5193.96 & 0.77 & 223.83 & 7591.86 & 0.87 \\
\hline Vanuatu & 0.00 & 375.50 & 3720.27 & 0.20 & 374.42 & 5666.81 & 0.25 \\
\hline Vanuatu & 0.00 & 372.42 & 5115.54 & 0.25 & 358.83 & 4446.33 & 0.30 \\
\hline Vanuatu & 0.50 & 306.08 & 5477.36 & 0.59 & 338.08 & 8512.08 & 0.44 \\
\hline Vanuatu & 0.50 & 281.58 & 2662.45 & 0.79 & 337.08 & 8402.45 & 0.44 \\
\hline Chagos & 39.00 & 85.50 & 2544.43 & 1.00 & 104.80 & 1206.02 & 1.00 \\
\hline Chagos & 39.00 & 61.10 & 421.98 & 1.00 & 102.60 & 1327.26 & 1.00 \\
\hline Chagos & 39.00 & 77.00 & 1719.51 & 1.00 & 127.60 & 2031.92 & 1.00 \\
\hline Chagos & 39.00 & 80.10 & 2464.61 & 1.00 & 127.00 & 2024.19 & 1.00 \\
\hline
\end{tabular}




\section{CHAPTER TWO}

ASSESSMENT OF THE NAKODU VILLAGE (KORO ISLAND, FIJI)

PERIODICALLY-HARVESTED CLOSURE USING AN EMPIRICALLY

CALIBRATED FISHERIES MODEL 


\section{$\underline{\text { Introduction }}$}

Small-scale fisheries in developing countries are under increasing pressure from human population growth and dependence on marine resources (Cycon 1986, Béné 2006). If managed well, small-scale fisheries have the potential to provide substantial nutritional and economic benefits to millions of people around the world (Worm et al. 2009, Kawarazuka and Béné 2010, Costello et al. 2016;). However, oftentimes when centralized governance systems attempt to improve fisheries in developing countries using management strategies that are conventional in developed countries (e.g., gearbased restrictions, seasonal restrictions, marine-protected areas, etc.), they fail to achieve conservation and fisheries goals due to low compliance and poor enforcement (McClanahan 1999, Aswani 2005, McClanahan et al. 2006, Cinner and Aswani 2007). Lack of success with such "western-style" conventional management presents an ongoing challenge to identify alternative strategies that are appropriate for small-scale fisheries in developing countries and can simultaneously promote fishery productivity and conservation goals (Cohen et al. 2013).

Community-based co-management systems in small-scale fisheries throughout the Indo-Pacific have been well documented (Govan et al. 2009, Jupiter et al. 2014). These systems involve collaboration between communities and government or non-government organizations (Pomeroy and Rivera-Guieb 2005) in management of fish stocks and fish harvest. Strategies utilized within these systems are similar to conventional management strategies (i.e., marine protected areas), but they are governed by local institutions (not a remote, centralized government) and use scientific and indigenous knowledge for guiding adaptive management of the resource (Cinner and Aswani 2007, Jupiter et al. 2014). 
Communities that practice co-management typically have high compliance and thus have the potential to achieve fisheries and conservation goals in developing countries (Ruddle 1998, McClanahan et al. 2006, Bartlett et al. 2009, Gutiérrez et al. 2011) .

An increasing number of co-management communities are utilizing periodicallyharvested closures (PHCs) - an alternative form of marine protected area (MPA) in which a proportion of fishing grounds is closed temporarily between short, intensive harvest events (Bartlett et al. 2009, Jupiter et al. 2012). For centuries, communities across the Indo-Pacific have been using PHCs for cultural purposes and efficient exploitation of fisheries resources. In contrast, PHCs typically were not used by these communities for achieving conservation or sustainability goals, at least explicitly (Govan et al. 2009). Yet, today many PHCs are being developed and promoted - both locally and by outside institutions (e.g., conservation organizations) - within co-management frameworks to achieve cultural, as well as fisheries productivity and fish conservation goals (Jupiter et al. 2014). Despite this trend, there is little evidence that PHCs can simultaneously achieve all three of these goals in practice (Bartlett et al. 2009, Cohen et al. 2013). Thus, assessment of PHCs and guidance for communities for simultaneously achieving fisheries and conservation goals is needed.

The success of PHC management in achieving fisheries productivity and fish conservation goals depends on recovery rates of fish populations between PHC harvest events, and fishing intensity in the PHC when re-opened and in the areas always open to fishing (Cohen and Alexander 2013). Population recovery rates during PHC closure periods are complex because rates are expected to be site specific due to variability in habitat quality and food availability and species specific because each species has 
different recovery rates (Jennings 2000, Cohen and Foale 2013). Harvest dynamics of PHCs also are complex because closed-open harvest cycles are rarely consistent and are affected by gear-types used by fishers, fish catchability, and intensity and duration of harvest events (Cohen and Foale 2013). Empirical studies of PHCs demonstrate that periodic harvesting can potentially reduce fish populations to dangerously low levels if harvested too frequently or with excessive effort (Williams et al. 2006, Jupiter et al. 2012). However, some studies found that PHCs can provide short-term ecological benefits with larger fish and greater biomass in PHCs than in open-to-fishing areas (Cinner et al. 2005, McClanahan et al. 2006, Bartlett et al. 2009). PHCs are predicted to be more suitable for small, short-lived, fast growing species, while large, long-lived, slow-growing species are predicted to be more vulnerable to decline under PHC management (Jennings et al. 1999). Overall, recovery rates during closures and harvest dynamics of PHCs still remain poorly understood, and there is little evidence that the closed-open harvest cycles, harvest intensity, and harvest durations used in practice by small-scale fisheries in developing countries can achieve cultural, fisheries, and conservation goals.

The aim of this study is to develop a modeling framework that can reveal potential outcomes for different PHC management actions and used as a communication tool for co-management partners to inform communities of potential long-term consequences of management actions. In this study we used a modeling approach to simulate harvest dynamics and fish stock recovery in a small-scale fishery managed with a PHC to determine if current PHC management and harvest rates can simultaneously meet cultural, conservation, and fisheries goals. We focused on Nakodu Village on Koro 
Island in Fiji. Nakodu Village opened their PHC in 2013 for a church gathering and again in 2014 for an experimental harvest at the request of the Wildlife Conservation Society (WCS). We used empirical scientific data on fish stock and fishery harvest levels at Nakodu, collected over a time series and from within and outside the PHC, to calibrate a fisheries model of the Nakodu Village fishery, which consisted of an open-to-fishing area, PHC, and fore reef. Following model calibration, we used the model to estimate the outcome of four future scenarios: (1) one harvest event in the PHC every year at present yield (i.e., empirical yield); (2) one harvest event in the PHC every 5 years at present yield (i.e., empirical yield); (3) one harvest event in the PHC every year when effort is optimized to achieve maximum sustainable yield; (4) and one harvest event in the PHC every 5 years when effort is optimized to achieve maximum sustainable yield. We analyzed our models at the family level for five families: Acanthuridae, Labridae, Scarinae (Labridae subfamily), Lethrinidae, and Lutjanidae.

\section{Methods}

$\underline{\text { Study Site }}$

Nakodu Village is located on the southeast side of Koro Island in Fiji. The Nakodu Village customary marine tenure area extends from lagoon to fore reef and covers $2.1 \mathrm{~km}^{2}$ (Fig. 2.1). In 2008, the Nakodu Village periodically-harvested closure (PHC; $0.68 \mathrm{~km}^{2}$ ) was established in the lagoon and back reef in front of the village where it is easily monitored by community members (Fig. 2.1).

In addition to fishing, Nakodu residents farm and weave grass mats for sustenance and income, respectively. Little to moderate dependence on marine resources for their 
livelihoods allowed Nakodu to close their PHC for 5 years after its inception in 2008. Also, Nakodu residents reported high compliance (no poaching) with PHC closure. In 2013, Nakodu Village hosted a church gathering and opened their PHC to harvest to feed attendees. Before the harvest event the village informed the Wildlife Conservation Society (WCS) of their decision to open the PHC. WCS crew and a team of scientists from the University of Western Australia (UWA) surveyed three sites in the PHC and six sites in the open-to-fishing area using diver operated stereo-video (DOV) surveys. The WCS and UWA team conducted surveys before and after the PHC harvest event in May 2013.

Nakodu village closed their PHC for about a year (57 weeks) after the May 2013 harvest, and compliance with PHC regulations was reported to be high. One year after the May 2013 harvest, Nakodu residents re-opened their PHC for an experimental harvest event at the request of WCS to assess the recovery benefits of a 1-year closure. The WCS and UWA team surveyed the same three sites inside the PHC and six sites in the open-tofishing area in June 2014.

\section{Diver Operated Stereo-Video (DOV)}

At three sites in the PHC and six sites in the fished area, the UWA team completed $5 \mathrm{~m} \times 50 \mathrm{~m}$ belt transect fish surveys (as in Shedrawi et al. 2014). Each transect was separated by $10 \mathrm{~m}$ and took approximately 2.5 minutes to complete (as in Goetze et al. 2014). Video data collection and analysis of the transect video was conducted following Goetze et al. (2014). For this study we focused on fish families: Acanthuridae, Labridae, Scarinae (Labridae subfamily), Lethrinidae and Lutjanidae because these families comprised a large proportion of the catch and often are key target taxa 
throughout the Indo-Pacific (Williams et al. 2006, Bartlett et al. 2009, Jupiter et al. 2012). We used the mean biomass density pre- and post-harvest in our model calibration (Table 2.1).

\section{Catch and Effort Data}

We recorded species and total length for all fish caught during PHC harvest events. We calculated biomass from total length and the standard length-weight expression, $W=a L^{b}$, with existing published values from FishBase (Froese and Pauly 2012). Parameter values $a$ and $b$ were selected from sites close to Fiji, and when no length-weight parameters were available for the species we recorded, we used parameters from another species with similar morphological traits in the same genus as the fish recorded in surveys (as in Jupiter et al. 2012). When needed, we obtained from FishBase (Froese and Pauly 2012) a length-length conversion factor to convert from total length to fork length before biomass calculation (as in Jupiter et al. 2012). Also, residents of Nakodu Village focused all their fishing effort in intensively harvesting the PHC when it was opened in both years. Thus, during PHC open periods yield from the open-to-fishing area was zero.

Nakodu residents collected catch data from harvesting in the open-to-fishing area that occurred between the 2013 and 2014 PHC harvests. They identified catch at least to the family level and recorded total length for fish caught. Catch data in the open-tofishing area was collected weekly for 14 weeks out of the 57 weeks between PHC harvests (Table 2.2). Catch and effort in the open area was reported to be consistent throughout the year, thus we assumed weekly catch and effort in the open-to-fishing area 
for the 57 week PHC closure period to be equivalent to the mean catch for the 14 weeks recorded by Nakodu residents.

Several fishing gear types are used by Nakodu villagers: net/vines, Hawaiian slings, spearguns (rifle style spearguns), and drive-in gill net (only used during PHC harvest). We recorded the gear type, number of fishers and hours spent fishing during PHC harvest events and Nakodu residents collected the same data between the 2013 and 2014 PHC harvests (for 14 weeks).

\section{Fishery Model Summary}

We developed a spatially- and temporally-explicit logistic fish population model coupled with a fisheries harvest model to simulate recovery dynamics of fish populations and harvest dynamics of the Nakodu Village customary marine tenure area. There are three patches $(i)$ in the model that collectively cover the tenure area: an open-to-fishing area, the periodically-harvested closure (PHC), and the adjacent fore reef. The size of each patch represents the rocky reef area present, estimated using Google Earth Pro (Fig. 2.1).

First, the PHC is harvested and a proportion of the remaining stock is lost to the open-to-fishing area and fore reef via bail-out. Bail-out occurs when fish swim out of a PHC to seek refuge during an intensive fishing event (Jupiter et al. 2012). Following PHC harvest and bail-out, the open-to-fishing area is harvested, and the residual (i.e., escaped) stock in each patch grows. Grown populations disperse between all three patches based on their dimensions and a site-fidelity parameter, and dispersed populations indicate the population in each patch at the subsequent time step. 


\section{$\underline{\text { Harvest }}$}

Harvest (i.e., yield) in a patch (PHC or open-to-fishing area) is a function of fish stock $\left(N_{i}\right)$, harvest effort and fish catchability $\left(f\left(E_{i}\right)\right)$, and area $\left(A_{i}\right)$ :

$$
h_{i}=N_{i} f\left(E_{i}\right) A_{i}
$$

where $f\left(E_{i}\right)$ is the fraction of the stock harvested and calculated using the exponential survival function:

$$
f\left(E_{i}\right)=1-e^{-E_{i} q_{i}},
$$

where $q_{i}$ is fish catchability. The residual (i.e., escaped) stock density after PHC harvest is thus:

$$
e_{i}=N_{i}\left(1-f\left(E_{i}\right)\right)
$$

$\underline{\text { Effort }}$

Fishing effort in each patch $(i)$ was parameterized with empirical data on number of fishers $\left(W_{i}\right)$, hours spent fishing $\left(t_{i}\right)$, and patch area $\left(A_{i}\right)$ :

$$
E_{i}=\frac{W_{i} t_{i}}{A_{i}}
$$

Drive-in gill nets were used for 2013 and 2014 PHC harvests. Drive-in gill nets involve deploying a vine rope in a large circle in the PHC. Some people hang on the vine and scare fish towards the center of the circle while others pull the ends of the vine rope slowly reducing the diameter of the circle. The process of tightening the circle takes $\sim 3$ hours, and once the circle is small enough a gill net is deployed on one side of the circle and fishers in the water scare fish into the net. This method of fishing is a community activity and many residents participate in the event; however, adding more and more 
fishers on the vine rope does not necessarily lead to more fish caught in the net. Thus, effort data from drive-in gill nets may be overestimating realized effort for the PHC harvest. At a certain number of people participating in the harvest, effort becomes saturated and additional fishers are not expected to increase the realized effort and, ultimately, yield. Thus, we generated a $\log$ function with a adjustment variable $(\gamma)$ to modulate realized fishing effort $\left(E_{r}\right)$ in the PHC relative to potential fishing effort $\left(E_{P}\right.$, Fig. 2.2). Potential fishing effort is equivalent to the empirical effort value (equation 2.4), and realized fishing effort is a function of potential fishing effort:

$$
E_{r}=\gamma \log \left(E_{P}\right)
$$

Nakodu residents do not utilize drive-in gill nets outside the PHC, thus realized effort in the open-to-fishing area was equivalent to potential effort.

$\underline{\text { Fish Catchability }}$

Fish catchability for each year in each patch $\left(q_{t, i}\right)$ was determined based on a catchability curve generated from empirical data on fish flight-initiation-distance from Chapter 1:

$$
q_{t, i}=\frac{0.1724 \log \left(C_{t, i}+1\right)+0.4314}{0.4314}
$$

where $C_{t, i}$ is the number of years a patch is protected from fishing. However, this catchability curve was based on fish flight-initiation-distance in response to simulated spearfishers that is unlikely to represent other gear types used in Nakodu. Thus, we introduced a adjustment variable, $\alpha$, to modulate the rate and magnitude of change in fish catchability to consider the different gear types used in Nakodu: 


$$
q_{t, i}=\frac{\alpha(0.1724) \log \left(C_{t, i}+1\right)+0.4314}{0.4314} .
$$

\section{$\underline{\text { Bail-Out }}$}

Empirical yields for PHC harvests in 2013 and 2014 were less than the change in stock density pre- to post-harvest, suggesting that fish swim out of the PHC during intensive harvest events to seek refuge. Known as "bail-out", such movement of fish to areas adjacent to PHCs during an intensive PHC harvest event has been observed elsewhere in Fiji (Jupiter et al. 2012). We assumed the difference between empirical yield in the PHC $\left(Y_{P}\right)$ and empirical change in stock density pre- $\left(N_{P 1}\right)$ to post-harvest $\left(N_{P 2}\right)$ in the PHC to be bail-out $\left(B_{P}\right)$ :

$$
\left(N_{P 1}-N_{P 2}\right)-Y_{P}=B_{P}
$$

The proportion of the population lost from the PHC via bail-out $\left(b_{P}\right)$ calculated using empirical data is thus:

$$
b_{P}=\frac{B_{P}}{N_{P 1}},
$$

This term was then integrated into the model, where stock density in the PHC after harvest was the difference between escaped stock density $\left(e_{p}\right)$ and proportion of the population lost via bail-out $\left(N_{P 1} b_{p}\right)$ :

$$
N_{P 2}=e_{P}-N_{P 1} b_{p}
$$

We set the bail-out proportion in the model for the 2013 and 2014 harvests to match the empirical estimates of bail-out for each year. For future (unrealized) years, we set bailout proportion as the mean value from the 2013 and 2014 harvests. 
We also considered biomass density changes in the open-to-fishing area pre- to post-harvest of the PHC that cannot be explained by fishing or population growth. Nakodu residents shift all fishing effort to the PHC when the PHC is re-opened, thus no harvest occurs during that time from the open-to-fishing area. Also, the time between preand post-harvest surveys (less than 1 week) was too short to detect population growth. Thus, any empirical change in fish biomass in the open-to-fishing area pre- $\left(N_{F 1}\right)$ to post-harvest $\left(N_{F 2}\right)$,

$$
\Delta N_{F}=N_{F 1}-N_{F 2},
$$

was considered to result from fish movement into the (not fished) open-to-fishing area "spill-in", if positive ( $\left.\Delta N_{F}>0\right)$, or bail-out, if negative $\left(\Delta N_{F}<0\right)$. Spill-in or bail-out for the open-to-fishing area in relation to bail-out from the PHC is thus:

$$
b_{F}=\frac{\Delta N_{F}}{B_{p}} .
$$

In the model, biomass in the open-to-fishing area after PHC harvest $\left(N_{F 2}\right)$ is thus:

$$
N_{F 2}=N_{F 1}+N_{P 1} b_{p} b_{F} .
$$

Bail-out from the PHC (that did not move to the open-to-fishing area) and the open-to-fishing area (if bail-out occurred from the open-to-fishing area pre- to postharvest in the PHC) moves to the fore reef where no fishing occurs. Thus, biomass in the fore reef after PHC harvest $\left(N_{R 2}\right)$ is: 


$$
N_{R 2}=N_{R 1}+\left(N_{P 1} b_{p}-N_{P 1} b_{p} b_{F}\right)
$$

\section{$\underline{\text { Logistic Growth }}$}

Residual stock in each patch after harvest of the open-to-fishing area grew logistically (Schaefer 1957):

$$
g_{i}=N_{i}+r_{d} N_{i}\left(1-\frac{N_{i}}{K}\right)
$$

where $r_{d}$ is the discrete population growth rate and $K$ is the carrying capacity in units of biomass density $(\mathrm{kg} / \mathrm{ha})$. Discrete population rate of growth is derived from the intrinsic rate of population growth ( $r$; Gotelli 1995);

$$
r_{d}=e^{r}-1
$$

The intrinsic population growth rate for each family was equivalent to the median value of all species surveyed in that family (Table 2.3; Froese and Pauly 2012). MacNeil et al. (2015) estimate that globally, 64\% of coral reefs with some form of fisheries management have fish populations above half carrying capacity. Based on this study we assumed carrying capacity for each family was equivalent to double the average preharvest biomass in 2013 and 2014 (Table 2.1). Also, the fore reef patch of the Nakodu customary marine tenure area is never fished, thus we assumed initial fish populations to be at carrying capacity.

\section{Dispersal}

Stocks that escaped harvest and grew then dispersed between patches. Dispersal is based on a "common pool" model with enhanced site-fidelity ( $S$; White and Costello 2014). Side-fidelity is constrained to values $0 \leq S \leq 1$. When $S=0$, dispersal is equivalent 
to "common pool" dispersal and movement between patches is determined by the proportion of area in each patch. When $S=1$ (100\% site-fidelity) there is no fish movement between patches. The "common pool" model simulates a well-mixed domain in which dispersal depends on only the proportional size of each patch (White and Costello 2014):

$$
\mathbf{D}=\left(\begin{array}{lll}
Q_{1,1} & Q_{1,2} & Q_{1,3} \\
Q_{2,1} & Q_{2,2} & Q_{2,3} \\
Q_{3,1} & Q_{3,2} & Q_{3,3}
\end{array}\right)
$$

where row-column cells represent the proportion of the stock that moves from a source patch (row) to a destination patch (column). The site-fidelity parameter increases the fraction of stock that remains in a source patch (diagonals in equation 2.15) and decreases the fraction of stock that moves to destination patches by a commensurate amount (offdiagonals in equation 2.15). The dispersal matrix with enhanced site-fidelity is thus:

$$
\mathbf{D}=\left[\begin{array}{ccc}
Q_{1,1}+\left(1-Q_{1,1}\right) S & Q_{1,2}-\left(1-Q_{1,2}\right) S\left(Q_{1,2} /\left(1-Q_{1,2}\right)\right) & \ldots \\
Q_{2,1}-\left(1-Q_{2,1}\right) S\left(Q_{2,1} /\left(1-Q_{2,1}\right)\right) & Q_{2,2}+\left(1-Q_{2,2}\right) S & \ldots \\
Q_{3,1}-\left(1-Q_{3,1}\right) S\left(Q_{3,1} /\left(1-Q_{3,1}\right)\right) & Q_{3,2}-\left(1-Q_{3,2}\right) S\left(Q_{3,2} /\left(1-Q_{3,2}\right)\right) & \ldots
\end{array}\right]
$$

After dispersal, stocks in each patch indicate biomass density at the beginning of the subsequent time step.

\section{$\underline{\text { Model Calibration }}$}

We calibrated the fisheries model by "tuning" the fish catchability adjustment parameter $(\alpha)$, enhanced site-fidelity $(S)$ and fishing effort adjustment parameter $(\gamma)$. Tuning these parameters allows the model to find values that reduces the difference between model outputs and empirical data without having empirical values for the 
parameters. We set the initial fish biomass in the PHC and open-to-fishing areas equivalent to the 2013 pre-harvest values from DOV surveys and arbitrarily set initial values for the "tuning" parameters. We simulated recovery and harvest dynamics for Nakodu in 2013 and 2014. We recorded the model simulation data for pre- and postharvest (PHC harvest) biomass and harvest in the PHC (for years 2013 and 2014) and open-to-fishing area (between the 2013 and 2014 PHC harvest events). We used proportional empirical data $\left(O_{P}\right)$ and proportional model simulation data $\left(M_{P}\right)$ to calculate the sum of squared error (SSE) for all data points (biomass pre- and postharvest in 2013 and 2014, and yield from the PHC in 2013 and 2014 and from the opento-fishing area in 2014; Table 2.4).

$$
\begin{aligned}
& S S E=\sum\left(M_{P}-O_{P}\right)^{2}, \\
& M_{P}=\frac{M}{O}, \\
& O_{P}=\frac{O}{O} .
\end{aligned}
$$

We focused on proportional difference between model and empirical data because biomass and yield were used to calculate the sum of squared errors, but biomass and yield are different variables. We recorded biomass using DOV surveys and recorded yield from catch landed at Nakodu Village. We used a function to find the combination of values for the "tuning" parameters that minimized sum of squared errors to simulate the Nakodu Village marine tenure area as accurately as possible. 


\section{$\underline{\text { Predicted Future Scenarios }}$}

We model future scenarios to predict fishery outcomes for the Nakodu Village customary marine tenure area under a range of alternative management actions. We began by modeling 1-year closures between short pulse harvests at present average annual yield. We increased effort (effort estimated after calibration of fishing effort adjustment parameter) to achieve present average annual yield in the year following the 2014 harvest (i.e., first simulated year without empirical data). This scenario addresses the question whether it is sustainable for Nakodu to conduct an annual PHC harvest of amounts similar to that observed for the cultural/church and experimental harvests. Next we modeled 5-year closures between short pulse harvests at present average annual yield. Again, we increased effort to achieve average annual yield in the year following the 2014 harvest. Five years is the maximum closure period that communities are willing to keep a PHC closed and addresses the question whether 5-year closures are long enough to achieve sustainability while maintaining present harvest rates. Next, we optimized effort to achieve maximum sustainable average annual yield for 1-year closures and 5-year closures to determine whether Nakodu is harvesting above or below maximum sustainable yield and whether 1-year or 5-year closures generate greater average annual maximum sustainable yield.

\section{$\underline{\text { Results }}$}

$\underline{\text { Acanthuridae - Model Calibration }}$

Model fit to empirical data was poor after the model "tuned" free parameters (Fig. 2.3; Table 2.5): catchability adjustment $(\alpha=0.001)$, site-fidelity $(S=0)$, and 
realized effort adjustment $(\gamma=5.2)$. Site-fidelity of zero indicates that Acanthuridae movement throughout the domain is based on the proportional size of each patch (i.e., open-to-fishing, periodically-harvested closure, and fore reef). Model biomass predictions for post-harvest 2013 were accurate, but underestimated pre- and post-harvest biomass 2014 (Fig. 2.3). Although model predictions for 2014 were underestimated, the pattern of biomass pre- to post-harvest in the model was consistent with empirical data (Fig 2.3). Model predictions for yield were consistently lower than empirical measurements, and lower by two orders of magnitude in the open-to-fishing area (Fig. 2.3). During 2013 and 2014 periodically-harvested closure (PHC) harvests, $51.9 \%$ and 47.3\% pre-harvest biomass bailed out of the PHC to the fore reef, respectively. For the open-to-fishing area, $43.7 \%$ and $0.2 \%$ pre-harvest biomass in the open-to-fishing area bailed out to the fore reef. Mean values of bail-out from the PHC and open-to-fishing area $(49.6 \%$ and $22.9 \%$, respectively) were used in the predicted future scenarios of the Nakodu Village customary marine tenure area.

\section{$\underline{\text { Acanthuridae - Predicted Future Scenarios }}$}

\section{$\underline{\text { Scenario 1: One-Year Closure Between PHC Harvests at Present Average Annual Yield }}$}

Empirical present average annual yield for Acanthuridae in Nakodu was $22.6 \mathrm{~kg} / \mathrm{ha}$. Our model predictions for 1-year of closure and effort required to generate present yield levels for Acanthuridae results in an unsustainable population (Fig. 2.4). Biomass density drops to low levels within 5 years, and continues toward zero (15 years; Fig. 2.4). Also, model results indicate that only the first simulated PHC harvest generates yield equivalent to empirical present average annual yield, then yield decreases to zero at 15 years (Fig. 2.4). Catch per unit effort (CPUE [kg/\# fishers/hour/ha]) follows trends of 
biomass and yield and declines to zero at 15 years (Fig. 2.4). Though our model results in an unsustainable population, model calibration was poor and no conclusions can be drawn from this analysis.

Scenario 2: Five-Year Closure Between PHC Harvests at Present Average Annual Yield

Model results indicate that a 5-year closure between short PHC harvest bouts with effort required to generate present average annual yield is not sustainable (Fig. 2.5). Biomass density steadily decreases in all patches overtime and reaches zero density just after 25 years (Fig. 2.5). All patches have equal biomass density during closed years, but the fore reef receives bail-out from the PHC and open-to-fishing area during PHC harvests (Fig. 2.5). Yield and CPUE decrease steadily for the open-to-fishing area and PHC, reaching zero just after 25 years (Fig. 2.5). Though our model results in an unsustainable population, model calibration was poor and no conclusions can be drawn from this analysis.

$\underline{\text { Scenario 3: Maximum Sustainable Average Annual Yield for One-Year Closures }}$

When effort was optimized to achieve maximum sustainable average annual yield (MSY) for 1-year closures, equilibrium biomass densities in the open-to-fishing, PHC, and fore reef were $45.7 \mathrm{~kg} / \mathrm{ha}, 33.9 \mathrm{~kg} / \mathrm{ha}$, and $61.9 \mathrm{~kg} / \mathrm{ha}$, respectively (Fig. 2.6). Yield for the PHC at equilibrium was $4.3 \mathrm{~kg} / \mathrm{ha}$ and $3.3 \mathrm{~kg} / \mathrm{ha}$ for the open-to-fishing area (Fig. 2.6). Thus, average annual yield at equilibrium was $3.8 \mathrm{~kg} / \mathrm{ha}$, a sixth of the empirical present average annual yield (22.6 kg/ha). Also, CPUE was higher in the PHC than in the open-to-fishing area suggesting that increased CPUE during PHC harvest 
events might make up for the costs of harvesting less fish (Fig. 2.6). No conclusion can be drawn from this model due to poor model calibration.

\section{Scenario 4: Maximum Sustainable Average Annual Yield for Five-Year Closures}

When effort was optimized to achieve MSY for 5-year closures, annual average biomass at equilibrium in the open-to-fishing, PHC, and fore reef was $83.9 \mathrm{~kg} / \mathrm{ha}$, $77.2 \mathrm{~kg} / \mathrm{ha}$, and $90.3 \mathrm{~kg} / \mathrm{ha}$, respectively (Fig. 2.7). During closure periods, biomass density in all patches increase and are equivalent (Fig. 2.7). However, biomass bails out of the PHC and open-to-fishing area to the fore reef during PHC harvest events (Fig. 2.7). Average annual yield for the open-to-fishing area and PHC at equilibrium was 17.2 $\mathrm{kg} / \mathrm{ha}$, about four times greater than MSY for 1-year closures between PHC harvests (Fig. 2.7). Also, annual average CPUE was greater for 5-year closures compared with 1-year closures (Fig. 2.6 and 2.7). Thus 5-year closures emerge as optimal management because average annual CPUE and yield are greater than 1-year closures. No conclusion can be drawn from this model due to poor model calibration.

\section{$\underline{\text { Scarinae (Labridae Subfamily) - Model Calibration }}$}

Model fit to empirical data was moderate after the model "tuned" free parameters (Fig. 2.8; Table 2.5): catchability adjustment $(\alpha=0.001)$, site-fidelity $(S=0.1)$, and realized effort adjustment $(\gamma=5.9)$. Low site-fidelity indicates Scarinae movement is based mostly on the proportional size of each patch. Model predictions for biomass were accurate for pre- and post-harvest levels in 2013 and the open-to-fishing area pre- and post-harvest in 2014 (Fig. 2.8). Biomass density predictions for the PHC were lower than empirical estimates, but followed the same pattern as empirical data (Fig. 2.8). Yield 
predictions by the model were consistently lower than empirical yields. In 2013 and 2014 periodically-harvested closure (PHC) harvests, $44.1 \%$ and $46.8 \%$ of the pre-harvest biomass bailed out of the PHC to the fore reef, respectively. For the open-to-fishing area, $21.3 \%$ and $3.0 \%$ of the pre-harvest biomass in the open-to-fishing area bailed out to the fore reef. Mean values of bail-out from the PHC and open-to-fishing area (45.5\% and $12.2 \%$, respectively) were used in the predicted future scenarios of the Nakodu Village customary marine tenure area.

$\underline{\text { Scarinae (Labridae Subfamily) - Predicted Future Scenarios }}$ $\underline{\text { Scenario 1: One-Year Closure Between PHC Harvests at Present Average Annual Yield }}$ Empirical present average annual yield for Scarinae in Nakodu was $4.8 \mathrm{~kg} / \mathrm{ha}$. Our model suggests that 1-year of closure and effort required to generate present yield levels for Scarinae are sustainable (Fig. 2.9). Average annual biomass density at equilibrium in the open-to-fishing area, PHC, and fore reef was $119.5 \mathrm{~kg} / \mathrm{ha}, 90.6 \mathrm{~kg} / \mathrm{ha}$, and 152.4 $\mathrm{kg} / \mathrm{ha}$, respectively (Fig. 2.9). Also, biomass density is all patches increases after the 2014 harvest (year 2 of the model; Fig.2.9). Effort required to generate average annual yield equivalent to empirical data results in higher yield in subsequent years (Fig. 2.9). Yield in the open-to-fishing area and PHC at equilibrium was $5.9 \mathrm{~kg} / \mathrm{ha}$ and $7.4 \mathrm{~kg} / \mathrm{ha}$ respectively (Fig. 2.9). Average annual yield was $6.7 \mathrm{~kg} / \mathrm{ha}$. Catch per unit effort (CPUE [kg/\# fishers/hour/ha]) follows trends of biomass and yield increasing after 2014 harvest to 
equilibrium at 40 years (Fig. 2.9). Nakodu residents may see an improvement in Scarinae biomass and yield if present harvest rates are continued into the future.

\section{$\underline{\text { Scenario 2: Five-Year Closure Between PHC Harvests at Present Average Annual Yield }}$}

Five years of closure between harvest cycles at present empirical average annual yield was sustainable (Fig. 2.10). During closure periods all patches have the same biomass density, but fish bail-out of the PHC and open-to-fishing area into the fore reef during PHC harvests (Fig. 2.10). Average annual biomass density for the open-to-fishing area, PHC, and fore reef was $213.1 \mathrm{~kg} / \mathrm{ha}, 202.5 \mathrm{~kg} / \mathrm{ha}, 225.3 \mathrm{~kg} / \mathrm{ha}$, respectively (Fig. 2.10). Effort required to generate empirical average annual yield following the 2014 harvest produces greater yields in subsequent years (Fig. 2.10). At equilibrium average annual yield for the open-to-fishing area and PHC was $8.1 \mathrm{~kg} / \mathrm{ha}$ (Fig. 2.10). Also, CPUE increased in the PHC and open-to-fishing area following the 2014 harvest and reached equilibrium in 20 years (Fig. 2.10). Average annual yield is greater for 5-year closures than 1-year closures, suggesting that Nakodu residents may receive greater benefits from their PHC and open-to-fishing area if the PHC is closed for 5 years between harvest events.

\section{$\underline{\text { Scenario 3: Maximum Sustainable Average Annual Yield for One-Year Closures }}$}

When effort was optimized to generate MSY with 1-year closures, equilibrium biomass density in the open-to-fishing area, PHC, and fore reef was $85.0 \mathrm{~kg} / \mathrm{ha}, 62.4$ $\mathrm{kg} / \mathrm{ha}$, and $108.4 \mathrm{~kg} / \mathrm{ha}$, respectively (Fig. 2.11). Also, yield was greater than present empirical yield in the PHC and open-to-fishing area $(9.3 \mathrm{~kg} / \mathrm{ha}$ and $7.4 \mathrm{~kg} / \mathrm{ha}$, respectively; Fig. 2.11). At MSY, CPUE was greater in the PHC than in the open-to- 
fishing area (Fig. 2.11). These results show that Nakodu may be harvesting Scarinae at rates below MSY.

\section{$\underline{\text { Scenario 4: Maximum Sustainable Average Annual Yield for Five-Year Closures }}$}

When effort was optimized to generate MSY with 5-year closures, equilibrium average annual biomass density in the open-to-fishing area, PHC, and fore reef was 129.1 $\mathrm{kg} / \mathrm{ha}, 118.9 \mathrm{~kg} / \mathrm{ha}$, and $136.8 \mathrm{~kg} / \mathrm{ha}$, respectively (Fig. 2.12). Biomass density in each patch was equivalent during closure periods, but fish bailed out of the PHC and open-tofishing area into the fore reef during PHC harvests (Fig. 2.12). Average annual yield for the PHC and open-to-fishing area was $27.2 \mathrm{~kg} / \mathrm{ha}$ and CPUE increased in the PHC and open-to-fishing area following the 2014 harvest (Fig. 2.12). These results show that increasing harvest rates for Scarinae and using 5-year PHC closures generates the greatest benefits to Nakodu residents.

\section{$\underline{\text { Labridae - Model Calibration }}$}

Model fit to empirical data was good after the model "tuned" free parameters

(Fig. 2.13; Table 2.5): catchability adjustment $(\alpha=0.001)$, site-fidelity $(S=0.6)$, and realized effort adjustment $(\gamma=1.5)$. Biomass density is slightly underestimated in the PHC pre- and post-harvest 2014, but follows the pattern of empirical data (Fig. 2.13). The model accurately simulates biomass density in the open-to-fishing area in 2013 and 2014 and the PHC in 2013 (Fig. 2.13). Yield is underestimated for the PHC 2013 harvest, but accurate for the open-to-fishing area and PHC 2014 harvest (Fig. 2.13). During 2013 and 2014 periodically-harvested closure (PHC) harvests, $38.1 \%$ and $20.9 \%$ of the pre-harvest biomass bailed out of the PHC to the fore reef, respectively. For the open-to-fishing area, 
$46.6 \%$ of the pre-harvest biomass in the open-to-fishing area bailed out to the fore reef during the 2013 harvest. However, post-harvest Labridae biomass increased by $5.9 \%$ after the 2014 harvest via spill-in from the PHC. Mean values of bail-out (or spill-in) from the PHC and open-to-fishing area (29.5\% and $20.4 \%$, respectively) were used in the predicted future scenarios of the Nakodu Village customary marine tenure area.

\section{$\underline{\text { Labridae - Predicted Future Scenarios }}$}

$\underline{\text { Scenario 1: One-Year Closure Between PHC Harvests at Present Average Annual Yield }}$

Empirical present average annual yield for Labridae in Nakodu was $0.6 \mathrm{~kg} / \mathrm{ha}$. Our model suggests that 1-year of closure and effort required to generate present yield levels for Labridae are sustainable (Fig. 2.14). Average annual biomass density at equilibrium in the open-to-fishing area, PHC, and fore reef was $50.9 \mathrm{~kg} / \mathrm{ha}, 37.1 \mathrm{~kg} / \mathrm{ha}$, and $65.2 \mathrm{~kg} / \mathrm{ha}$, respectively (Fig. 2.14). Also, biomass density is all patches increased after the 2014 harvest (year 2 of the model; Fig. 2.14). Effort required to generate average annual yield equivalent to empirical data results in higher yield in subsequent years (Fig. 2.14). Yield in the open-to-fishing area and PHC at equilibrium was $1.8 \mathrm{~kg} / \mathrm{ha}$ and 0.6 $\mathrm{kg} / \mathrm{ha}$ respectively (Fig. 2.14). Catch per unit effort (CPUE [kg/\# fishers/hour/ha]) follows trends of biomass and yield increasing after 2014 harvest to equilibrium between 15 and 20 years (Fig. 2.14). These results suggest that Nakodu residents are currently harvesting Labridae at sustainable rates.

\section{$\underline{\text { Scenario 2: Five-Year Closure Between PHC Harvests at Present Average Annual Yield }}$}

Five years of closure between harvest cycles at present empirical average annual yield was sustainable for Labridae (Fig. 2.15). During closure periods biomass densities 
in the open-to-fishing area and PHC increase while biomass density in the fore reef remains constant, and fish bail-out of the PHC and open-to-fishing area into the fore reef during PHC harvests (Fig. 2.15). Average annual biomass density for the open-to-fishing area, PHC, and fore reef was $57.3 \mathrm{~kg} / \mathrm{ha}, 54.8 \mathrm{~kg} / \mathrm{ha}, 60.8 \mathrm{~kg} / \mathrm{ha}$, respectively (Fig. 2.15). Effort required to generate empirical average annual yield following the 2014 harvest produces greater yields in subsequent years (Fig. 2.15). At equilibrium average annual yield for the open-to-fishing area and PHC was $0.8 \mathrm{~kg} / \mathrm{ha}$, and yield in the open-to-fishing area was greater than that in the PHC (Fig. 2.15). Also, CPUE increased in the PHC and open-to-fishing area following the 2014 harvest and reached equilibrium between 15 and 20 years (Fig. 2.15). Nakodu residents can achieve sustainability for Labridae at current harvest rates with 5-year PHC closures.

\section{Scenario 3: Maximum Sustainable Average Annual Yield for One-Year Closures}

When effort was optimized to generate MSY for Labridae with 1-year closures, equilibrium biomass density in the open-to-fishing area, $\mathrm{PHC}$, and fore reef was $30.9 \mathrm{~kg} / \mathrm{ha}, 22.0 \mathrm{~kg} / \mathrm{ha}$, and $53.7 \mathrm{~kg} / \mathrm{ha}$, respectively (Fig. 2.16). Also, yield was greater than present empirical yield in the PHC and open-to-fishing area $(2.8 \mathrm{~kg} / \mathrm{ha}$ and 7.7 $\mathrm{kg} / \mathrm{ha}$, respectively; Fig. 2.16). At MSY, CPUE was greater in the PHC than in the opento-fishing area (Fig. 2.16). These results show that Nakodu residents can potentially increase harvest rates of Labridae and still benefit from greater yields and CPUE in the future. 
$\underline{\text { Scenario 4: Maximum Sustainable Average Annual Yield for Five-Year Closures }}$

When effort was optimized to generate MSY with 5-year closures, equilibrium average annual biomass density in the open-to-fishing area, PHC, and fore reef was $33.1 \mathrm{~kg} / \mathrm{ha}, 41.4 \mathrm{~kg} / \mathrm{ha}$, and $51.1 \mathrm{~kg} / \mathrm{ha}$, respectively (Fig. 2.17). Average annual yield for the PHC and open-to-fishing area was $11.3 \mathrm{~kg} / \mathrm{ha}$ and yield was greater in the open-tofishing area (Fig. 2.17), but CPUE was almost three times greater in the PHC (Fig. 2.17). Results suggest that Nakodu residents can maximize their benefits (yield and CPUE) by increasing harvest rates and using 5-year closures.

\section{Lethrinidae - Model Calibration}

Model fit to empirical data was moderate after the model "tuned" free parameters (Fig. 2.18; Table 2.5): catchability adjustment $(\alpha=0.001)$, site-fidelity $(S=1.0)$, and realized effort adjustment $(\gamma=6.6)$. High site-fidelity indicates no fish movement between patches occurs during dispersal, thus fish movement only occurs via bail-out or spill-in during a PHC harvest event. Yield for 2013 and 2014 PHC harvests were underestimated, and yield for the open-to-fishing area was slightly underestimated (Fig. 2.18). Biomass density changes pre- to post-harvest and between 2013 and 2014 were very small (Fig. 2.18). During 2013 and 2014 periodically-harvested closure (PHC) harvests, $62.2 \%$ and $0.8 \%$ of the pre-harvest biomass bailed out of the PHC to the fore reef, respectively. Mean bail-out for the PHC for the two harvest events was used as bailout for the future predicted scenarios (31.5\% of the pre-harvest biomass in the PHC). For the open-to-fishing area, biomass increased pre- to post-harvest by $121.1 \%$ and $98.9 \%$ via spill-in from the PHC in 2013 and 2014, respectively. Mean spill-in to the open-tofishing area (110.0\% of the pre-harvest biomass in the open-to-fishing area) was used in 
future predicted scenarios. However, spill-in to the open-to-fishing area did not exceed spill-out from the PHC during a harvest.

\section{$\underline{\text { Lethrinidae - Predicted Future Scenarios }}$}

$\underline{\text { Scenario 1: One-Year Closure Between PHC Harvests at Present Average Annual Yield }}$

Empirical present average annual yield for Lethrinidae in Nakodu was $2.1 \mathrm{~kg} / \mathrm{ha}$.

Our model suggests that 1-year of closure and effort required to generate present yield levels for Lethrinidae are sustainable in the open-to-fishing area and fore reef, but not sustainable for the PHC (Fig. 2.19). Average annual biomass density at equilibrium in the open-to-fishing area and fore reef was $13.8 \mathrm{~kg} / \mathrm{ha}$ and $29 \mathrm{~kg} / \mathrm{ha}$, respectively (Fig. 2.19). Between 15 and 20 years, biomass density reached zero in the PHC (Fig. 2.19). Yield in the open-to-fishing area at equilibrium was $2.4 \mathrm{~kg} / \mathrm{ha}$ (Fig. 2.19). Catch per unit effort (CPUE [kg/\# fishers/hour/ha]) increased in the open-to-fishing area after the 2014 harvest, average annual CPUE in the open-to-fishing area and PHC was $2.0 \mathrm{~kg} / \mathrm{ha}$ (Fig. 2.19). Results show that Lethrinidae might be more vulnerable to PHC harvests.

\section{$\underline{\text { Scenario 2: Five-Year Closure Between PHC Harvests at Present Average Annual Yield }}$}

Five years of closure between harvest cycles at present empirical average annual yield was sustainable for Lethrinidae (Fig. 2.20). Average annual biomass density for the open-to-fishing area, PHC, and fore reef was $20.0 \mathrm{~kg} / \mathrm{ha}, 15.2 \mathrm{~kg} / \mathrm{ha}, 30.0 \mathrm{~kg} / \mathrm{ha}$, respectively (Fig. 2.20). Effort required to generate empirical average annual yield following the 2014 harvest produces greater yields in subsequent years in the open-tofishing area and relatively constant yields for PHC harvests (Fig. 2.20). At equilibrium average annual yield for the open-to-fishing area and PHC was $3.5 \mathrm{~kg} / \mathrm{ha}$, and yield in the 
PHC during harvests was greater than harvest in the open-to-fishing area (Fig. 2.20). Also, CPUE increased in the open-to-fishing area after the 2014 harvest and reached equilibrium between 25 and 30 years, and CPUE remained constant throughout time (Fig. 2.20). Results show that Nakodu residents can potentially increase benefits from their fishery if they use 5-year closures and maintain present harvest rates for Lethrinidae.

\section{$\underline{\text { Scenario 3: Maximum Sustainable Average Annual Yield for One-Year Closures }}$}

When effort was optimized to generate MSY for Lethrinidae with 1-year closures, equilibrium biomass density in the open-to-fishing area and fore reef was $17.1 \mathrm{~kg} / \mathrm{ha}$ and $29 \mathrm{~kg} / \mathrm{ha}$, respectively (Fig. 2.21). Biomass density in the fore reef was equivalent to fore reef biomass density at present empirical average annual yield (Fig. 2.19 and 2.21). At annual average MSY, biomass density in the PHC drops to zero in 10 years (Fig. 2.21). There was only a $4 \%$ difference in the equilibrium yield for the open-to-fishing area at MSY and at present yield (2.5 kg/ha and $2.4 \mathrm{~kg} / \mathrm{ha}$, respectively; Fig. 2.19 and 2.21). However, CPUE was 20\% higher when effort was optimized to achieve MSY (Fig. 2.19 and 2.21). Although Nakodu residents can potentially increase harvest rates of Lethrinidae, model results suggest that Lethrinidae will still be vulnerable in the PHC if only 1-year closures are used.

\section{$\underline{\text { Scenario 4: Maximum Sustainable Average Annual Yield for Five-Year Closures }}$}

When effort was optimized to generate MSY with 5-year closures, equilibrium average annual biomass density in the open-to-fishing area, PHC, and fore reef was $17.8 \mathrm{~kg} / \mathrm{ha}, 13.7 \mathrm{~kg} / \mathrm{ha}$, and $30.0 \mathrm{~kg} / \mathrm{ha}$, respectively (Fig. 2.22). Average annual yield for 
the PHC and open-to-fishing area was $3.5 \mathrm{~kg} / \mathrm{ha}$ (Fig. 2.22). Results show that 5 -year closures generate the greatest benefits to Nakodu residents.

\section{$\underline{\text { Lutjanidae - Model Calibration }}$}

Model fit to empirical data was good after the model "tuned" free parameters (Fig. 2.23; Table 2.5): catchability adjustment $(\alpha=0.001)$, site-fidelity $(S=0.9)$, realized effort adjustment $(\gamma=5.7)$. Pre- and post-harvest 2013 biomass density in the open-to-fishing area and PHC are accurately simulated by the model, but PHC biomass density is underestimated in 2014 and overestimated post-harvest 2014 (Fig. 2.23). Yield in the open-to-fishing area is accurately simulated but underestimated in the PHC (Fig. 2.23). During 2013 and 2014 periodically-harvested closure (PHC) harvests, $74.3 \%$ and $46.0 \%$ of the pre-harvest biomass bailed out of the PHC to the fore reef, respectively. For the open-to-fishing area, $42.6 \%$ and $39.2 \%$ of the pre-harvest biomass in the open-tofishing area bailed out to the fore reef. Mean values of bail-out from the PHC and opento-fishing area $(60.2 \%$ and $40.9 \%$, respectively) were used in the predicted future scenarios of the Nakodu Village customary marine tenure area.

\section{$\underline{\text { Lutjanidae - Predicted Future Scenarios }}$}

\section{$\underline{\text { Scenario 1: One-Year Closure Between PHC Harvests at Present Average Annual Yield }}$}

Empirical present average annual yield for Lutjanidae in Nakodu was $0.5 \mathrm{~kg} / \mathrm{ha}$.

Our model suggests that 1-year of closure and effort required to generate present yield levels for Lutjanidae are sustainable (Fig. 2.24). Average annual biomass density at equilibrium in the open-to-fishing area, PHC, and fore reef was $40.1 \mathrm{~kg} / \mathrm{ha}, 2.6 \mathrm{~kg} / \mathrm{ha}$, and $53.7 \mathrm{~kg} / \mathrm{ha}$ respectively (Fig. 2.24). Yield in the open-to-fishing area and PHC at 
equilibrium was $2.1 \mathrm{~kg} / \mathrm{ha}$ and $0.2 \mathrm{~kg} / \mathrm{ha}$ (Fig. 2.24). Yield slightly decreased in the PHC after the 2014 PHC harvest and increased in the open-to-fishing area after 2014 harvest (Fig. 2.24). Average annual CPUE was greater in the open-to-fishing area than in the PHC (Fig. 2.24).

Scenario 2: Five-Year Closure Between PHC Harvests at Present Average Annual Yield

Five years of closure between harvest cycles at present empirical average annual yield was sustainable for Lutjanidae (Fig. 2.25). Average annual biomass density for the open-to-fishing area, PHC, and fore reef was $44.0 \mathrm{~kg} / \mathrm{ha}, 27.2 \mathrm{~kg} / \mathrm{ha}, 58.9 \mathrm{~kg} / \mathrm{ha}$, respectively (Fig. 2.25). Effort required to generate empirical average annual yield following the 2014 harvest produces greater yields in subsequent years (Fig. 2.25). At equilibrium average annual yield for the open-to-fishing area and PHC was $1.2 \mathrm{~kg} / \mathrm{ha}$, and yield in the PHC during harvest was greater than the open-to-fishing area (Fig. 2.25). Also, CPUE increased following the 2014 harvest and reached equilibrium at 30 years (Fig. 2.25). At present harvest rates for Lutjanidae, Nakodu residents will receive the greatest benefits using a 5-year closure cycle between PHC harvest events.

\section{Scenario 3: Maximum Sustainable Average Annual Yield for One-Year Closures}

When effort was optimized to generate MSY for Lutjanidae with 1-year closures, equilibrium biomass density in the open-to-fishing area, PHC, and fore reef was $26.3 \mathrm{~kg} / \mathrm{ha}, 1.4 \mathrm{~kg} / \mathrm{ha}$, and $49.8 \mathrm{~kg} / \mathrm{ha}$ respectively (Fig. 2.26). Biomass density decreased in the PHC and fore reef after the 2014 harvest, but increased in the open-to-fishing area (Fig. 2.26). Equilibrium MSY in the open-to-fishing area and PHC was $3.7 \mathrm{~kg} / \mathrm{ha}$ and $0.4 \mathrm{~kg} / \mathrm{ha}$ respectively. Also, CPUE was greater in the open-to-fishing area than PHC 
(Fig. 2.26). MSY is about four times greater than present yield for Lutjanidae when 1year PHC closures are used.

\section{Scenario 4: Maximum Sustainable Average Annual Yield for Five-Year Closures}

When effort was optimized to generate MSY with 5-year closures, equilibrium average annual biomass density in the open-to-fishing area, PHC, and fore reef was $26.7 \mathrm{~kg} / \mathrm{ha}, 12.9 \mathrm{~kg} / \mathrm{ha}$, and $53.6 \mathrm{~kg} / \mathrm{ha}$, respectively (Fig. 2.27). Average annual yield for the PHC and open-to-fishing area was $3.8 \mathrm{~kg} / \mathrm{ha}$ (Fig. 2.27). Results show that Nakodu residents can maximize their benefits from Lutjanidae using 5-years PHC closure cycles.

\section{$\underline{\text { Discussion }}$}

Hundreds of communities across the Indo-Pacific use periodically-harvested closures (PHCs) to achieve fisheries and conservation goals (Bartlett et al. 2009). Many studies have focused on the effects of PHC harvest events on short-term recovery of fish populations (Cinner et al. 2005, Bartlett et al. 2009), but research assessing the long-term sustainability of fisheries under PHC management is scarce. In Chapter 1 we investigated the long-term effects of PHC management and reveal that, in theory, PHCs can achieve long-term sustainability; however, this research was based on long-term equilibrium results which do not represent outcomes or guidance for a particular PHC. Also, results in Chapter 1 highlight the performance of PHCs with spearfishing only and demonstrate that MPAs in the form of PHCs can simultaneously achieve cultural, fisheries, and conservation goals when change in fish catchability is considered. In this study we use empirical data (i.e., biomass, yield, and effort) in relation to two PHC harvest events in Nakodu Village on Koro Island in Fiji to calibrate a fisheries model and determine the 
effectiveness of current PHC management in achieving long-term sustainability. Also, we estimated maximum sustainable yield to compare with present yields in Nakodu and predict the state of the fishery in the future under alternative management scenarios. Our model is unable to accurately calibrate for all fish families in this study; however, models that had a good fit (Labridae and Lutjanidae) to empirical data reveal current PHC management in Nakodu is sustainable.

Our results also corroborate findings of other studies that suggest PHC management may be sustainable for lightly fished taxa (Bartlett et al. 2009). Scarinae (moderate model fit) are harvested relatively lightly in Nakodu, and they recovered rapidly from harvest, allowing for the highest average annual yield out of all of the families analyzed. Similar patterns of Scarinae recovery following fishing pressure has been observed in MPAs in the Philippines (Russ and Alcala 1998). Also, Scarinae (parrotfishes) biomass in Nakodu was dominated by Ctenocheatus striatus and Chlorurus sordidus; two small-bodied species typically not targeted by communities in Fiji (Jupiter et al. 2012). Thus, there is a tradeoff in that Scarinae are sustainable under current PHC management, but not providing much nutritional value to Nakodu residents. High abundance of non-target parrotfishes on fished reefs has also been documented elsewhere in Fiji (Jupiter et al. 2012). Results also suggest that parrotfishes are resilient under PHC management and that greater harvest rates can be sustainable, especially when 5-year closures are used between PHC harvest events.

We also found that 5-year closures generate the greatest average annual yields for all families in Nakodu with a good to moderate model fit (Table 2.5). Recovery rates in combination with fish movement outside of the PHC during closure periods may explain 
this outcome for families with low to moderate site-fidelity (Scarinae and Labridae). Density-dependent driven spillover from the PHC may increase annual yield in areas adjacent to fisheries closures (Kellner et al. 2008, Halpern et al. 2009). However, recovery rates alone may explain the high yield outcomes for families with high sitefidelity because accumulated recovery benefits are realized when the PHC is re-opened and harvested intensely (i.e., Labridae and Lutjanidae). Five-year closures emerging as optimal management for Nakodu suggests that longer closures periods may generate greater fisheries and conservation benefits for Nakodu, which has been suggested for other small-scale fisheries in developing countries (Russ and Alcala 1996, McClanahan et al. 2007, Bartlett et al. 2009).

Limitations and assumptions required to model the Nakodu management area hindered our ability to model all families with high accuracy, but we were able to generate similar biomass patterns pre- to post- harvest. Our "tuned" parameters might present a limitation to our model design. Site-fidelity in particular is a single value that controls fish movement for an entire family. Studies have found that body-size of coralreef fishes, which varies widely within families, typically indicates the size of homerange for a species (Kramer and Chapman 1999, Chapman and Kramer 2000). In addition to home-range, some reef fish migrate seasonally or relocate home-ranges throughout the year (Chateau and Wantiez 2009, Meyer et al. 2010). These complex movement patterns of reef fish are difficult to measure empirically and capture in a fisheries model with a single parameter. Site-fidelity for Acanthuridae $(S=0)$ and Scarinae $(S=0.1)$ indicate that fish movement rates between patches are higher than we would expect for smallerbodied reef fish (Meyer et al. 2010). Also, studies have found that high rates of spill-over 
from closures to open-to-fishing areas results in higher yield outside a fisheries closure (Kellner et al. 2008) potentially eroding the recovery benefits if harvest effort is too intense. Thus, high fish movement (which likely does not accurately represent Acanthuridae) in combination with high harvest rates for Acanthuridae might explain long-term model outcomes of the fish population in Nakodu. Also, site-fidelity values for Lethrinidae $(S=1.0)$ and Lutjanidae $(S=0.9)$ could be underestimating fish movement across patches. Previous studies on lutjanids in the Northwestern Hawaiian Islands and on lethrinids in Kenya documented species in both families travelling 19-148 km, while the Nakodu marine tenure area is spans only $\sim 2 \mathrm{~km}$ (Kaunda-Arara and Rose 2004, Meyer et al. 2007). High site-fidelity (i.e., no movement) between patches for these families could possibly overestimate population recovery in the PHC during closures periods because all fish are protected from fishing pressure and contributing to population growth. Thus, our model is possibly underestimating potential yield in the open-tofishing area and overestimating potential yield in the PHC.

Another limitation of our model was the estimation of fish catchability $(q)$ and the catchability adjustment parameter $(\alpha)$. Fish catchability in our model was estimated using a catchability curve derived from empirical data on fish flight response to simulated spearfishers and that curve was modulated with an adjustment parameter to calculate realized effort from potential effort. It is unlikely that our catchability adjustment parameter captured the complex dynamics of fish catchability in relation to multiple gear types and closure period. Also, the catchability adjustment parameter for all families was estimated to be very low $(\alpha=0.001)$, decreasing the catchability and thus underestimating yield in the calibration process. Our catchability curve introduces a 
constraint that fish catchability in the PHC after a closure period is greater than fish catchability in the open-to-fishing area. However, this may not be the case for drive-in gill nets because 60 to 100 people in the water scaring fish into a gill-net might immediately reverse any effects of PHC closure period on fish behavior resulting in a lower harvest efficiency during PHC harvest events than in the open-to-fishing area.

Model limitations resulted in outcomes that did not exactly match empirical estimates of biomass density and yield during the calibration process, but it is important to note that patterns in biomass change through time were replicated in our model outcomes. More extensive data sets for PHCs will contribute to our understanding of harvest and recovery dynamics for PHCs and allow scientists to more accurately model these fisheries. Our model presents a framework that can easily be altered to integrate more data on fish catchability in relation to gear types and closure periods and more complex fish movement patterns.

Our calibrated model framework for PHCs can be used to assess PHCs in any community with biomass, yield, and effort data. We are currently working with the Wildlife Conservation Society (WCS) Melanesia Program in converting our model into a graphical user interface app that allows WCS field scientists (and any organization working directly with communities that implement PHC management) to input data into the app and simulate possible fishery outcomes given a set of management conditions. An app which produces immediate results will allow communities to observe the long termconsequences of their management actions and explore alternative management options that will better achieve specific conservation and fishery goals. 


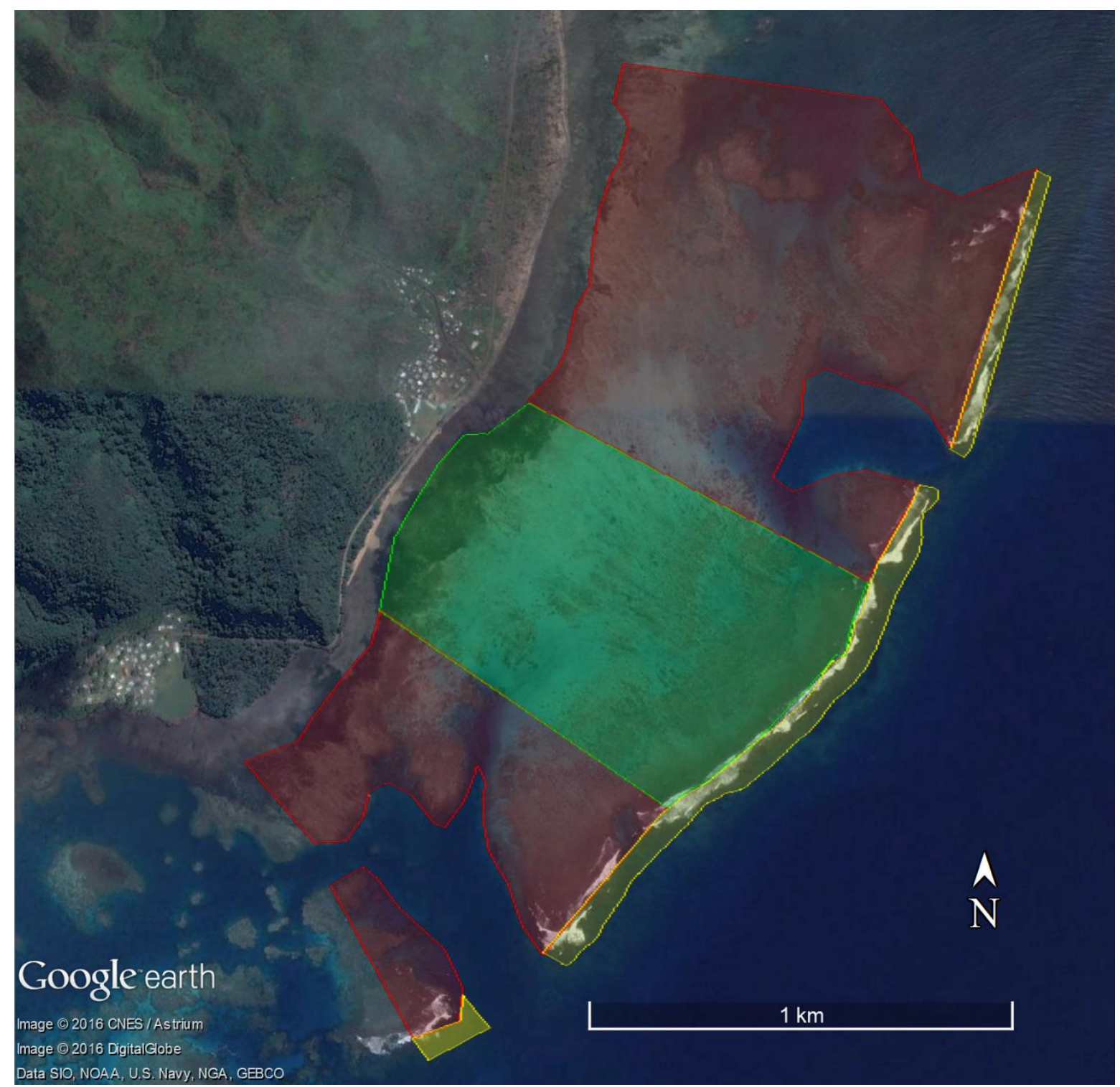

Figure 2.1. Map of Nakodu customary marine tenure area. Red shading indicates open-to-fishing area (115 ha), green indicates the periodically-harvested closure (68 ha), and yellow indicates the fore reef area ( $27 \mathrm{ha}$ ). Deep channels in the reef were excluded from our model due to the absence of target fish and fishing effort in these areas. Fore reef areas were included in our model because target fish are present, but fishing pressure is absent and fish movement from and to fore reef areas. 


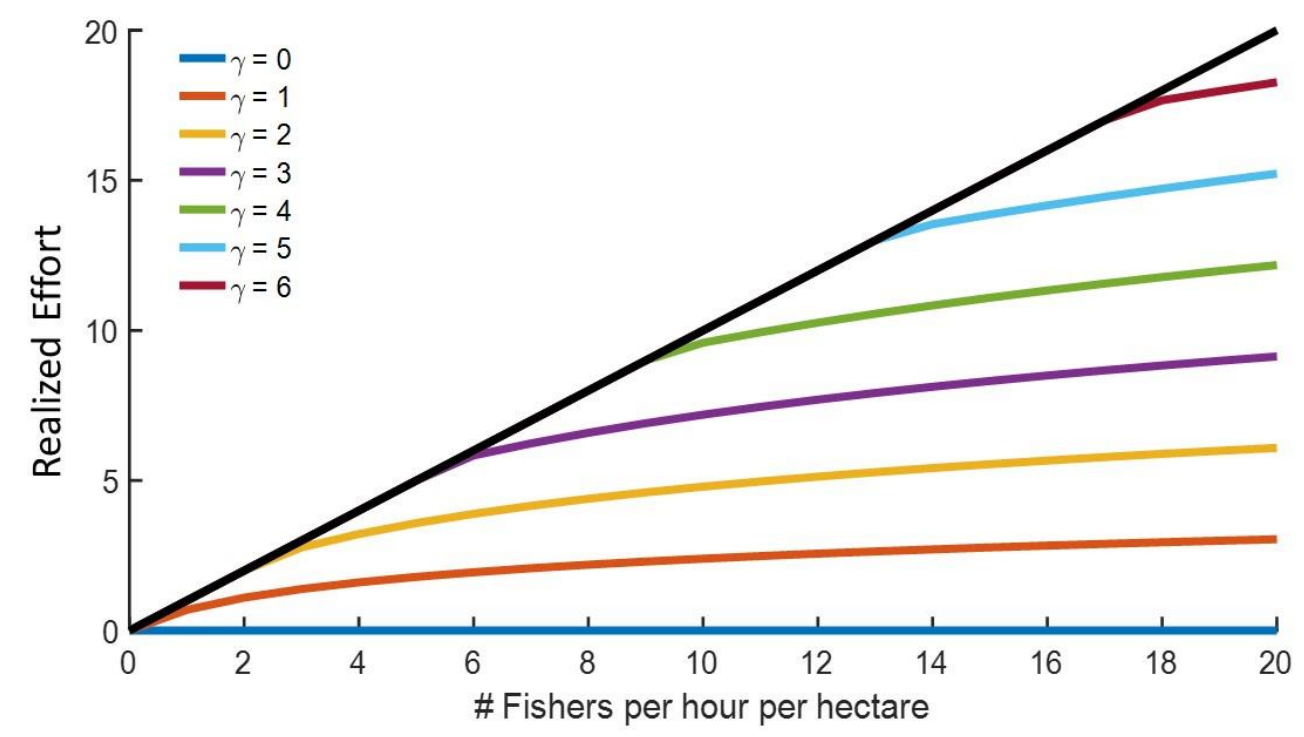

Figure 2.2. Realized effort in relation to number of fishers per hour per hectare (potential effort). Realized effort is modulated by a adjustment variable $(\gamma)$. The linear line indicates realized effort equal to empirical data for number of fishers per hour per hectare. The adjustment variable is a "free parameter" that is "tuned" by the model to best fit model outcomes to empirical data. 


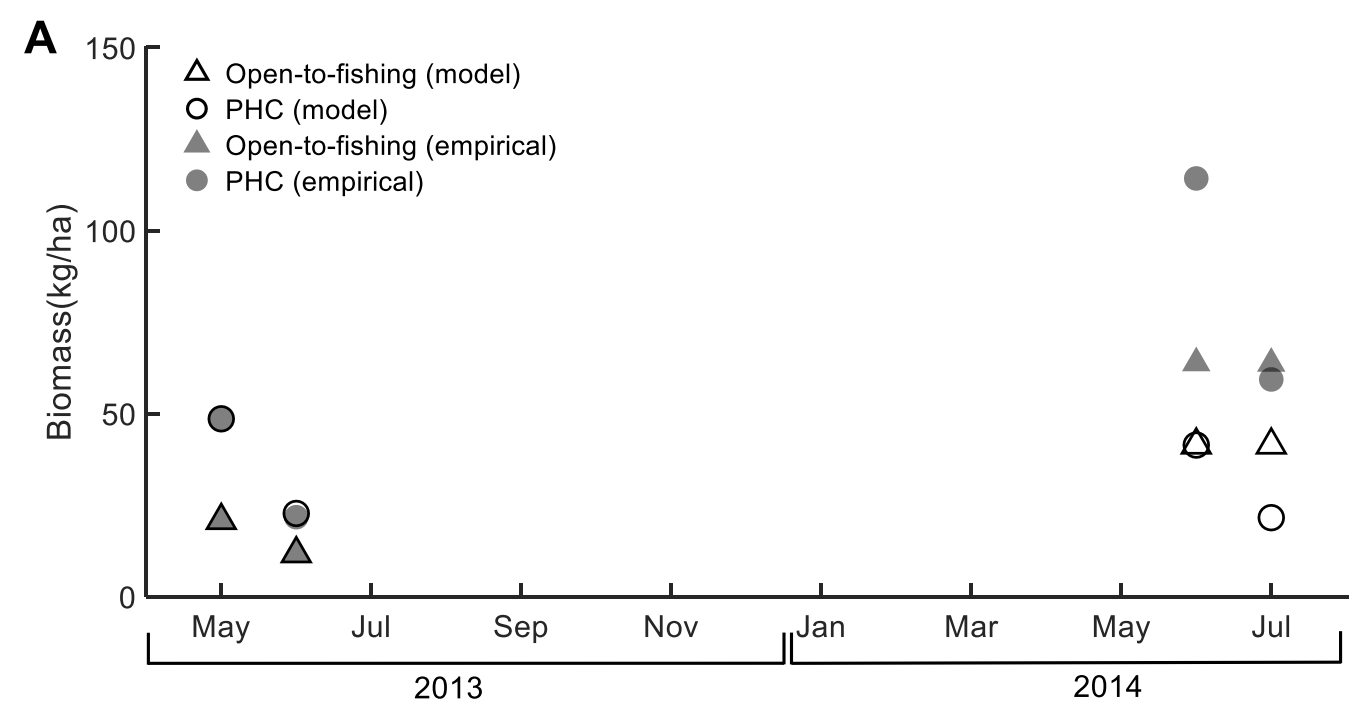

B

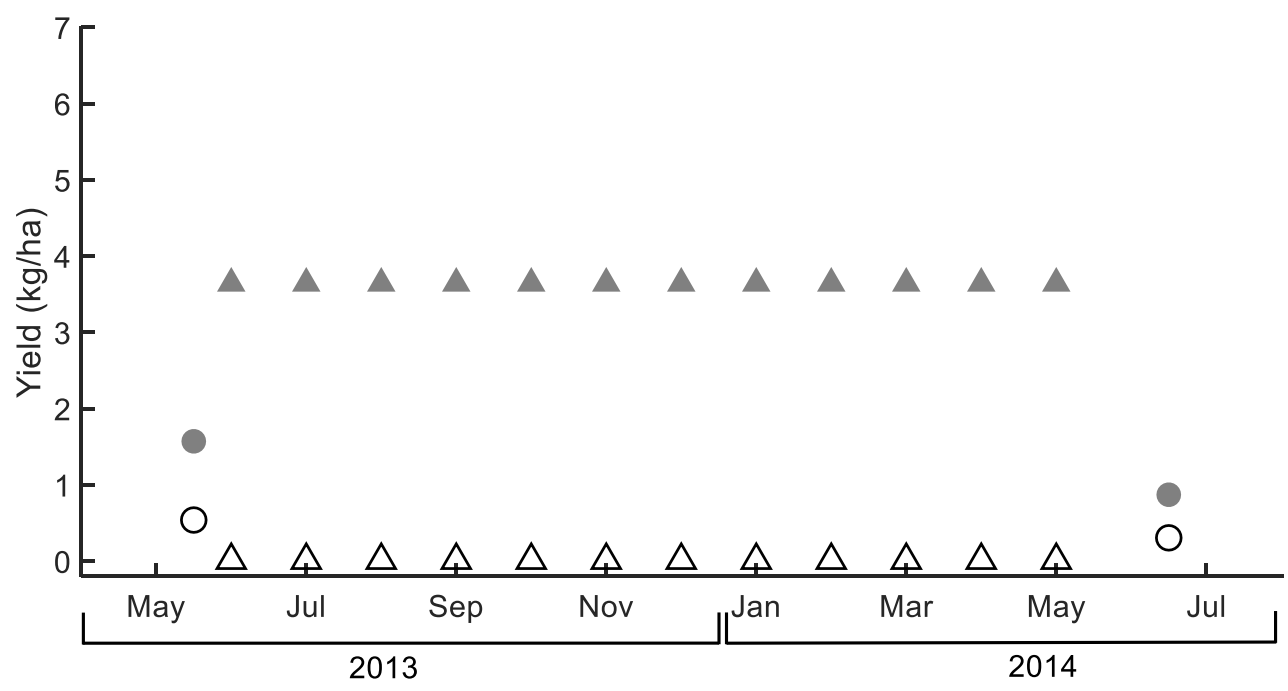

Figure 2.3. Model calibration results for Acanthuridae. The model is simultaneously calibrated to biomass (A) and yield (B) density empirical data.

Biomass density is calibrated using diver operated stereo-video (DOV) surveys pre- and post-harvest in 2013 and 2014. Yield density is calibrated using catch data from Nakodu during PHC harvest and between harvests. 

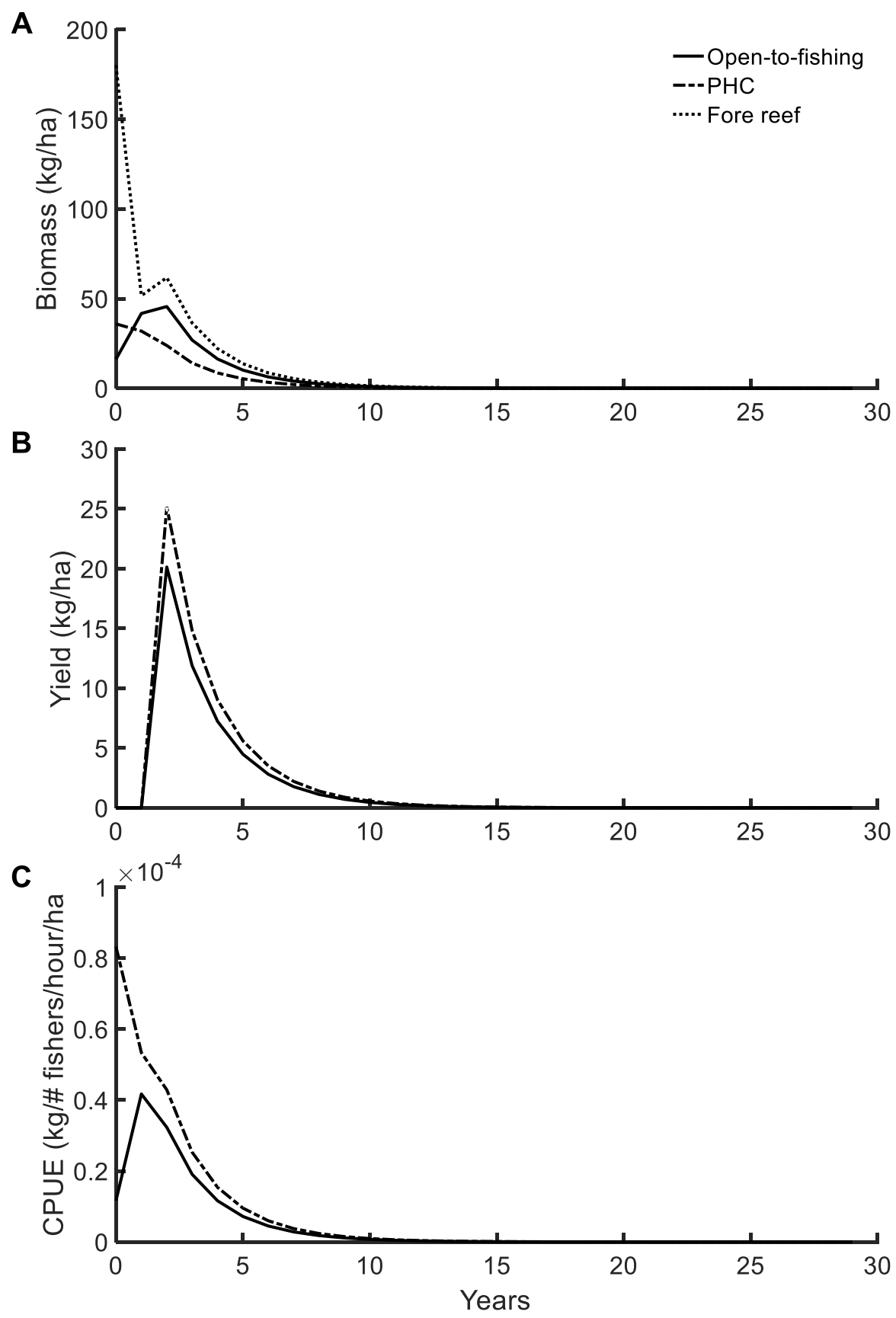

Figure 2.4. Time series data for Acanthuridae (A) biomass, (B) yield, and (C) catch per unit effort at present average annual yield in Nakodu when the PHC is harvested once a year. Lines indicate patch within Nakodu customary marine tenure area (i.e., open-to-fishing, periodically-harvested closure, and fore reef). Acanthuridae model calibration resulted in a poor fit to empirical data. 

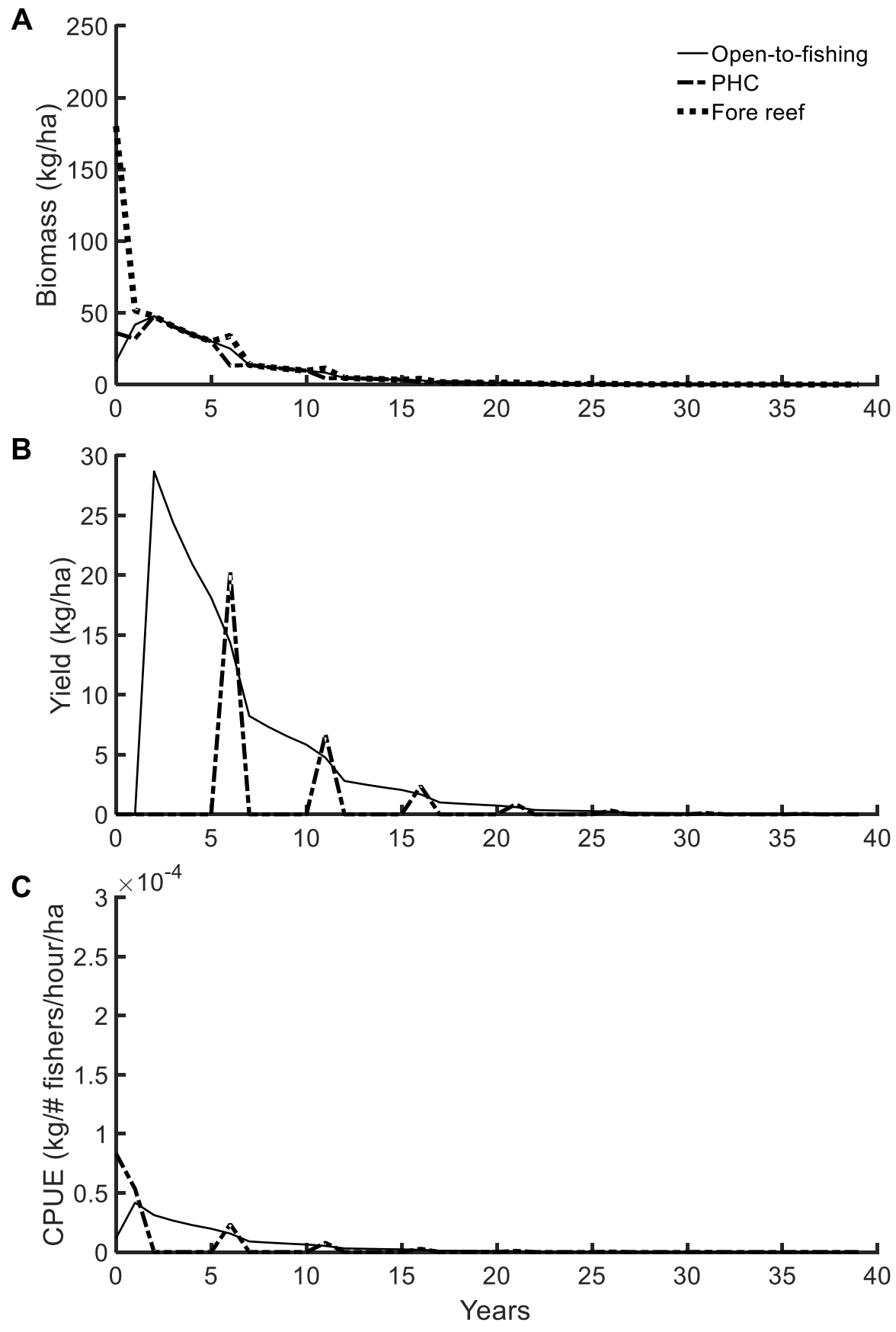

Figure 2.5. Time series data for Acanthuridae (A) biomass, (B) yield, and (C) catch per unit effort at present average annual yield in Nakodu with 5-year closures between PHC harvests. Lines indicate patch within Nakodu customary marine tenure area (i.e., open-to-fishing, periodically-harvested closure, and fore reef). Acanthuridae model calibration resulted in a poor fit to empirical data. 

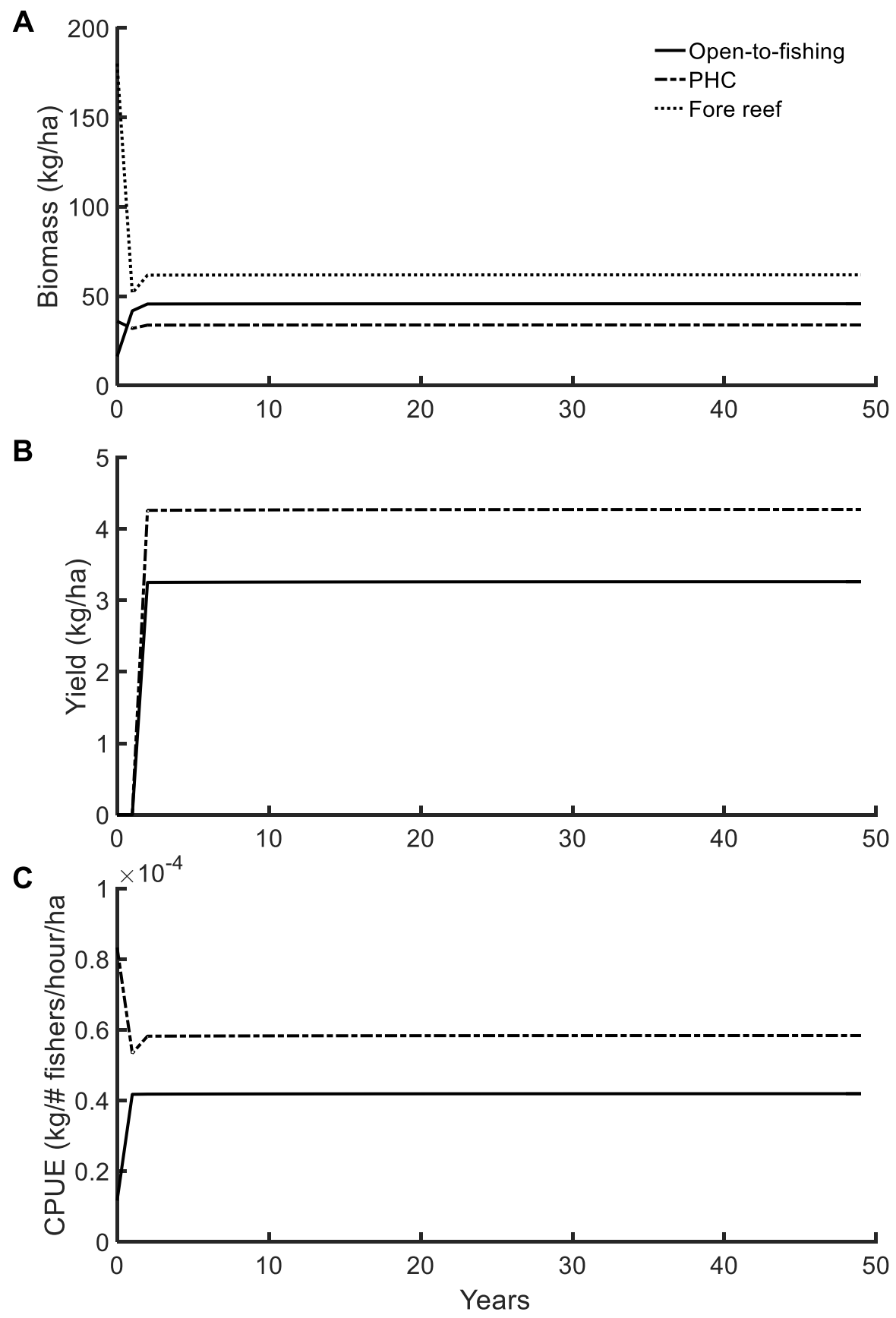

Figure 2.6. Time series data for Acanthuridae (A) biomass, (B) yield, and (C) catch per unit effort at maximum sustainable average annual yield (optimal harvest for each patch and year) in Nakodu when the PHC is harvested once a year. Lines indicate patch within Nakodu customary marine tenure area (i.e., open-to-fishing, periodically-harvested closure, and fore reef). Acanthuridae model calibration resulted in a poor fit to empirical data. 

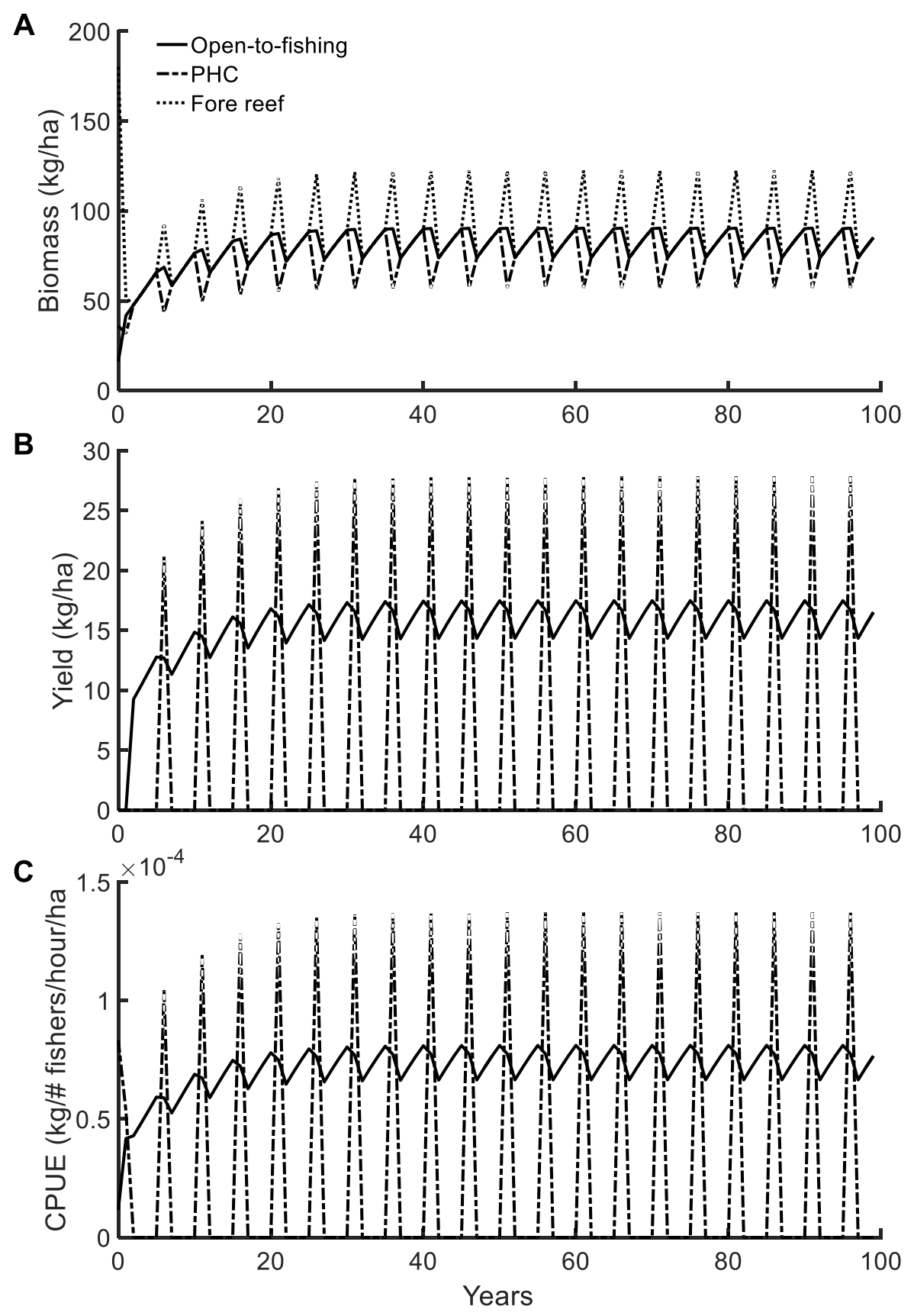

Figure 2.7. Time series data for Acanthuridae (A) biomass, (B) yield, and (C) catch per unit effort at maximum sustainable average annual yield (optimal harvest for each patch and year) in Nakodu with 5-year closures between PHC harvests. Lines indicate patch within Nakodu customary marine tenure area (i.e., open-to-fishing, periodically-harvested closure, and fore reef). Acanthuridae model calibration resulted in a poor fit to empirical data. 


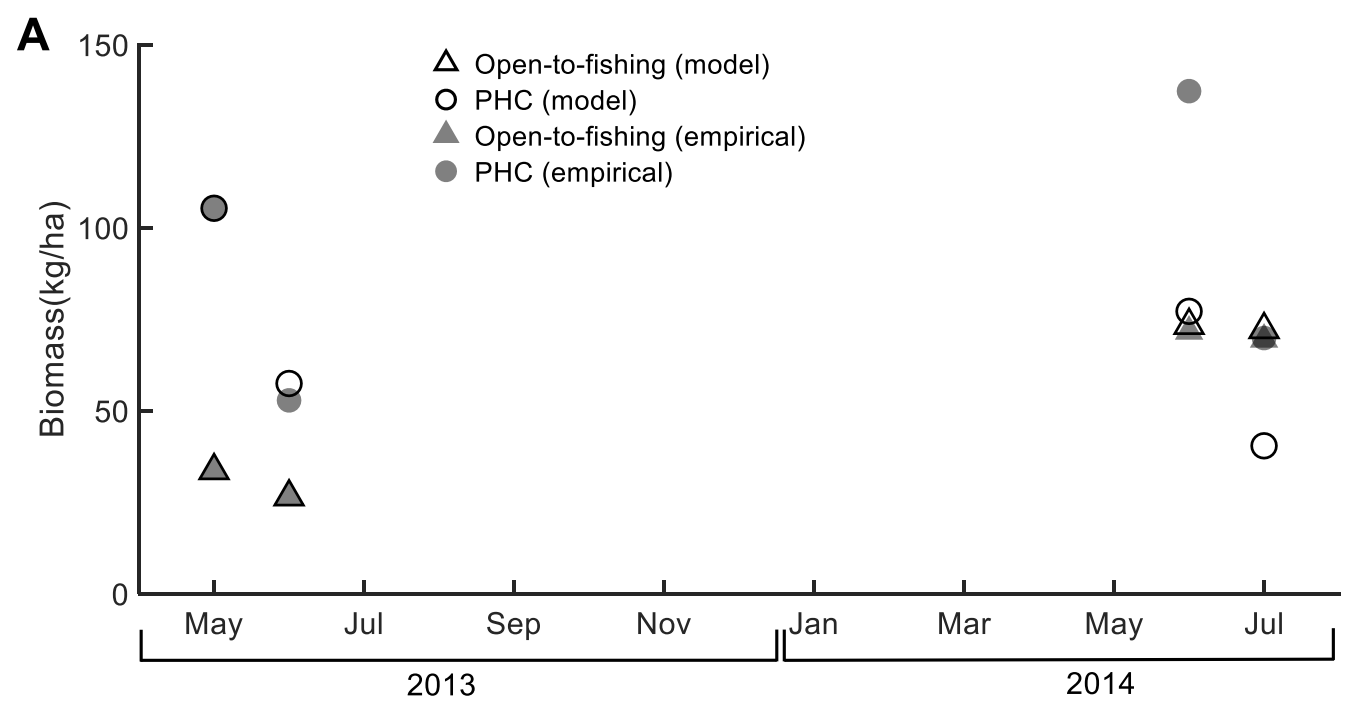

B

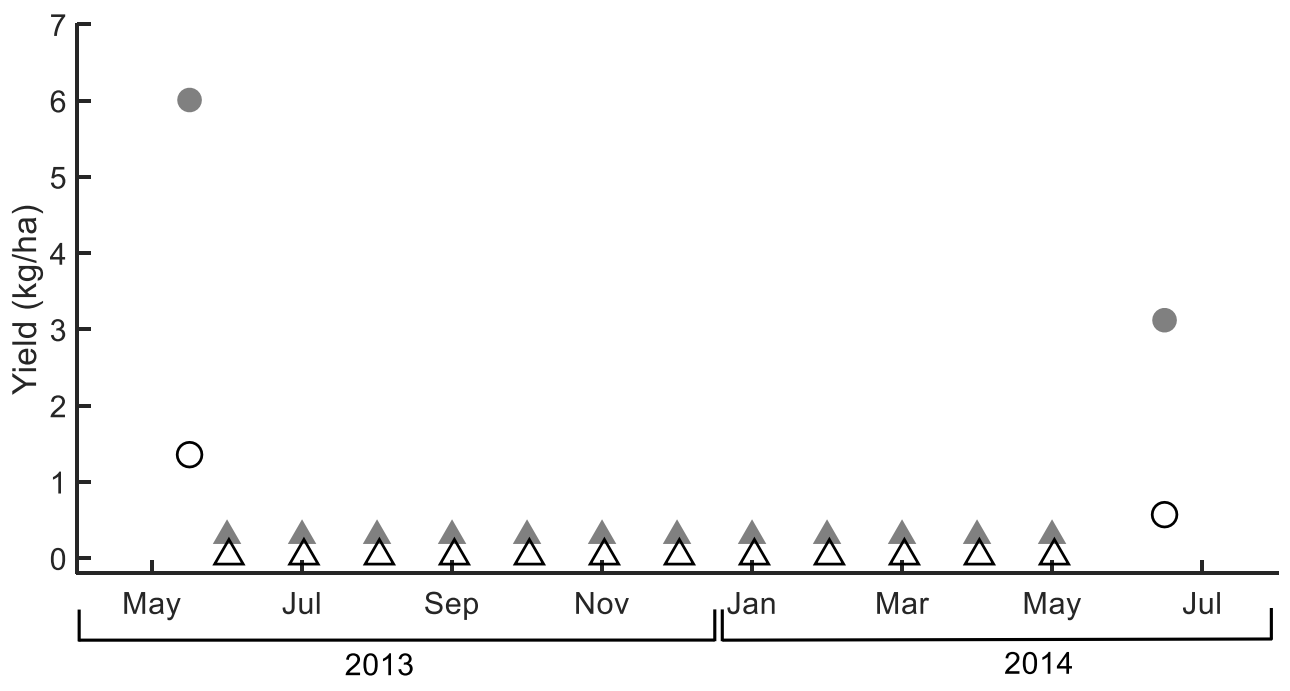

Figure 2.8. Model calibration results for Scarinae (Labridae subfamily). The model is simultaneously calibrated to biomass (A) and yield (B) density empirical data.

Biomass density is calibrated using diver operated stereo-video (DOV) surveys pre- and post-harvest in 2013 and 2014. Yield density is calibrated using catch data from Nakodu during PHC harvest and between harvests. 

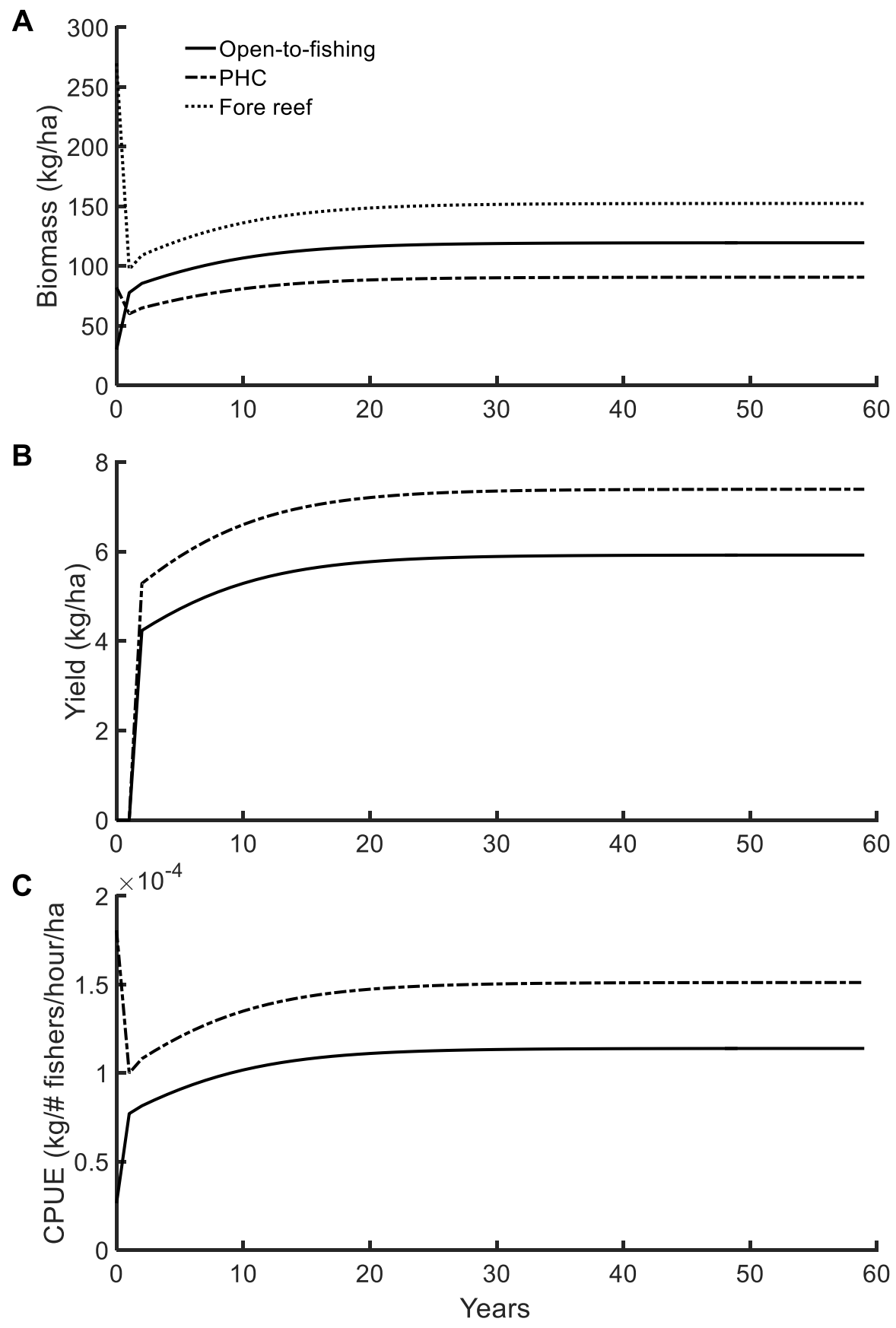

Figure 2.9. Time series data for Scarinae (A) biomass, (B) yield, and (C) catch per unit effort at present average annual yield in Nakodu when the PHC is harvested once a year. Lines indicate patch within Nakodu customary marine tenure area (i.e., open-to-fishing, periodically-harvested closure, and fore reef). 

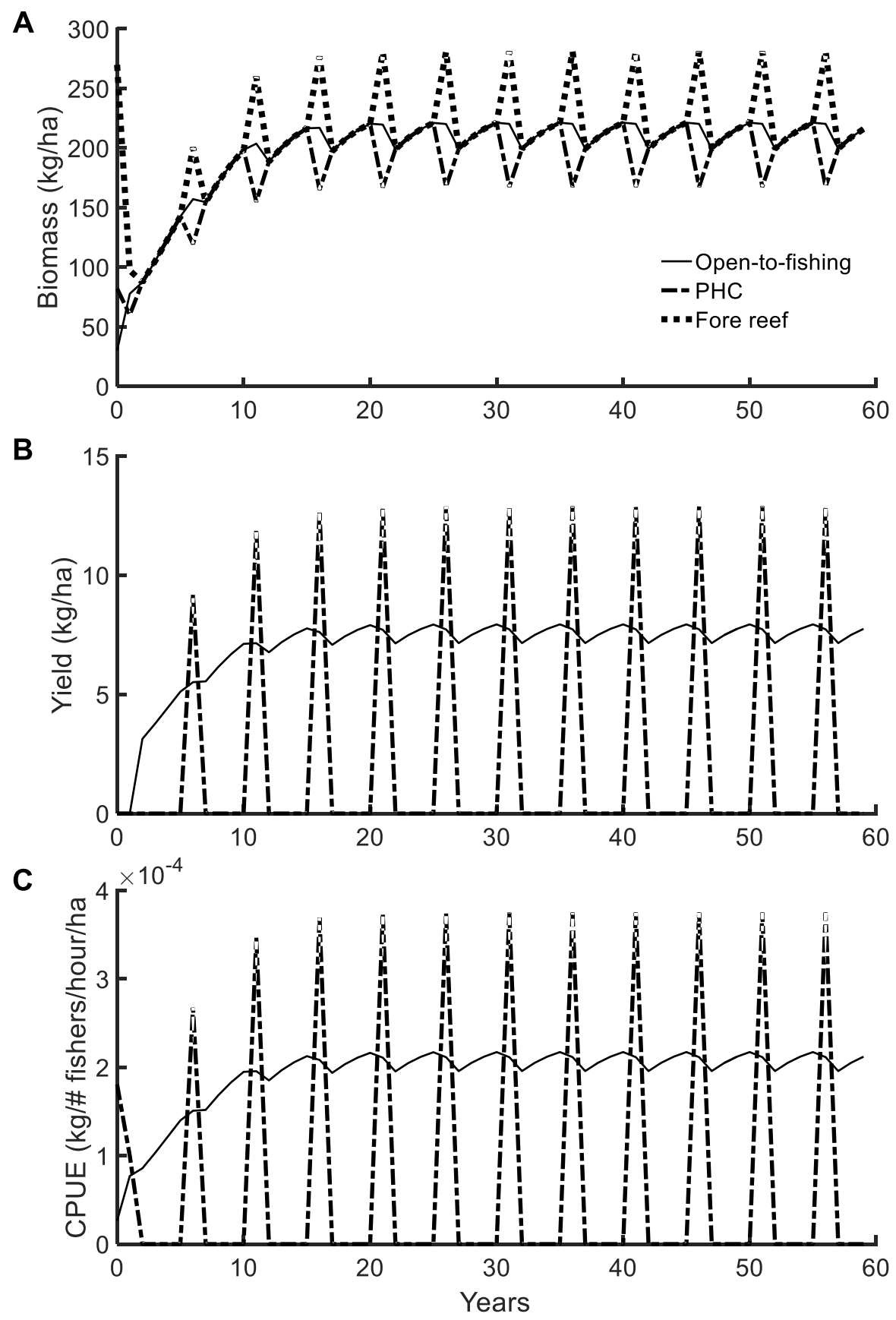

Figure 2.10. Time series data for Scarinae (A) biomass, (B) yield, and (C) catch per unit effort at present average annual yield in Nakodu with 5-year closures between PHC harvests. Lines indicate patch within Nakodu customary marine tenure area (i.e., open-to-fishing, periodically-harvested closure, and fore reef). 

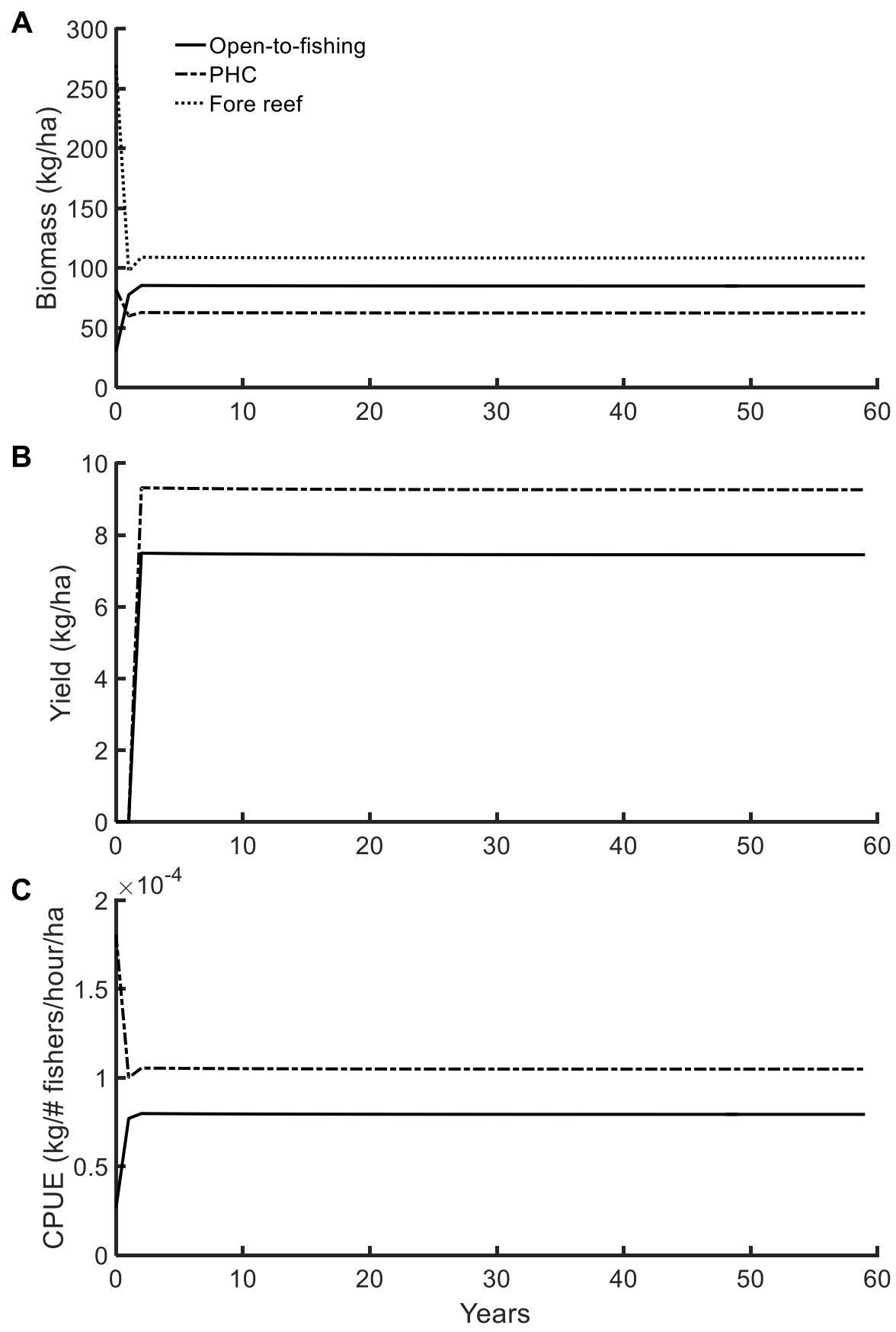

Figure 2.11. Time series data for Scarinae (A) biomass, (B) yield, and (C) catch per unit effort at maximum sustainable average annual yield (optimal harvest for each patch and year) in Nakodu when the PHC is harvested once a year. Lines indicate patch within Nakodu customary marine tenure area (i.e., open-to-fishing, periodicallyharvested closure, and fore reef). 


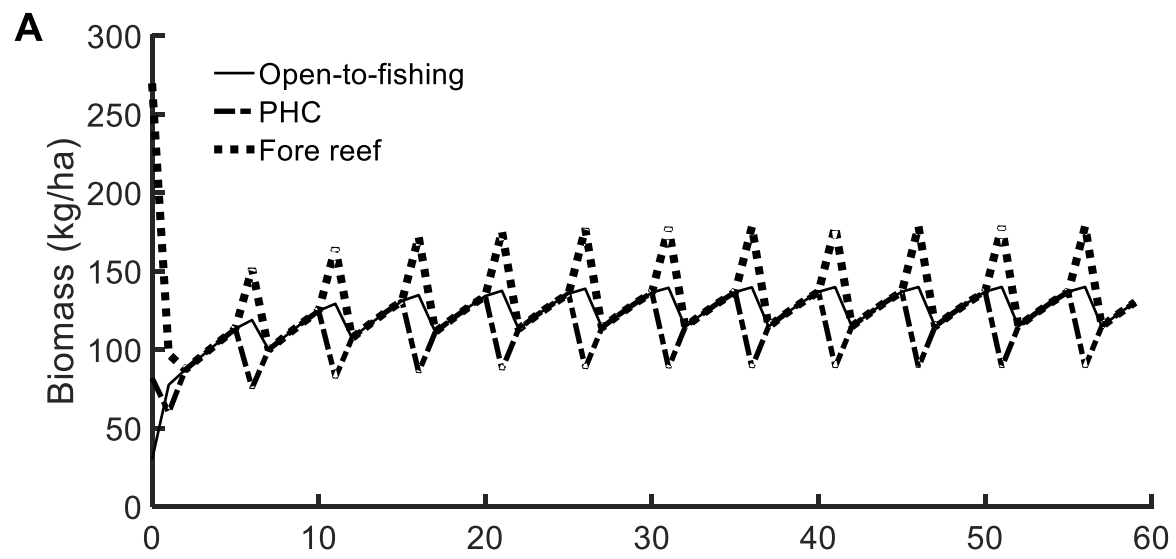

B
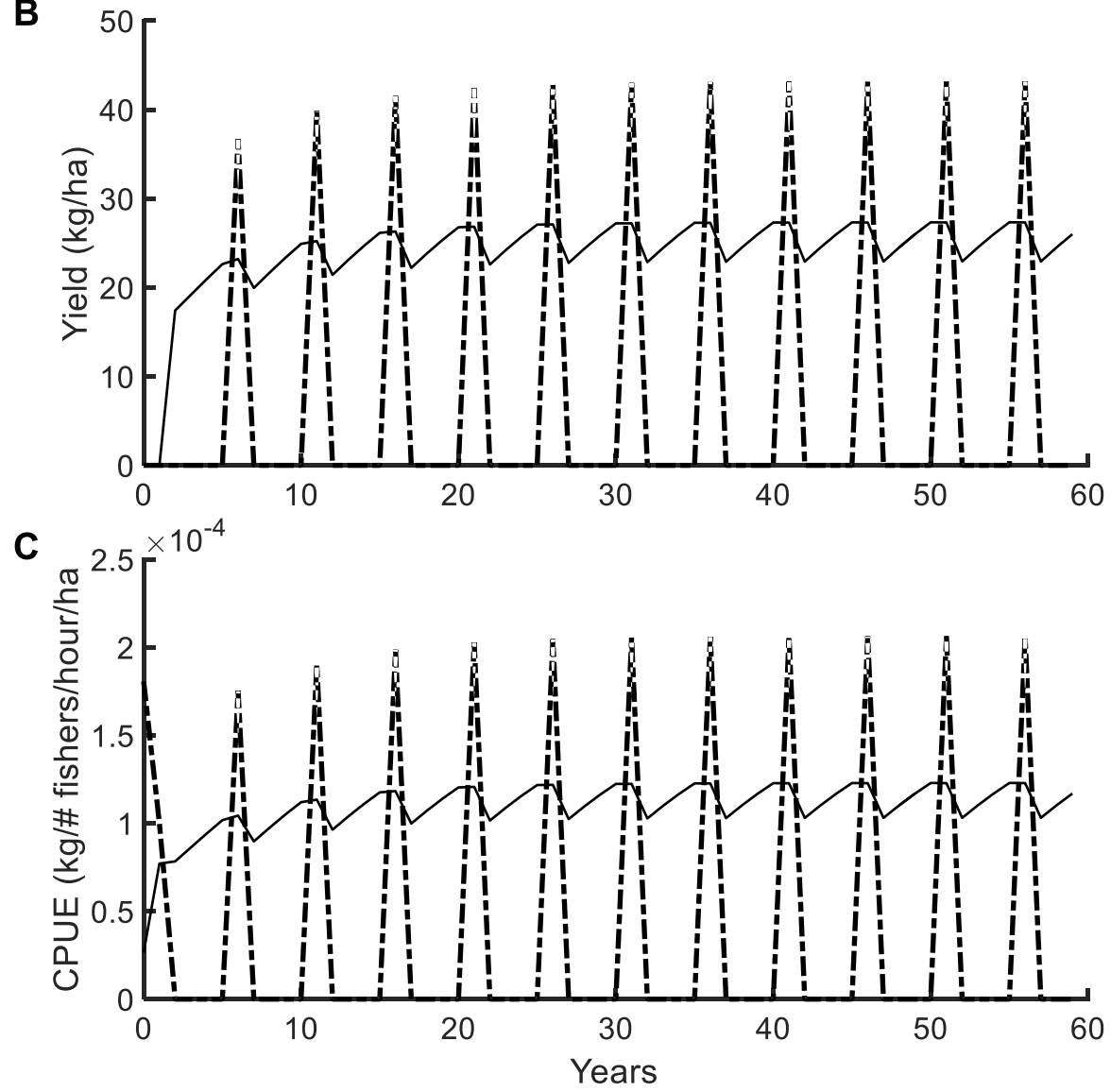

Figure 2.12. Time series data for Scarinae (A) biomass, (B) yield, and (C) catch per unit effort at maximum sustainable average annual yield (optimal harvest for each patch and year) in Nakodu with 5-year closures between PHC harvests. Lines indicate patch within Nakodu customary marine tenure area (i.e., open-to-fishing, periodically-harvested closure, and fore reef). 


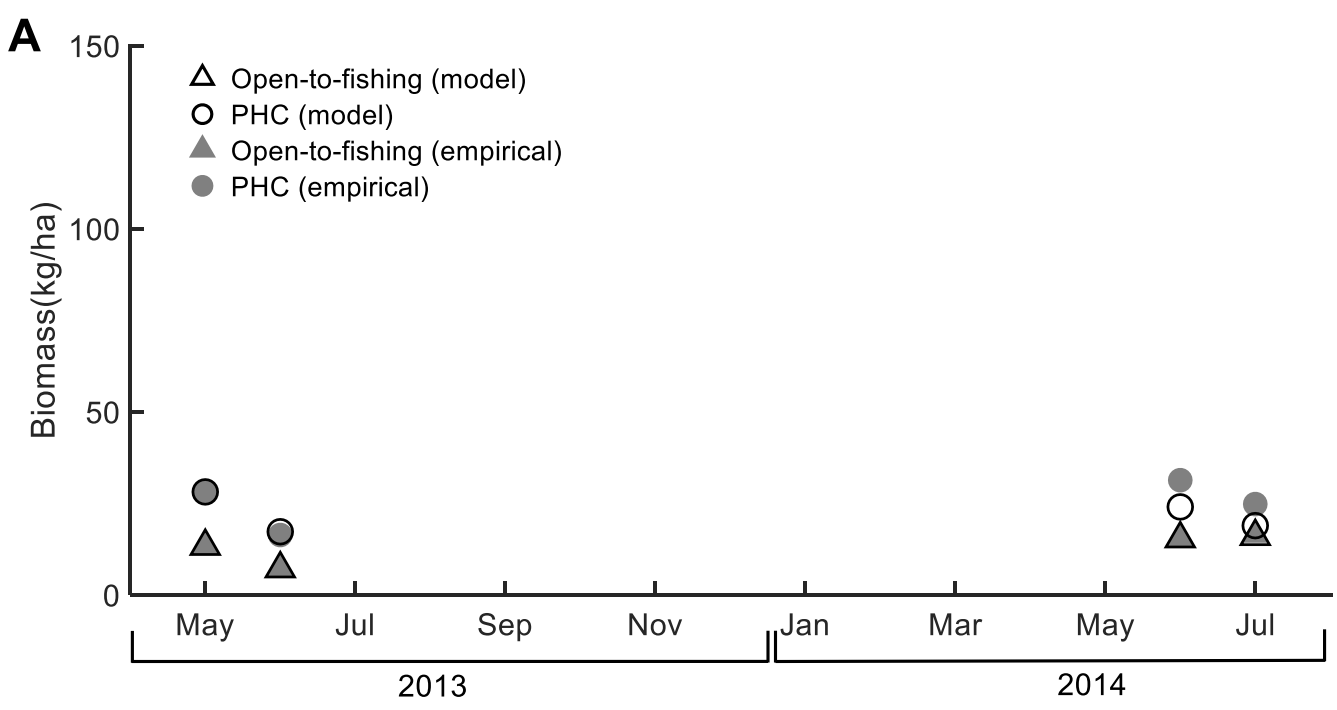

B

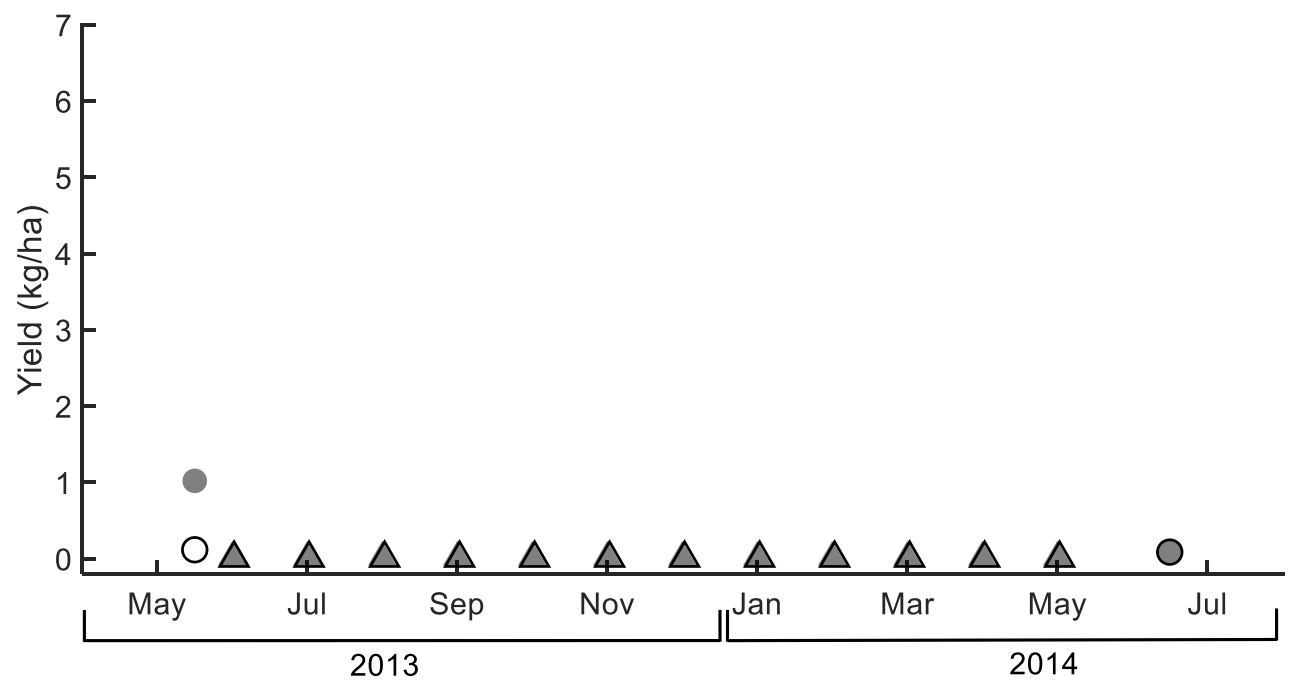

Figure 2.13. Model calibration results for Labridae. The model is simultaneously calibrated to biomass (A) and yield (B) density empirical data. Biomass density is calibrated using diver operated stereo-video (DOV) surveys pre- and post-harvest in 2013 and 2014. Yield density is calibrated using catch data from Nakodu during PHC harvest and between harvests. 
A

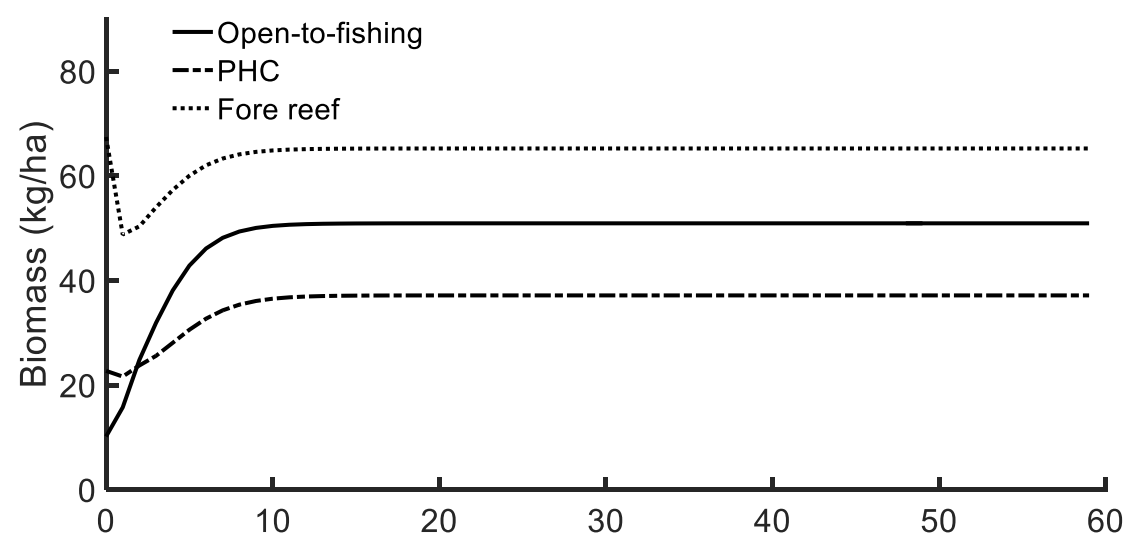

B
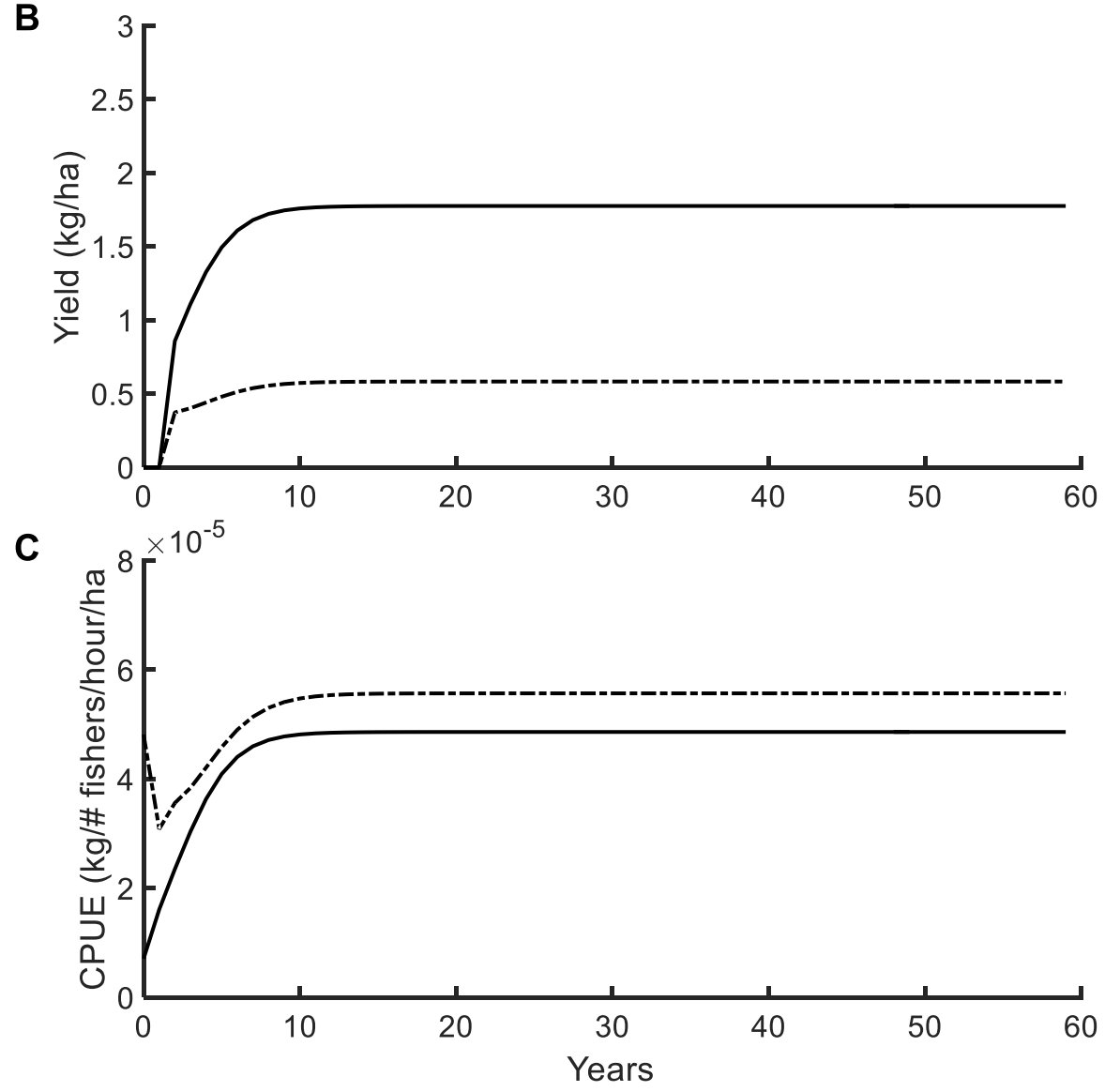

Figure 2.14. Time series data for Labridae (A) biomass, (B) yield, and (C) catch per unit effort at present average annual yield in Nakodu when the PHC is harvested once a year. Lines indicate patch within Nakodu customary marine tenure area (i.e., open-to-fishing, periodically-harvested closure, and fore reef). 
A

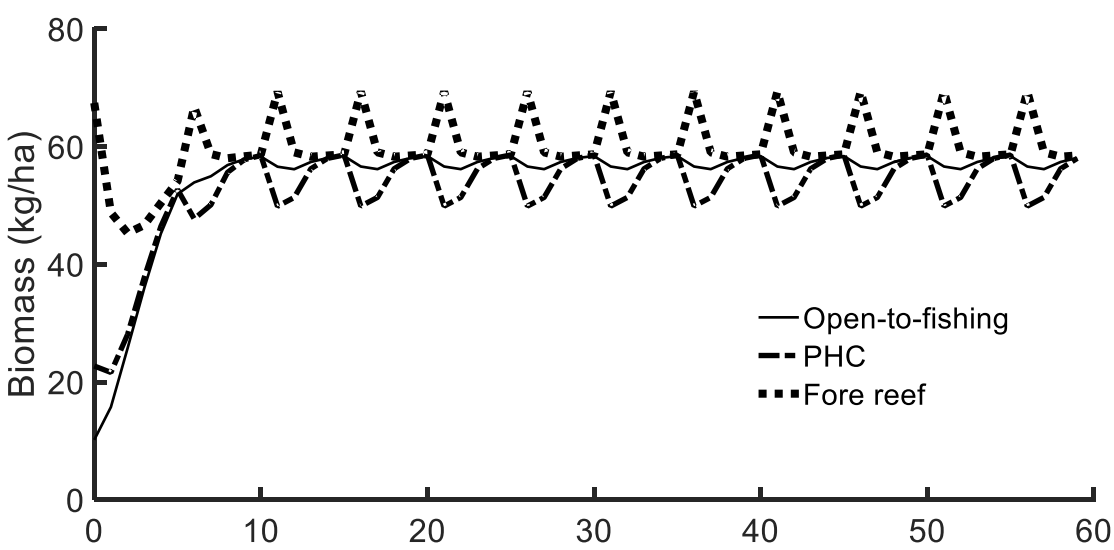

B
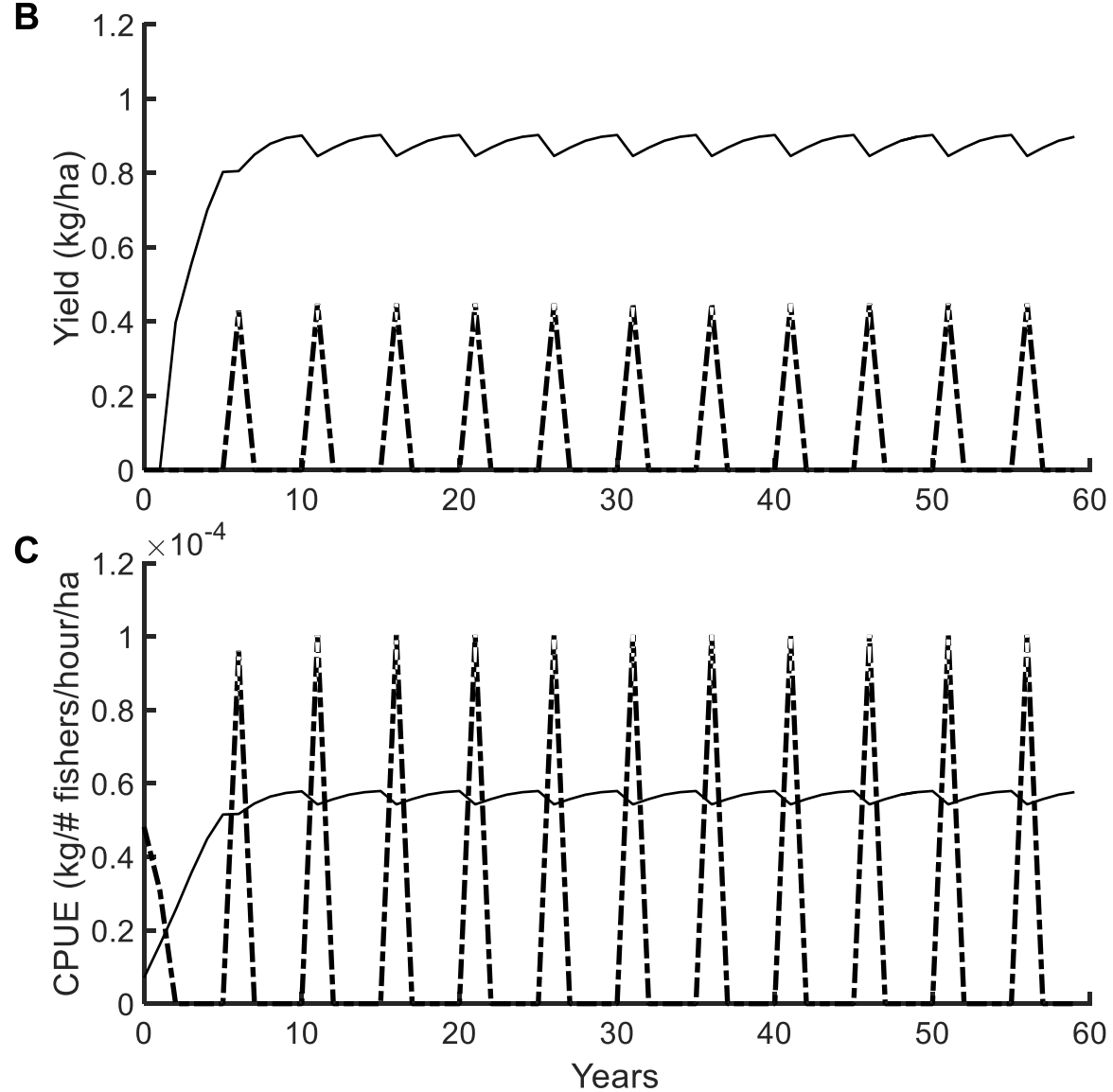

Figure 2.15. Time series data for Labridae (A) biomass, (B) yield, and (C) catch per unit effort at present average annual yield in Nakodu with 5-year closures between PHC harvests. Lines indicate patch within Nakodu customary marine tenure area (i.e., open-to-fishing, periodically-harvested closure, and fore reef). 


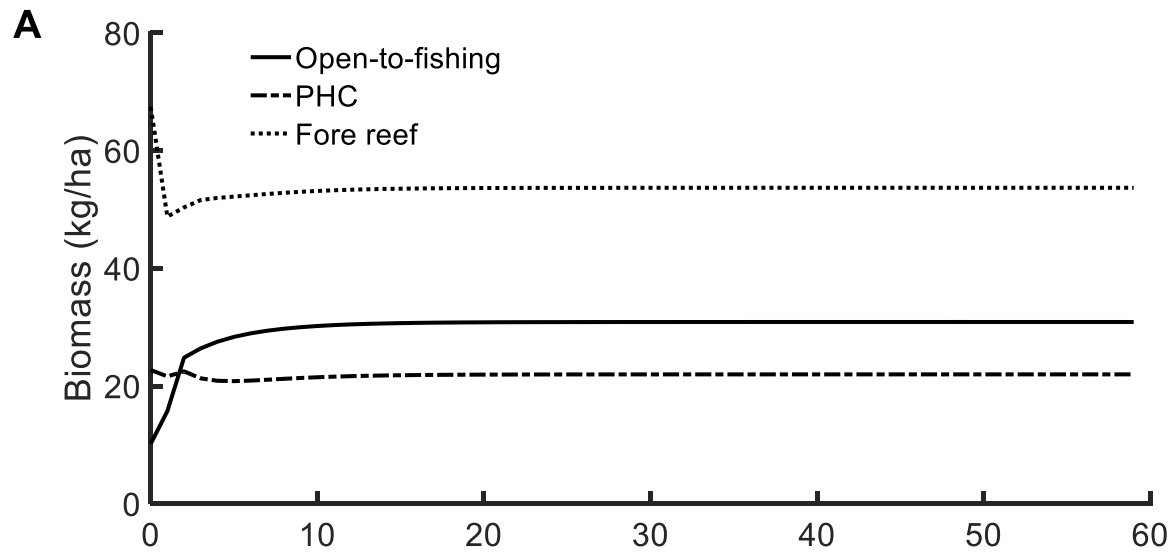

B

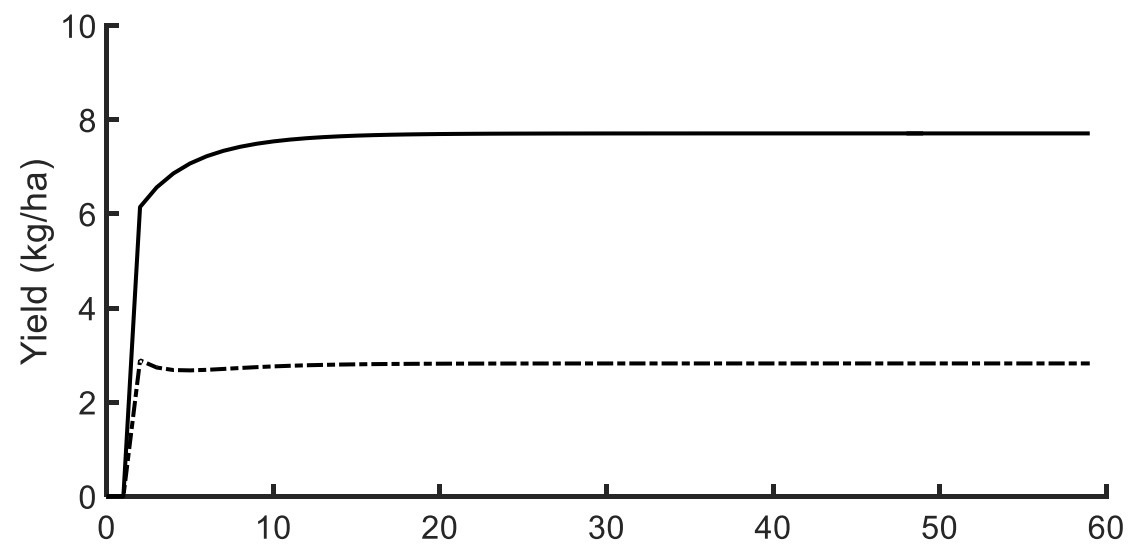

C

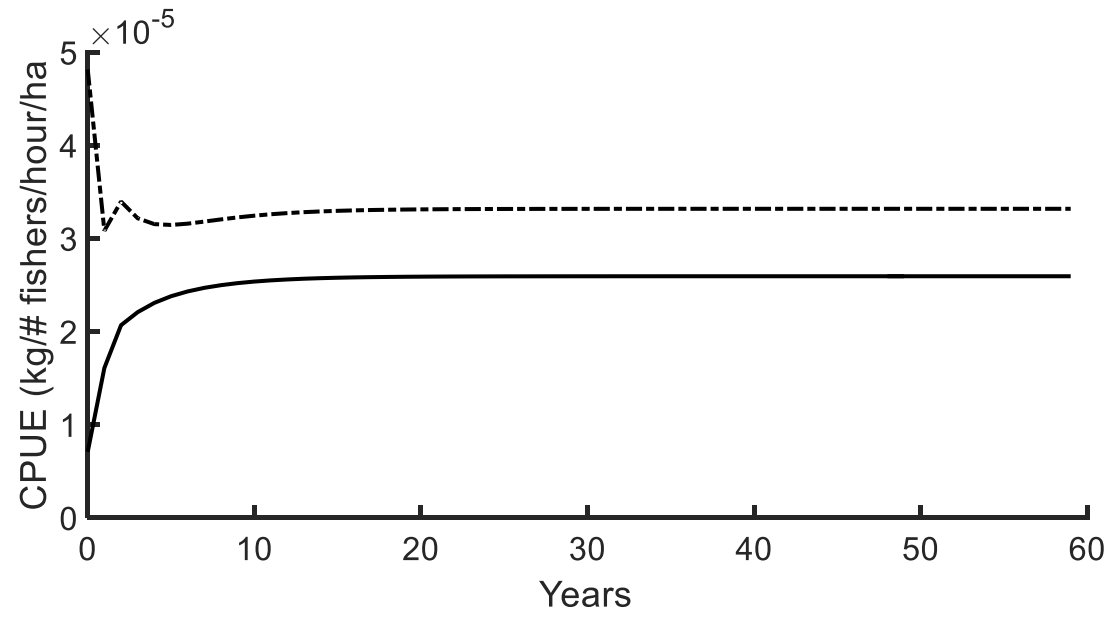

Figure 2.16. Time series data for Labridae (A) biomass, (B) yield, and (C) catch per unit effort at maximum sustainable average annual yield (optimal harvest for each patch and year) in Nakodu when the PHC is harvested once a year. Lines indicate patch within Nakodu customary marine tenure area (i.e., open-to-fishing, periodicallyharvested closure, and fore reef). 

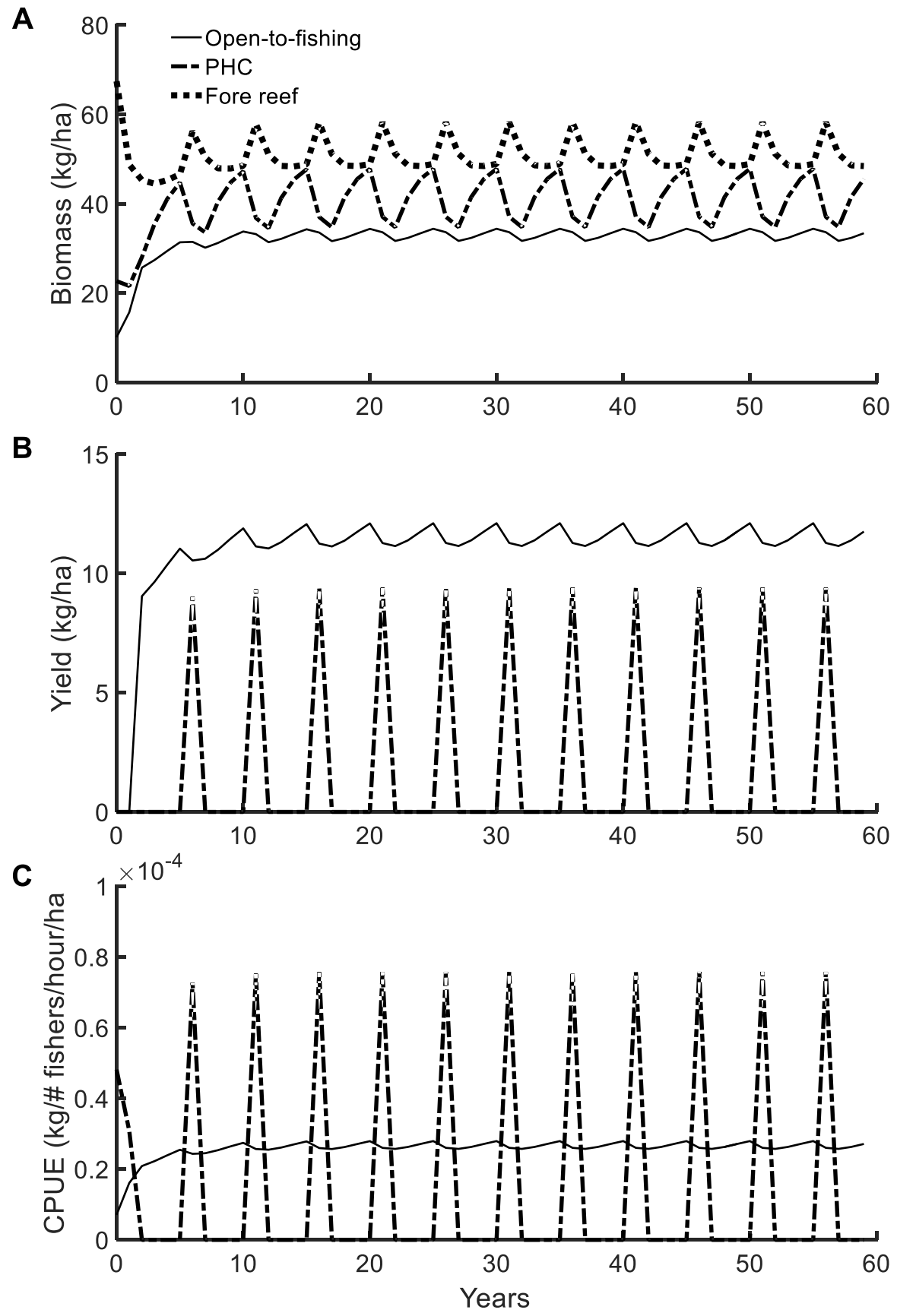

Figure 2.17. Time series data for Labridae (A) biomass, (B) yield, and (C) catch per unit effort at maximum sustainable average annual yield (optimal harvest for each patch and year) in Nakodu with 5-year closures between PHC harvests. Lines indicate patch within Nakodu customary marine tenure area (i.e., open-to-fishing, periodically-harvested closure, and fore reef). 

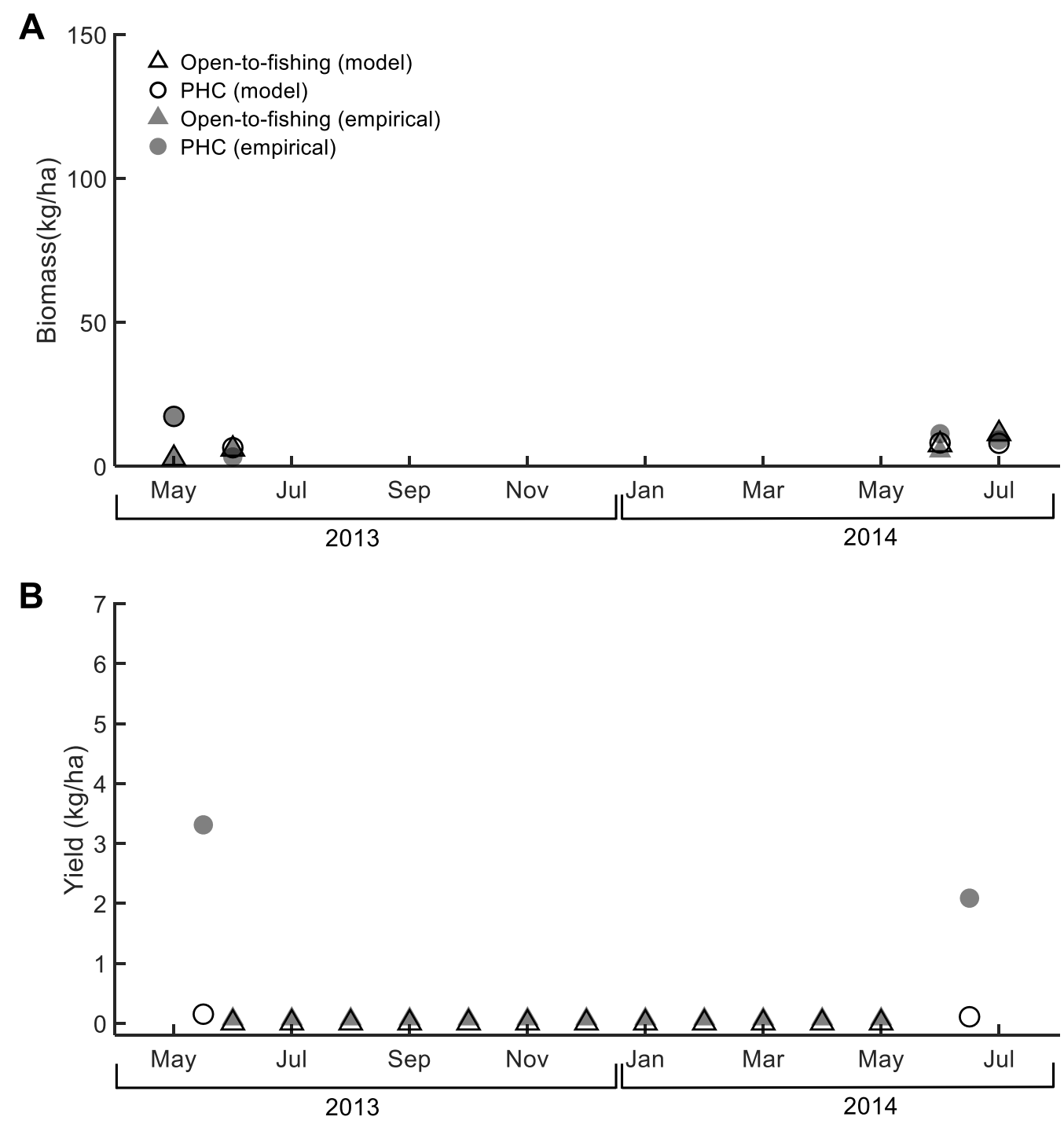

Figure 2.18. Model calibration results for Lethrinidae. The model is simultaneously calibrated to biomass (A) and yield (B) density empirical data. Biomass density is calibrated using diver operated stereo-video (DOV) surveys pre- and post-harvest in 2013 and 2014. Yield density is calibrated using catch data from Nakodu during PHC harvest and between harvests. 

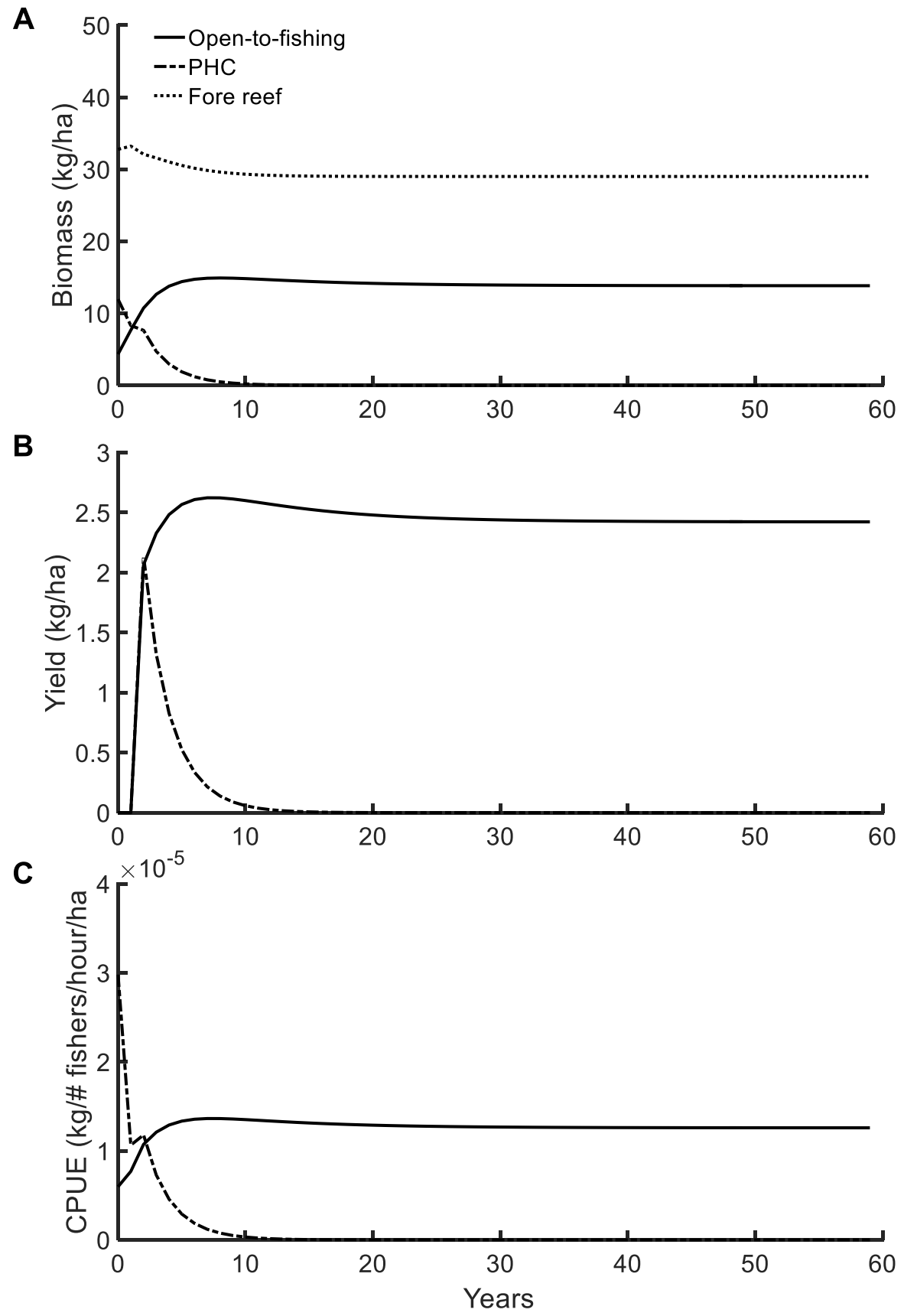

Figure 2.19. Time series data for Lethrinidae (A) biomass, (B) yield, and (C) catch per unit effort at present average annual yield in Nakodu when the PHC is harvested once a year. Lines indicate patch within Nakodu customary marine tenure area (i.e., open-to-fishing, periodically-harvested closure, and fore reef). 
A

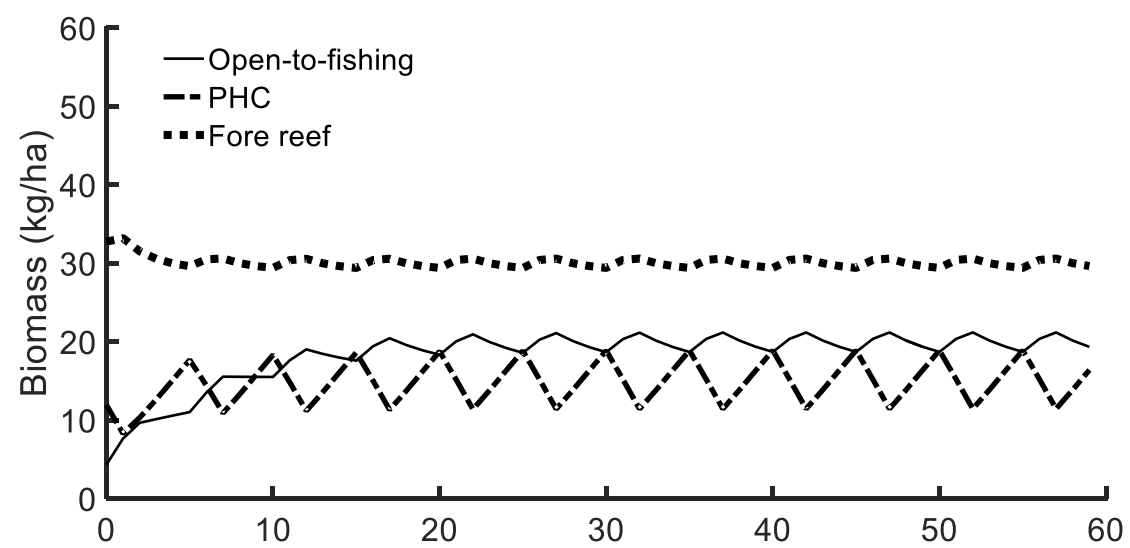

B

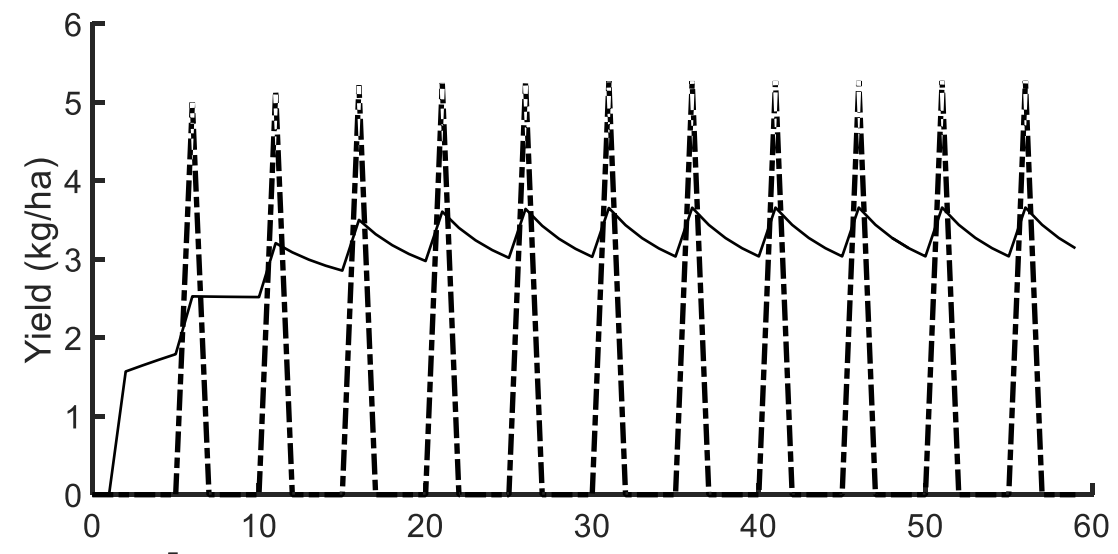

C

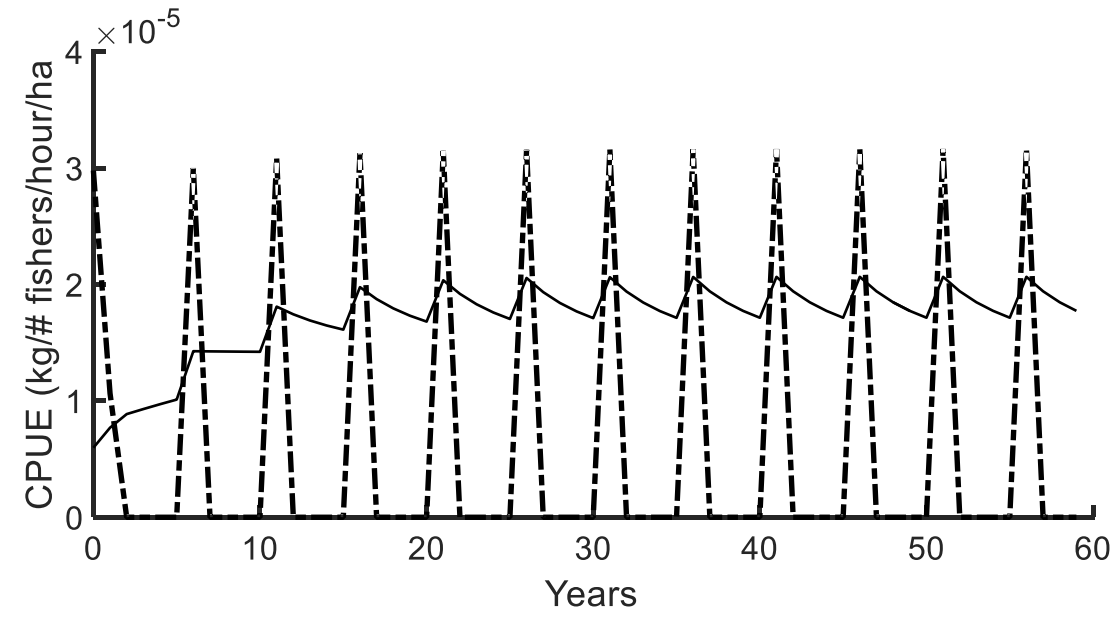

Figure 2.20. Time series data for Lethrinidae (A) biomass, (B) yield, and (C) catch per unit effort at present average annual yield in Nakodu with 5-year closures between PHC harvests. Lines indicate patch within Nakodu customary marine tenure area (i.e., open-to-fishing, periodically-harvested closure, and fore reef). 

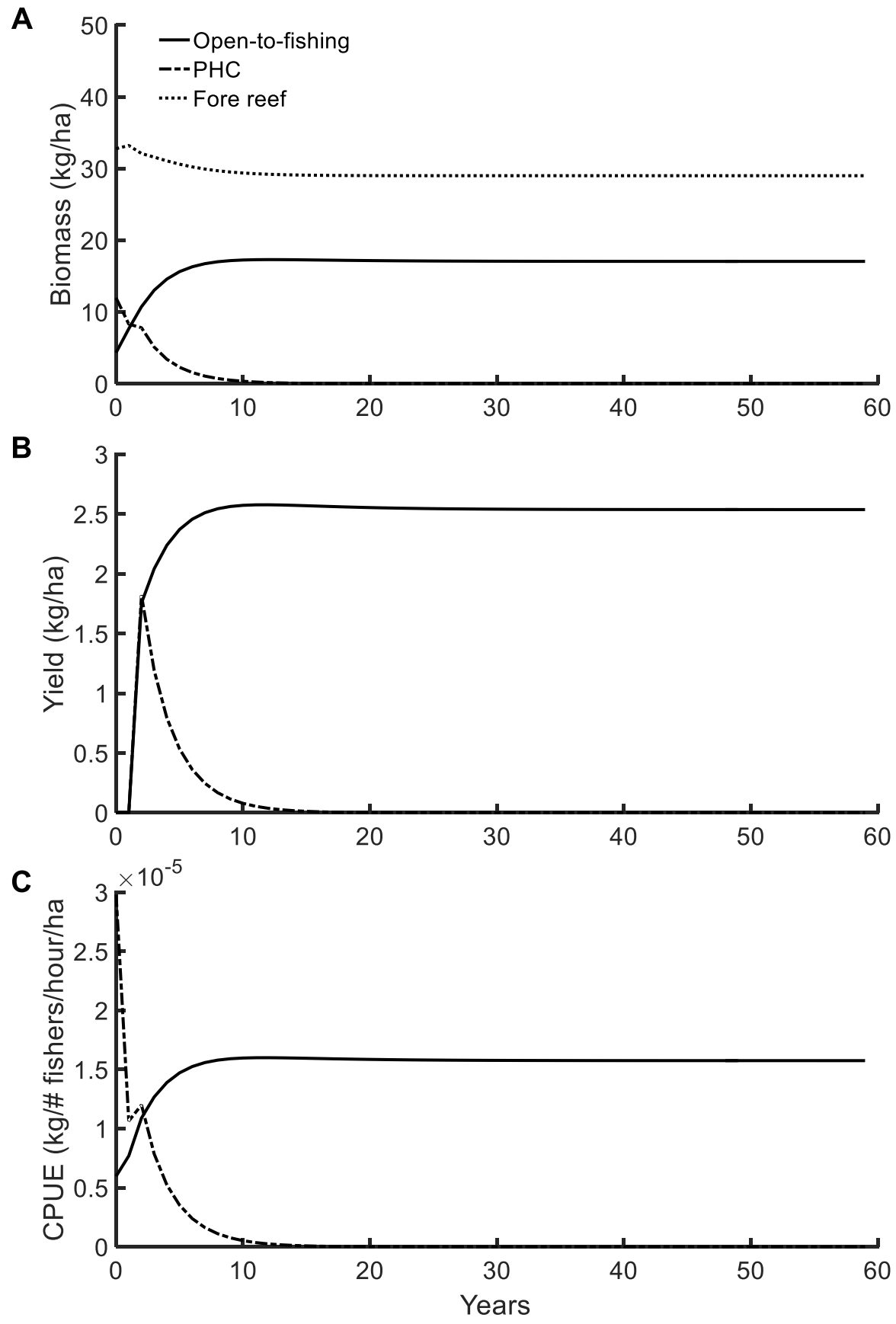

Figure 2.21. Time series data for Lethrinidae (A) biomass, (B) yield, and (C) catch per unit effort at maximum sustainable average annual yield (optimal harvest in each patch and year) in Nakodu when the PHC is harvested once a year. Lines indicate patch within Nakodu customary marine tenure area (i.e., open-to-fishing, periodically-harvested closure, and fore reef). 

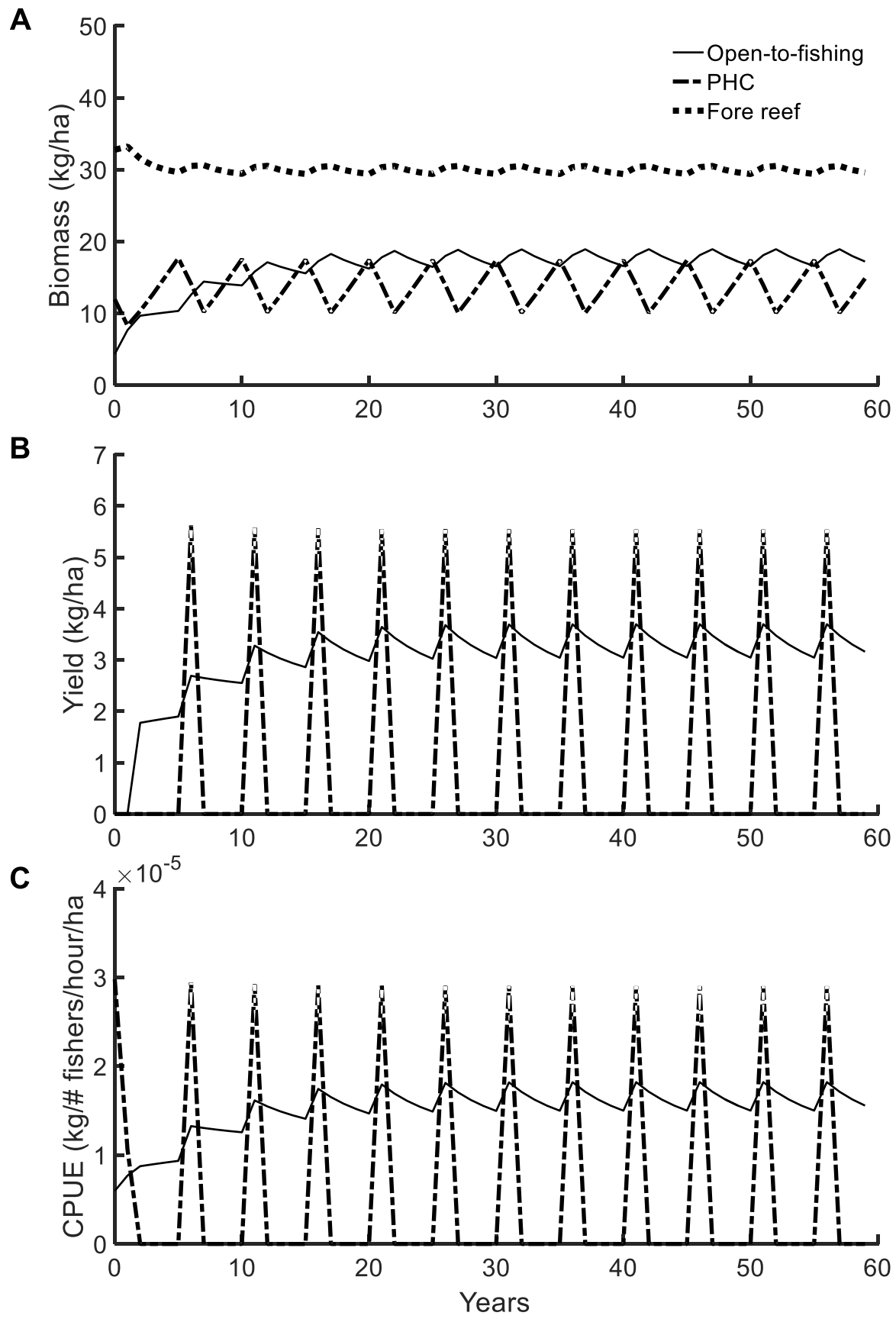

Figure 2.22. Time series data for Lethrinidae (A) biomass, (B) yield, and (C) catch per unit effort at maximum sustainable average annual yield (optimal harvest in each patch and year) in Nakodu with 5-year closures between PHC harvests. Lines indicate patch within Nakodu customary marine tenure area (i.e., open-to-fishing, periodically-harvested closure, and fore reef). 


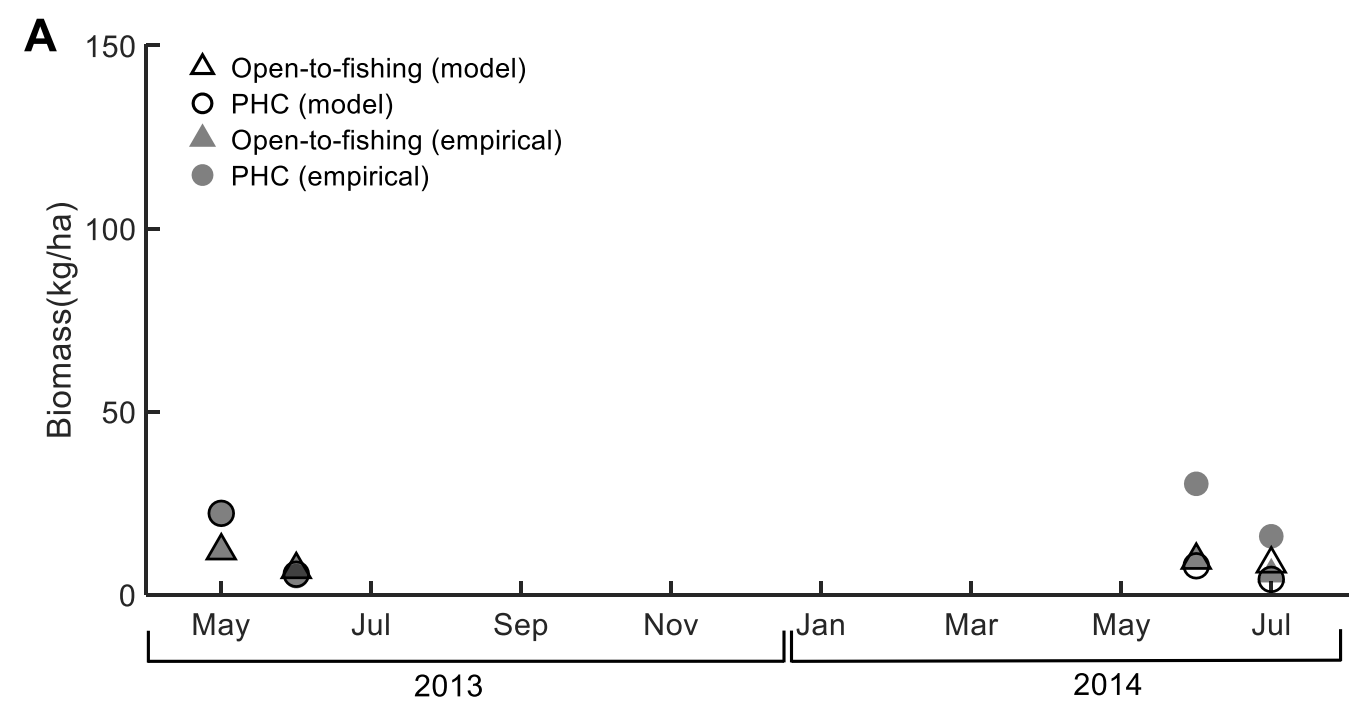

B

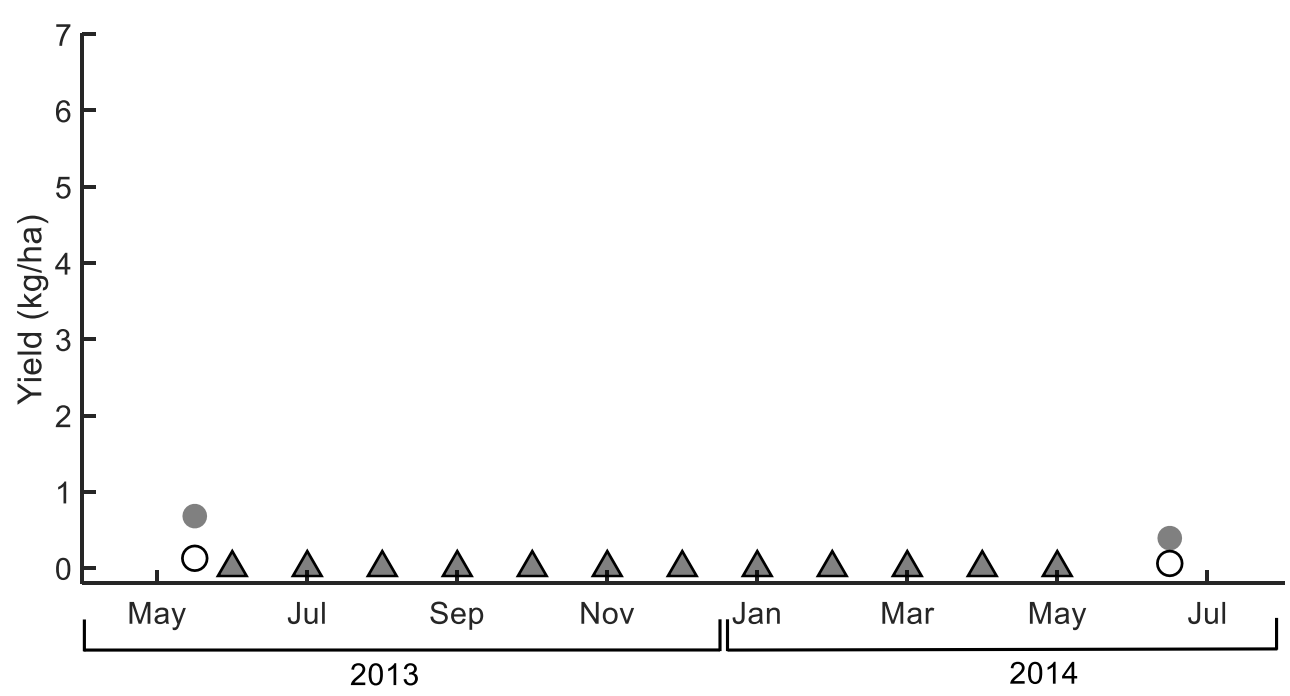

Figure 2.23. Model calibration results for Lutjanidae. The model is simultaneously calibrated to biomass (A) and yield (B) density empirical data. Biomass density is calibrated using diver operated stereo-video (DOV) surveys pre- and post-harvest in 2013 and 2014. Yield density is calibrated using catch data from Nakodu during PHC harvest and between harvests. 

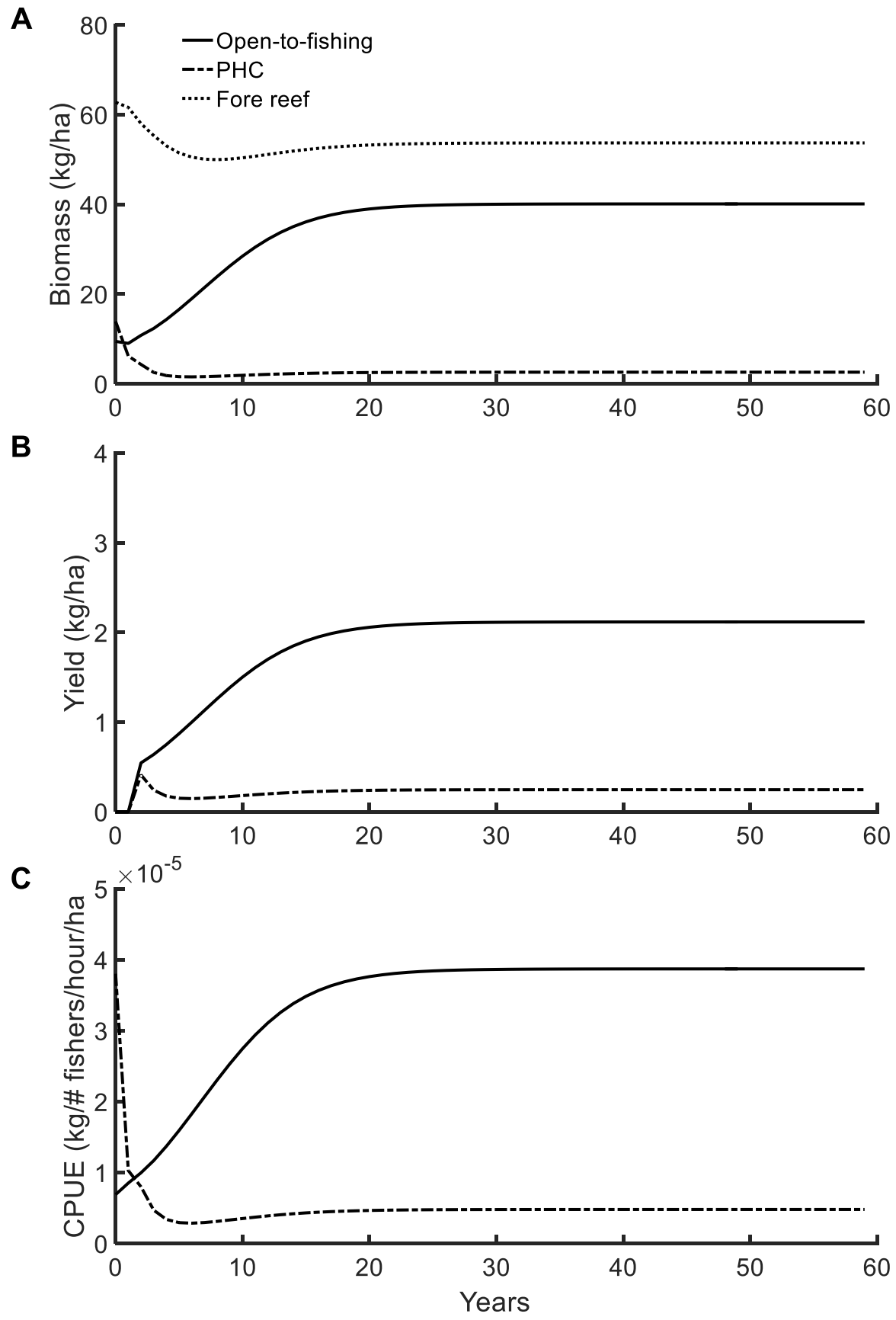

Figure 2.24. Time series data for Lutjanidae (A) biomass, (B) yield, and (C) catch per unit effort at present average annual yield in Nakodu when the PHC is harvested once a year. Lines indicate patch within Nakodu customary marine tenure area (i.e., open-to-fishing, periodically-harvested closure, and fore reef). 

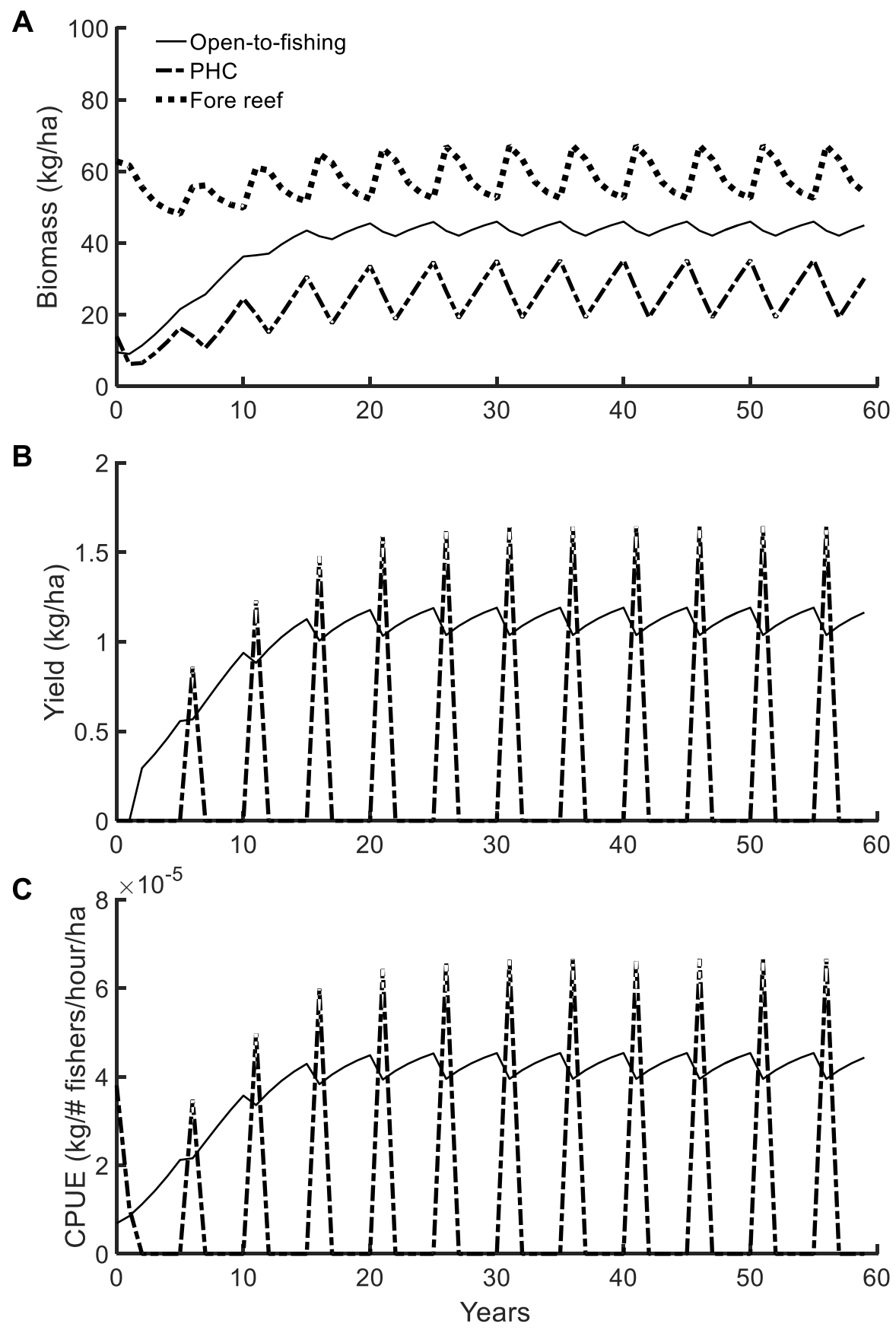

Figure 2.25. Time series data for Lutjanidae (A) biomass, (B) yield, and (C) catch per unit effort at present average annual yield in Nakodu with 5-year closures between PHC harvests. Lines indicate patch within Nakodu customary marine tenure area (i.e., open-to-fishing, periodically-harvested closure, and fore reef). 

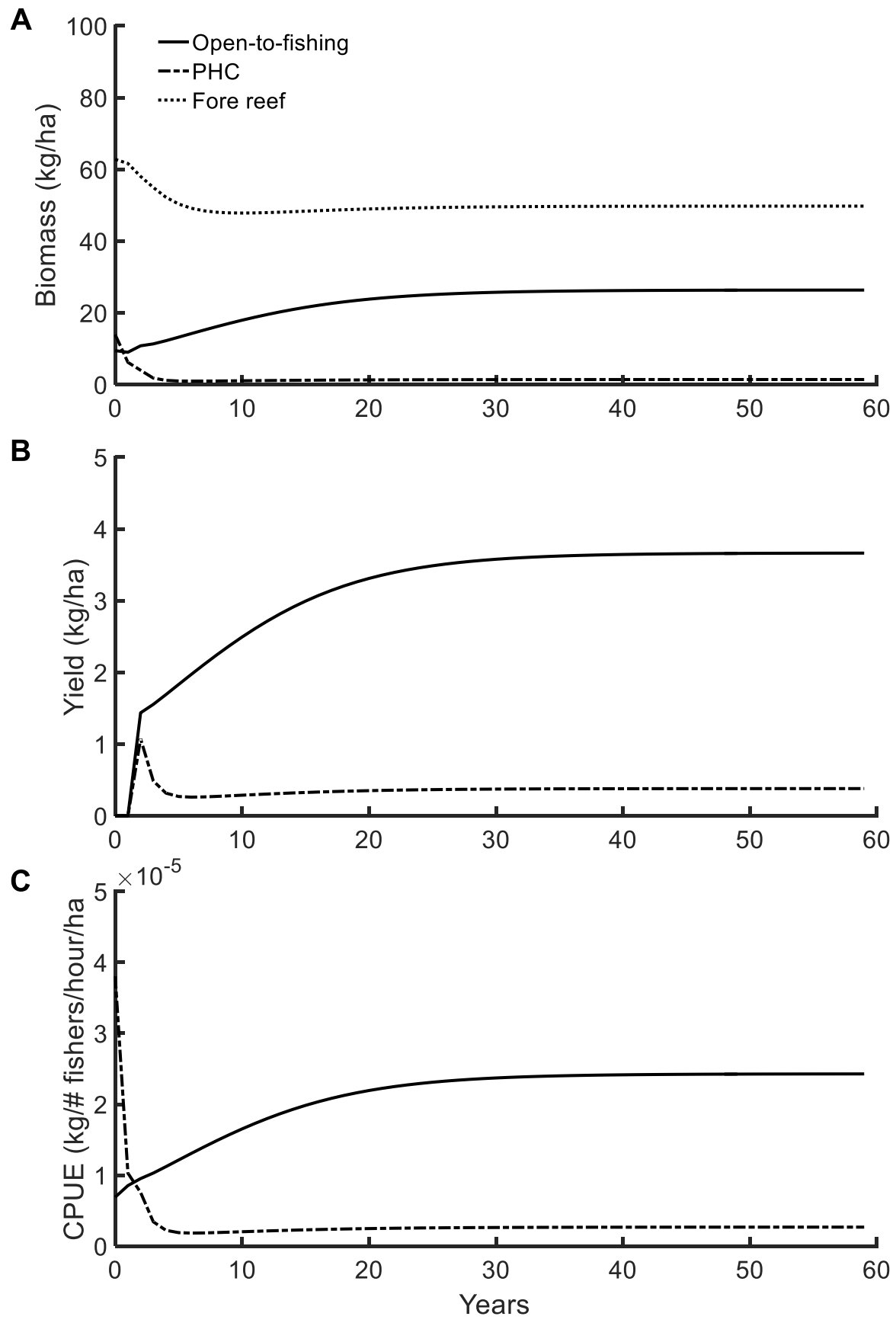

Figure 2.26. Time series data for Lutjanidae (A) biomass, (B) yield, and (C) catch per unit effort at maximum sustainable average annual yield (optimal harvest in each patch and year) in Nakodu when the PHC is harvested once a year. Lines indicate patch within Nakodu customary marine tenure area (i.e., open-to-fishing, periodically-harvested closure, and fore reef). 

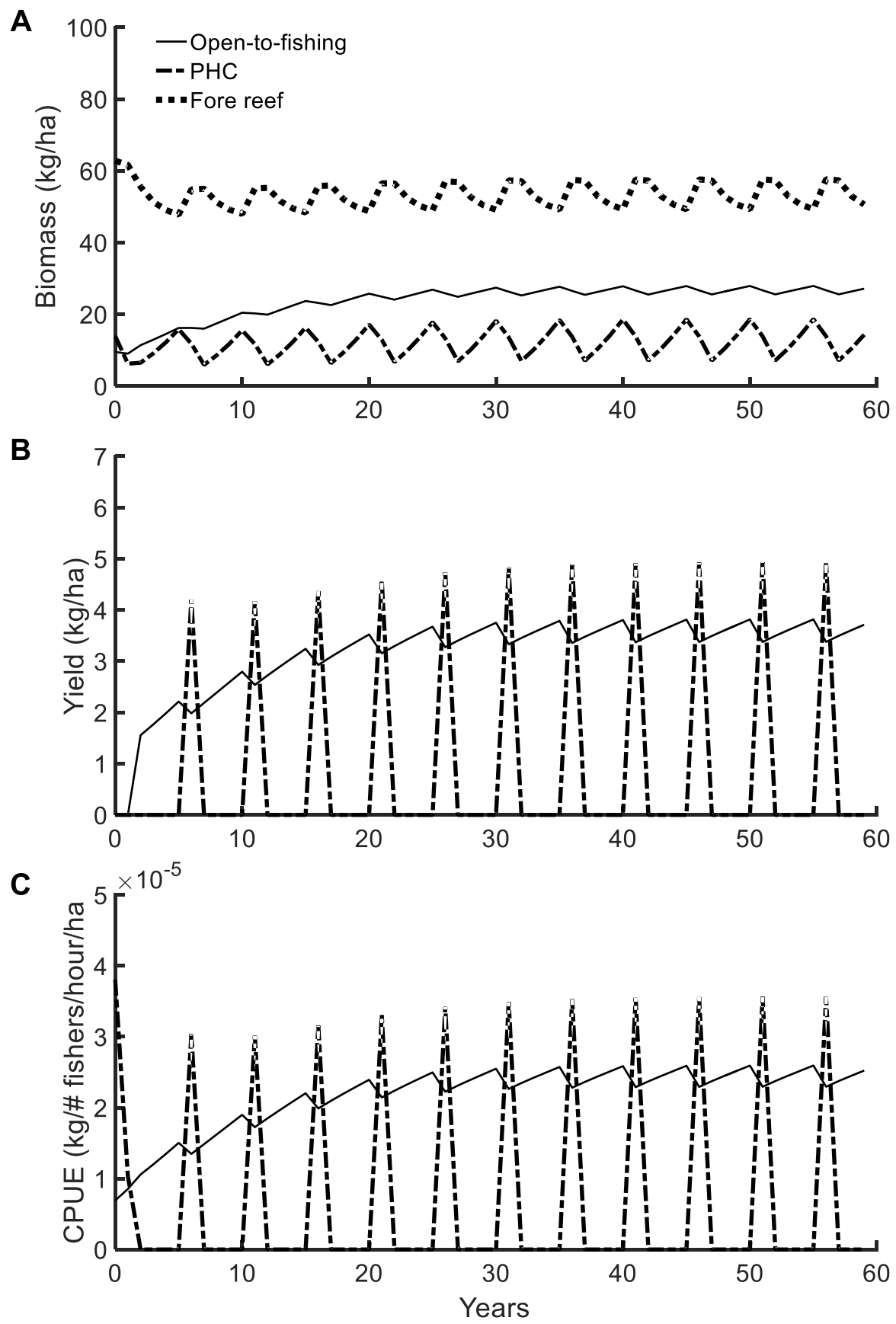

Figure 2.27. Time series data for Lutjanidae (A) biomass, (B) yield, and (C) catch per unit effort at maximum sustainable average annual yield (optimal harvest in each patch and year) in Nakodu with 5-year closures between PHC harvests. Lines indicate patch within Nakodu customary marine tenure area (i.e., open-to-fishing, periodically-harvested closure, and fore reef). 
Table 2.1. Biomass density (kg/ha) data by family from diver-operated-video surveys. Surveys were conducted in Nakodu marine management area at three sites in the periodically-harvested closure (PHC) and six sites in the open-to-fishing area (fished) in May 2013 and June 2014.

\begin{tabular}{|c|c|c|c|c|c|c|c|c|}
\cline { 2 - 9 } & \multicolumn{9}{c|}{ Biomass (kg/ha) } \\
\cline { 2 - 9 } & $\begin{array}{c}\text { Pre-harvest } \\
\mathbf{2 0 1 3}\end{array}$ & \multicolumn{2}{c|}{$\begin{array}{c}\text { Post-harvest } \\
\mathbf{2 0 1 3}\end{array}$} & $\begin{array}{c}\text { Pre-harvest } \\
\mathbf{2 0 1 4}\end{array}$ & \multicolumn{2}{c|}{$\begin{array}{c}\text { Post-harvest } \\
\mathbf{2 0 1 4}\end{array}$} \\
\cline { 2 - 9 } & PHC & Fished & PHC & Fished & PHC & Fished & PHC & Fished \\
\hline Acanthuridae & 48.53 & 20.74 & 21.74 & 11.67 & 114.17 & 63.76 & 59.31 & 63.61 \\
\hline Scarinae & 105.26 & 33.60 & 52.79 & 26.45 & 137.32 & 71.56 & 69.88 & 69.40 \\
\hline Labridae & 28.06 & 13.25 & 16.36 & 7.08 & 31.35 & 15.54 & 24.73 & 16.45 \\
\hline Lethrinidae & 17.36 & 2.69 & 3.25 & 5.97 & 11.33 & 5.35 & 9.15 & 10.64 \\
\hline Lutjanidae & 22.17 & 12.03 & 5.01 & 6.91 & 30.30 & 9.16 & 15.96 & 5.57 \\
\hline
\end{tabular}


Table 2.2. Diver operated stereo-video (DOV) survey and harvest (yield and effort) data collection timeline for Nakodu Village, Koro Island, Fiji. Black boxes indicate data collected in 2013 and gray boxes indicate data collected in 2014. Surveys were conducted before and after periodically-harvested closure (PHC) harvests in May 2013 and June 2014. Yield and effort data missing for the open-to-fishing area (fished) between 2013 and 2014 was assumed to be equal to average yield and effort for data collected in January 2014 and March through June 2014.

\begin{tabular}{|c|c|c|c|c|c|c|c|c|c|c|c|c|c|}
\hline & & Jan & Feb & Mar & Apr & May & Jun & Jul & Aug & Sep & Oct & Nov & Dec \\
\hline \multirow{2}{*}{ Harvest } & PHC & & & & & & & & & & & & \\
\hline & Fished & & & & & & & & & & & & \\
\hline \multirow{2}{*}{ DOV } & PHC & & & & & & & & & & & & \\
\hline & Fished & & & & & & & & & & & & \\
\hline
\end{tabular}


Table 2.3. Nakodu species list from diver operated stereo-video surveys and catch data with estimated intrinsic population growth rates.

\begin{tabular}{|l|l|l|}
\hline Family & Species & $\mathbf{r}$ \\
\hline Acanthuridae & Ctenochaetus striatus & 0.1 \\
\hline Acanthuridae & Acanthurus nigrofuscus & 0.3 \\
\hline Acanthuridae & Acanthurus nigricauda & 0.5 \\
\hline Acanthuridae & Zebrasoma scopas & 0.5 \\
\hline Acanthuridae & Acanthurus lineatus & 0.3 \\
\hline Acanthuridae & Acanthurus auranticavus & 0.1 \\
\hline Acanthuridae & Zebrasoma veliferum & 0.3 \\
\hline Acanthuridae & Acanthurus triostegus & 0.3 \\
\hline Acanthuridae & Acanthurus pyroferus & 0.3 \\
\hline Acanthuridae & Acanthurus olivaceus & 0.5 \\
\hline Acanthuridae & Ctenochaetus binotatus & 0.5 \\
\hline Acanthuridae & Ctenochaetus tominiensis & 0.5 \\
\hline Acanthuridae & Acanthurus guttatus & 0.5 \\
\hline Labridae (Scarinae) & Scarus oviceps & 0.5 \\
\hline Labridae (Scarinae) & Chlorurus sordidus & 0.3 \\
\hline Labridae (Scarinae) & Scarus dimidiatus & 0.3 \\
\hline Labridae (Scarinae) & Scarus globiceps & 0.3 \\
\hline Labridae (Scarinae) & Scarus frenatus & 0.3 \\
\hline Labridae (Scarinae) & Scarus spinus & 0.5 \\
\hline Labridae (Scarinae) & Scarus altipinnis & 0.1 \\
\hline Labridae (Scarinae) & Scarus niger & 0.5 \\
\hline Labridae (Scarinae) & Scarus schlegeli & 0.3 \\
\hline Labridae (Scarinae) & Scarus rubroviolaceus & 0.3 \\
\hline Labridae (Scarinae) & Scarus psittacus & 0.5 \\
\hline Labridae (Scarinae) & Scarus rivulatus & 0.3 \\
\hline Labridae (Scarinae) & Cetoscarus bicolor & 0.1 \\
\hline Labridae (Scarinae) & Scarus ghobban & 0.3 \\
\hline Labridae (Scarinae) & Chlorurus microrhinos & 0.1 \\
\hline Labridae (Scarinae) & Scarus prasiognathos & 0.3 \\
\hline Labridae (Scarinae) & Chlorurus bleekeri & 0.3 \\
\hline Labridae (Scarinae) & Scarus forsteni & 0.3 \\
\hline Labridae (Scarinae) & Calotomus spinidens & 0.5 \\
\hline Labridae (Scarinae) & Hipposcarus longiceps & 0.5 \\
\hline Labridae (Scarinae) & Cetoscarus ocellatus & 0.5 \\
\hline Labridae (Scarinae) & Scarus festivus & 0.3 \\
\hline Labridae (Scarinae) & Scarus chameleon & 0.3 \\
\hline Labridae & Halichoeres hortulanus & 0.5 \\
\hline
\end{tabular}




\begin{tabular}{|l|l|l|} 
Labridae & Hemigymnus melapterus & 0.3 \\
\hline Labridae & Novaculichthys taeniourus & 0.3 \\
\hline Labridae & Cheilinus trilobatus & 0.3 \\
\hline Labridae & Hologymnosus doliatus & 0.3 \\
\hline Labridae & Gomphosus varius & 0.3 \\
\hline Labridae & Anampses caeruleopunctatus & 0.3 \\
\hline Labridae & Coris aygula & 0.05 \\
\hline Labridae & Coris gaimard & 0.3 \\
\hline Labridae & Epibulus insidiator & 0.1 \\
\hline Labridae & Oxycheilinus unifasciatus & 0.3 \\
\hline Labridae & Hologymnosus annulatus & 0.3 \\
\hline Labridae & Cheilinus chlorourus & 0.3 \\
\hline Labridae & Hemigymnus fasciatus & 0.3 \\
\hline Labridae & Anampses geographicus & 0.3 \\
\hline Lethrinidae & Monotaxis grandoculis & 0.3 \\
\hline Lethrinidae & Lethrinus laticaudis & 0.3 \\
\hline Lethrinidae & Lethrinus harak & 0.3 \\
\hline Lethrinidae & Lethrinus xanthochilus & 0.1 \\
\hline Lethrinidae & Lethrinus microdon & 0.3 \\
\hline Lethrinidae & Lethrinus obsoletus & 0.1 \\
\hline Lethrinidae & Lethrinus erythropterus & 0.3 \\
\hline Lethrinidae & Gnathodentex aureolineatus & 0.3 \\
\hline Lethrinidae & Lethrinus nebulosus & 0.1 \\
\hline Lethrinidae & Lethrinus olivaceus & 0.1 \\
\hline Lethrinidae & Gymnocranius euanus & 0.3 \\
\hline Lutjanidae & Lutjanus gibbus & 0.3 \\
\hline Lutjanidae & Lutjanus fulvus & 0.3 \\
\hline Lutjanidae & Lutjanus kasmira & 0.3 \\
\hline Lutjanidae & Lutjanus bohar & 0.3 \\
\hline Lutjanidae & Lutjanus semicinctus & 0.3 \\
\hline Lutjanidae & Lutjanus monostigma & 0.3 \\
\hline Lutjanidae & Lutjanus fulviflamma & 0.3 \\
\hline & & \\
\hline
\end{tabular}


Table 2.4. Yield density (kg/ha) and effort (\# fisher hours/ha) density in the periodically-harvested closure (PHC) and open-to-fishing area (fished) area by family. Data from the fished area was collected between May 2013 and June 2014. Wildlife Conservation Society crew collected data during PHC harvest events.

\begin{tabular}{|l|c|c|c|c|c|c|}
\cline { 2 - 7 } \multicolumn{1}{c|}{} & \multicolumn{3}{c|}{ Yield (kg/ha) } & \multicolumn{3}{c|}{ Effort [(\# fishers * hours) / ha] } \\
\cline { 2 - 7 } \multicolumn{1}{c|}{} & PHC & PHC & Fished & PHC & PHC & Fished \\
\hline Acanthuridae & 1.57 & 0.87 & 43.72 & 13.63 & 11 & 13.09 \\
\hline Scarinae & 6.01 & 3.12 & 3.51 & 13.63 & 11 & 13.09 \\
\hline Labridae & 1.02 & 0.08 & 0.21 & 13.63 & 11 & 13.09 \\
\hline Lethrinidae & 3.31 & 2.09 & 0.89 & 13.63 & 11 & 13.09 \\
\hline Lutjanidae & 0.68 & 0.39 & 0.28 & 13.63 & 11 & 13.09 \\
\hline
\end{tabular}


Table 2.5. Parameter values after model calibration and quality of model fit to empirical data.

\begin{tabular}{|c|c|c|c|c|}
\hline Family & $\begin{array}{c}\text { Catchability } \\
\text { Adjustment }(\alpha)\end{array}$ & $\begin{array}{c}\text { Site-fidelity } \\
(S)\end{array}$ & $\begin{array}{c}\text { Realized effort } \\
\text { adjustment }(\gamma)\end{array}$ & Model fit \\
\hline Acanthuridae & 0.001 & 0 & 5.2 & Poor \\
\hline Scarinae & 0.001 & 0.1 & 5.9 & Moderate \\
\hline Labridae & 0.001 & 0.6 & 1.5 & Good \\
\hline Lethrinidae & 0.001 & 1.0 & 6.6 & Moderate \\
\hline Lutjanidae & 0.001 & 0.9 & 5.7 & Good \\
\hline
\end{tabular}




\section{REFERENCES}

Alós, J., M. Palmer, P. Trías, C. Díaz-Gil, and R. Arlinghaus. 2014. Recreational angling intensity correlates with alteration of vulnerability to fishing in a carnivorous coastal fish species. Canadian Journal of Fisheries and Aquatic Sciences 225: 1-9.

Askey, P. J., S. A. Richards, J.R. Post, and E.A. Parkinson. 2006. Linking angling catch rates and fish learning under catch-and-release regulations. North American Journal of Fisheries Management. 26(4): 1020-1029.

Aswani, S. 2005. Customary sea tenure in Oceania as a case of rights-based fishery management: Does it work? Reviews in Fish Biology and Fisheries. 15(3): 285-307.

Ayres, W. S. 1979. Easter Island fishing. Asian Perspectives 22(1): 61-92

Bartlett, C. Y., C. Manua, J. E. Cinner, S. Sutton, R. Jimmy, et al. 2009. Comparison of outcomes of permanently closed and periodically harvested coral reef reserves. Conservation Biology: The Journal of the Society for Conservation Biology 23(6): $1475-1484$.

Béné, C. 2006. Small-scale fisheries: assessing their contribution to rural livelihoods in developing countries. FAO Fisheries Circular No. 1008.

Bess, R. 2001. New Zealand's indigenous people and their claims to fisheries resources. Marine Policy 25: 23-32.

Chapman, M. R. and D. L. Kramer. 2000. Movements of fishes within and among finging coral reefs in Barbados. Environmental Biology of Fishes 57: 11-24.

Chateau, O. and L. Wantiez. 2009. Movement patterns of four coral reef fish species in a fragmented habitat in New Caledonia: implications for the design of marine protected area networks. ICES Journal of Marine Science 66(1): 50-55. 
Cinner, J. E. and S. Aswani. 2007. Integrating customary management into marine conservation. Biological Conservation 140(3-4): 201-216.

Cinner, J. E., M. J. Marnane, and T. R. Mcclanahan. 2005. Conservation and community benefits from traditional coral reef management at Ahus Island, Papua New Guinea. Conservation Biology. 19(6): 1714-1723.

Cinner, J. E., M. J. Marnane, T. R. McClanahan, and G. R. Almany. 2006. Periodic closures as adaptive coral reef management in the Indo- Pacific. Ecology and Society 11(1): 31 .

Cohen, P. J. and T. J. Alexander. 2013. Catch rates, composition and fish size from reefs managed with periodically-harvested closures. PLoS ONE 8(9): e73383.

Cohen, P. J., J. E. Cinner, and S. J. Foale. 2013. Fishing dynamics associated with periodically harvested marine closures. Global Environmental Change 23(6): 17021713.

Cohen, P. J. and S. J. Foale. 2013. Sustaining small-scale fisheries with periodically harvested marine reserves. Marine Policy 37: 278-287.

Costello, C., D. Ovando, T. Clavelle, C. K. Strauss, R. Hilborn, et al. 2016. Global fishery prospects under contrasting management regimes. Proceedings of the National Academy of Sciences 113(18): 5125-5129.

Costello, C., A. Rassweiler, D. Siegel, G. De Leo, F. Micheli, and A. Rosenberg. 2010. The value of spatial information in MPA network design. Proceedings of the National Academy of Sciences 107(43): 18294-18299.

Cycon, D. E. 1986. Managing fisheries in developing nations: a plea for appropriate development. Natural Resources Journal 26: 1-14. 
Feary, D. A., J. E. Cinner, N. A. J. Graham, and F. A. Januchowski-Hartley. 2011 Effects of customary marine closures on fish behavior, spear-fishing success, and underwater visual surveys 25(2): 341-349.

Froese, R. and D. Pauly. 2012. FishBase. www.fishbase.org. Accessed June.

Gerber, L. R., L. W. Botsford, A. Hastings, H. P. Possingham, S. D. Gaines, S. R. Palumbi, and S. Andelman. 2003. Population models for marine reserve design : a retrospective and prospective synthesis. Ecological Applications : A Publication of the Ecological Society of America 13(1): 547-564.

Goetze, J. S., S.D. Jupiter, T. J. Langlois, S. K. Wilson, E. S. Harvey, et al. 2014. Diver operated video most accurately detects the impacts of fishing within periodically harvested closures. Journal of Experimental Marine Biology and Ecology 462: 7482.

Gotelli, N. J. 1995. A primer of ecology, fourth edition. Pages 11-13. Sinaeur Associates Incorporated, Suderland, Massachusetts, USA.

Govan, H., A. Tawake, K. Tabunakawai, A. Jenkins, A. Lasgorceix, et al. 2009. Status and potential of locally-managed marine areas in the South Pacific: meeting nature conservation and sustainable livelihood targets through wide-spread implementation of LMMAs. SPREP/WWF/WorldFish-Reefbase/CRISP, Suva, Fiji. (http://www.spc.in/DigitalLibrary/Doc/FAME/Reports/Govan_09_Status_LMMAs. pdf).

Gutiérrez, N. L., R. Hilborn, and O. Defeo. 2011. Leadership, social capital and incentives promote successful fisheries. Nature 470(7334): 386-389.

Halpern, B. S., S. E. Lester, and J. B. Kellner. 2009. Spillover from marine reserves and 
the replenishment of fished stocks. Environmental Conservation 36(4): 268-276.

Hart, D. R. 2006. When do marine reserves increase fishery yield? Canadian Journal of Fisheries and Aquatic Sciences 63(7): 1445-1449.

Hastings, A. and L. W. Botsford. 1999. Equivalence in yield from marine reserves and traditional fisheries management. Science 284: 1537-1538.

Hilborn, R., K. Stokes, J.-J Maguire, T. Smith, L. W. Botsford, et al. 2004. When can marine reserves improve fisheries management? Ocean and Coastal Management 47(3-4): 197-205.

Januchowski-Hartley, F. A., N. A. J. Graham, J. E. Cinner, and G. R. Russ. 2013. Spillover of fish naïveté from marine reserves. Ecology Letters 16(2): 191-197.

Januchowski-Hartley, F. A., J. E. Cinner, and N. A. J. Graham. 2014. Fishery benefits from behavioural modification of fishes in periodically harvested fisheries closures. Aquatic Conservation: Marine and Freshwater Ecosystems 27: 777-790.

Januchowski-Hartley, F. A., N. A. J. Graham, J. E. Cinner, and G. R. Russ. 2015. Local fishing influences coral reef fish behavior inside protected areas of the Indo-Pacific. Biological Conservation 182: 8-12.

Jennings, S. 2000. Patterns and prediction of population recovery in marine reserves. Reviews in Fish Biology and Fisheries 10(2) 209-231.

Jennings, S., J. D. Reynolds, and N. V. C. Polunin. 1999. Predicting the vulnerability of tropical reef fishes to exploitation with phylogenies and life histories. Society of Conservation Biology 13(6): 1466-1475.

Jupiter, S., P. Cohen, R. Weeks, A. Tawake, and H. Govan. 2014. Locally-managed marine areas: multiple objectives and diverse strategies. Pacific Conservation 
Biology 20(2): 165-179.

Jupiter, S. D., R. Weeks, A. P. Jenkins, D. P. Egli, and A. Cakacaka. 2012. Effects of a single intensive harvest event on fish populations inside a customary marine closure. Coral Reefs 31(2): 321-334.

Jupiter, S. D., S. Mangubhai, R. T. Kingsford. 2014. Conservation of biodiversity in the Pacific Islands of Oceania: challenges and opportunities. 20(2): 206-220.

Kaunda-Arara, B. and G. A. Rose. 2004. Long-distance movements of coral reef fishes. Coral Reefs 23(3): 410-412.

Kawarazuka, N., and C. Béné. 2010. Linking small-scale fisheries and aquaculture to household nutritional security: An overview. Food Security 2(4): 343-357.

Kellner, J. B., R. M. Nisbet, and S. D. Gaines. 2008. Spillover from marine reserves related to mechanisms of population regulation. Theoretical Ecology 1(2): 117-127.

Kramer, D. L. and M. R. Chapman. 1999. Implications of fish home range size and relocation for marine reserve function. Environmental Biology of Fishes 55: 65-79.

Lester, S. E., and B. Halpern. 2008. Biological responses in marine no-take reserves versus partially protected areas. Marine Ecology Progress Series 367: 49-56.

Luna, R. W. 2003. Traditional food prohibitions (tapu) on marine turtles among Pacific Islanders. South Pacific Commission Traditional Resource Management and Knowledge Information Bulletin 15: 31-32.

MacNeil, M. A., N. A. J. Graham, J. E. Cinner, S. K. Wilson, I. D. Williams, et al. 2015. Recovery potential of the world's coral reef fishes. Nature 520: 341-344.

McClanahan, T. R. 1999. Is there a future for coral reef parks in poor tropical countries? Coral Reefs. 18(4): 321-325. 
McClanahan, T. R., N. A. J. Graham, J. M. Calnan, and A. M. MacNeil. 2007. Toward pristine biomass: Reef fish recovery in coral reef marine protected areas in Kenya. Ecological Applications 17(4): 1055-1067.

McClanahan, T. R., M. J. Marnane, J. E. Cinner, and W. E. Kiene. 2006. A comparison of marine protected areas and alternative approaches to coral-reef management. Current Biology 16(14): 1408-1413.

Meyer, C. G., Y. P. Papastamatiou, and T. B. Clark. 2010. Differential movement patterns and site fidelity among trophic groups of reef fishes in a Hawaiian marine protected area. Marine Biology 157(7): 1499-1511.

Meyer, C. G., Y. P. Papastamatiou, and K. N. Holland. 2007. Seasonal, diel, and tidal movements of green jobfish (Aprion virescens, Lutjanidae) at remote Hawaiian atolls: Implications for marine protected area design. Marine Biology 151(6): 21332143.

Mills, M., S. D. Jupiter, R. L. Pressey, N. C. Ban, and J. Comley. 2011. Incorporating effectiveness of community-based management in a national marine gap analysis for Fiji. Conservation Biology 25(6): 1155-1164.

Parrish, R. 1999. Marine reserves for fisheries management: Why not. California Cooperative Oceanic Fisheries Investigations 40: 77-86.

Pomeroy, R. S. and R. Rivera-Guieb. 2005. Fishery Co-management: A Practical Handbook. Cambridge, Massachusetts: CABI.

Rassweiler, A., C. Costello, and D. A. Siegel. 2012. Marine protected areas and the value of spatially optimized fishery management. Proceedings of the National Academy of Sciences 109(29): 11884-11889. 
Ruddle, K. 1998. The context of policy design for existing community-based fisheries management systems in the Pacific Islands. Ocean and Coastal Management 40(23): 105-126.

Russ, G. R. and A. C. Alcala. 1996. Do marine reserves export adult fish biomass? Evidence from Apo Island, central Philippines. Marine Ecology Progress Series 132 $1-9$.

Russ, G. R. and A. C. Alcala. 1998. Natural fishing experiments in marine reserves 19831993: Roles of life history and fishing intensity in family responses. Coral Reefs 17(4): 399-416.

Schaefer, M. B. 1957. A study of the dynamics of the fishery for yellowfin tuna in the eastern tropical Pacific Ocean. Bulletin of the Inter-American Tropical Tuna Commission 2: 247-285.

Shedrawi, G., E. S. Harvey, D. L. McLean, J. Prince, L. M. Bellchambers, and S. J. Newman. 2014. Evaluation of the effect of closed areas on a unique and shallow water coral reef fish assemblage reveals complex responses. Coral Reefs 33(3): 579591.

Smith, M. D., J. Lynham, J. N. Sanchirico, and J. A. Wilson. 2010. Political economy of marine reserves: Understanding the role of opportunity costs. Proceedings of the National Academy of Sciences 107(43): 18300-18305.

White, C. and C. Costello. 2014. Close the high seas to fishing? PLoS Biology 12(3): e1001826.

White, C., B. E. Kendall, S. D. Gaines, D. A. Siegel, and C. Costello. 2008. Marine reserve effects on fishery profit. Ecology Letters 11(4) 370-379. 
Williams, I. D., W. J. Walsh, A. Miyasaka, and A. M. Friedlander. 2006 Effects of rotational closure on coral reef fishes in Waikiki-Diamond Head Fishery Management Area, Oahu, Hawaii. Marine Ecology Progress Series 310: 139-149.

Worm, B., R. Hilborn, J. K. Baum, T. A. Branch, J. S. Collie, et al. 2009. Rebuilding global fisheries. Science 325: 578-585.

Young, R. G. and J. W. Hayes. 2004. Angling pressure and trout catchability: behavioral observations of brown trout in two New Zealand backcountry rivers. North American Journal of Fisheries Management 24(4): 1203-1213. 